\title{
SYNTHESIS AND INVESTIGATION OF NUCLEOBASE FUNCTIONALIZED $\beta$-PEPTIDE AS SNARES MODEL SYSTEM FOR MEMBRANEFUSION
}

\section{DISSERTATION}

\author{
zur Erlangung \\ des mathematisch-naturwissenschaftlichen Doktorgrades \\ "Doctor rerum naturalium" \\ der Georg-August-Universität Göttingen
}

Im Promotionsprogramm

der Georg-August-Universität school of sceince

(GAUSS)

\author{
vorgelegt von \\ Muheeb Sadek \\ aus Edlib
}

Göttingen, 2015 
This work was supported by the Deutsche Forschungsgemeinschaft via the Collaborative Research Center 803 (SFB 803).

Referent: Prof. Dr. Ulf Diederichsen

Institut für Organische und Biomolekulare Chemie, Georg-August-Universität Göttingen

Korreferent: Prof. Dr. Claudia Steinem

Institut für Organische und Biomolekulare Chemie, Georg-August-Universität Göttingen

Mitglieder der Prüfungskommission:

\section{Prof. Dr. Reinhard Jahn}

Max-Planck-Institut of Biophysical Chemistry, Georg-August-Universität Göttingen

\section{Prof. Dr. Hartmut Laatsch}

Institut für Organische und Biomolekulare Chemie, Georg-August-Universität Göttingen

\section{Prof. Dr. Claudia Höbartner}

Institut für Organische und Biomolekulare Chemie, Georg-August-Universität Göttingen

\section{Dr. Alexander Breder}

Institut für Organische und Biomolekulare Chemie, Georg-August-Universität Göttingen 
The work described in this doctoral dissertation has been carried out under the guidance and supervision of Prof. Dr. Ulf Diederichsen at the Institut für Organische und Biomolekulare Chemie of the Georg-August Universität Göttingen between October 2011 and May 2015.

I thank Prof. Dr. Ulf Diederichsen for the interesting research topic, for his encouraging guidance, practical advices, freedom of research and generous support throughout this work. 
Dedicated to your soul (Father), my spirit (Mother) and my love (Susanna) 


\section{Tabel of contents}

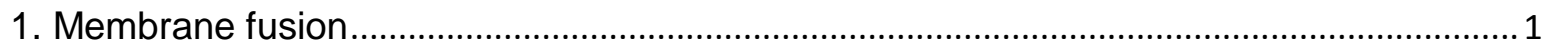

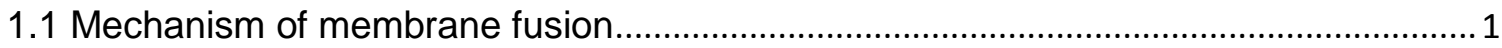

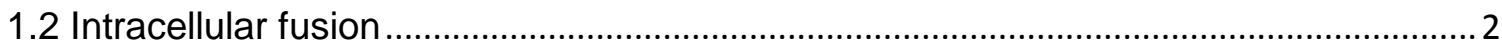

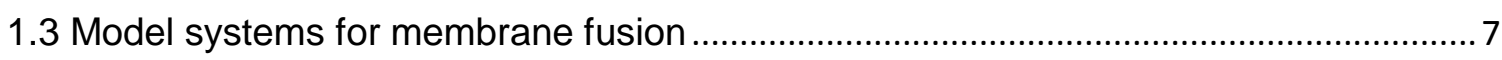

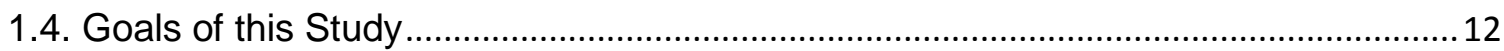

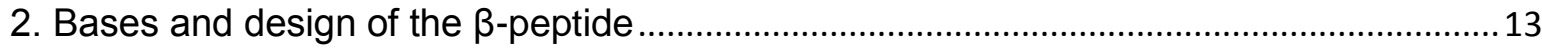

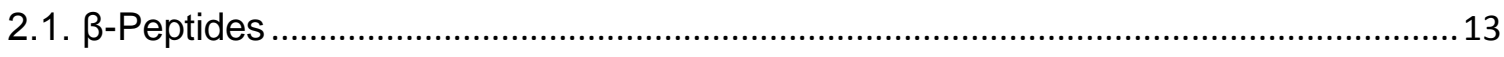

2.2. Nucleobase-functionalized $\beta$-peptides ( $\beta$-PNA) …................................................... 16

3. Design and synthesis of new artificial model systems for SNARE proteins.....................21

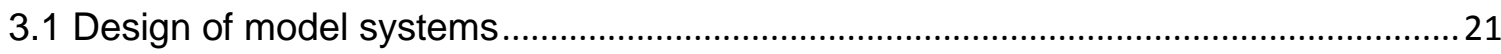

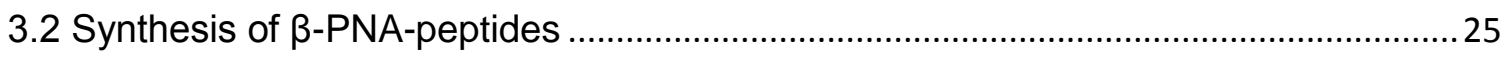

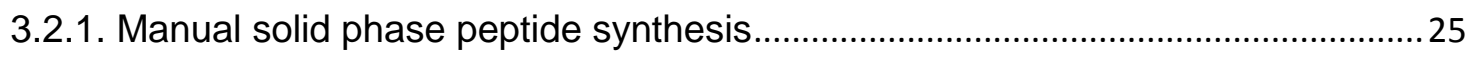

3.2.2. Manual SPPS of TMDs of syntaxin-1A and synaptobrevin 2..............................28

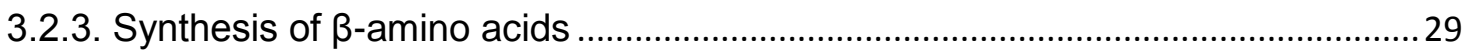

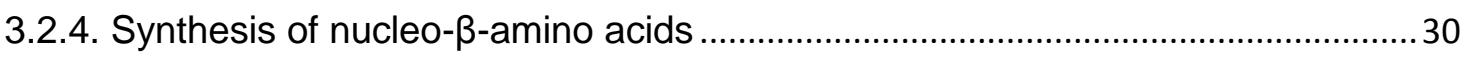

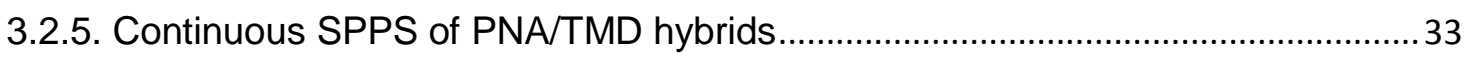

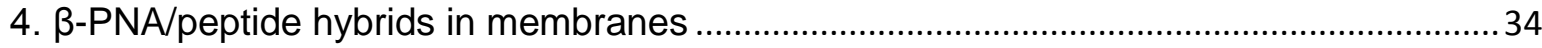

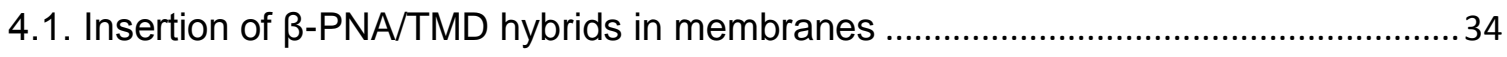

4.2. Distribution of the fluorophores in lipid membranes .................................................. 34

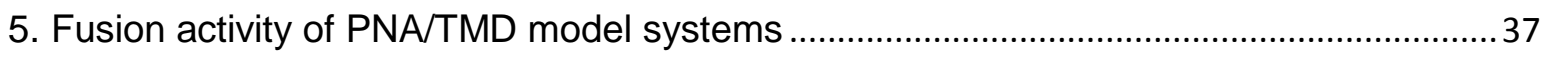

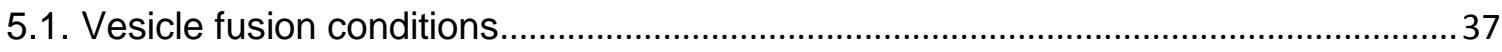

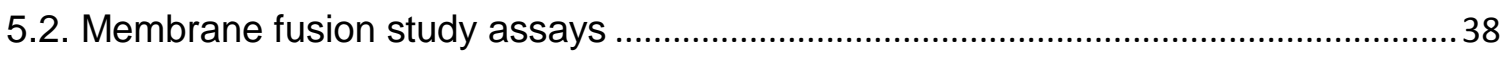

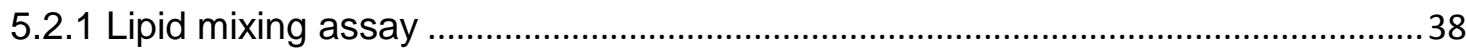

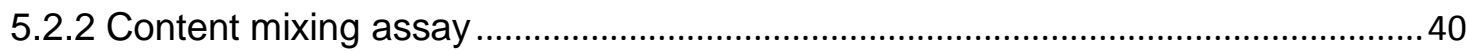

5.3. Fusogenic activity of $\beta$-PNA-peptide model system ............................................... 41

5.4. Parallel oriented $\beta$-PNA/peptide hybrid model system.............................................. 51

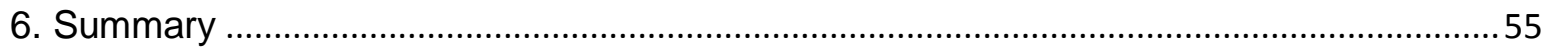

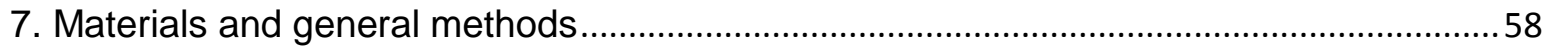




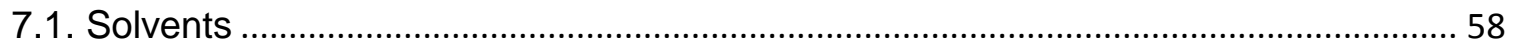

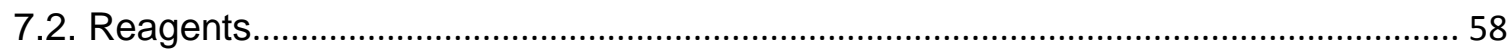

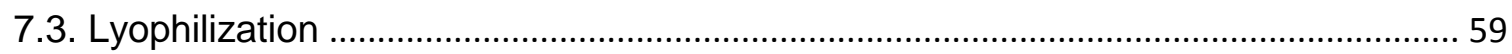

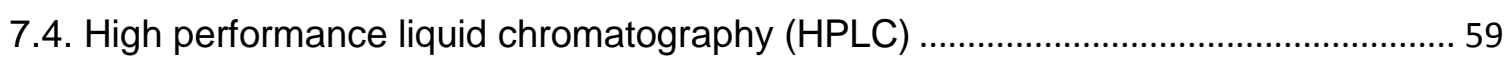

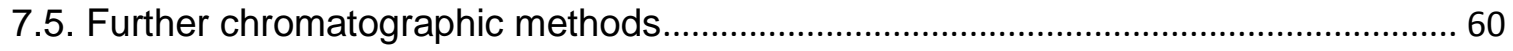

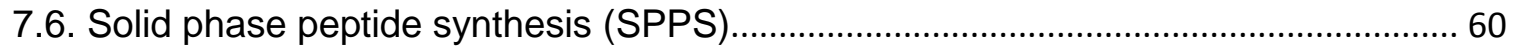

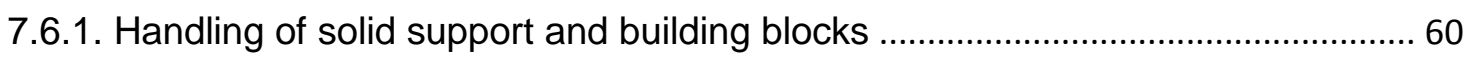

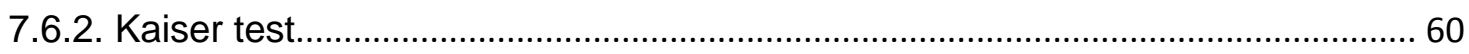

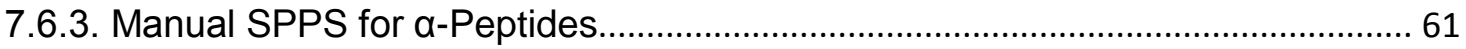

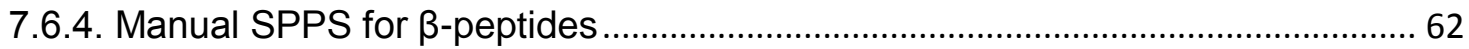

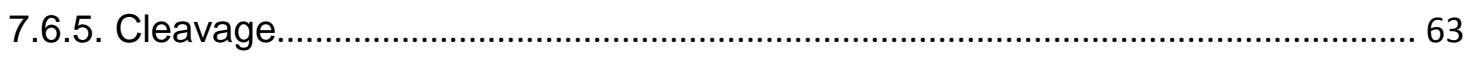

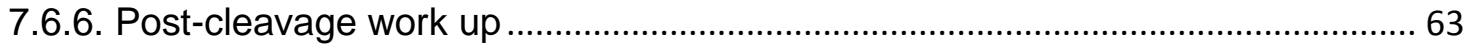

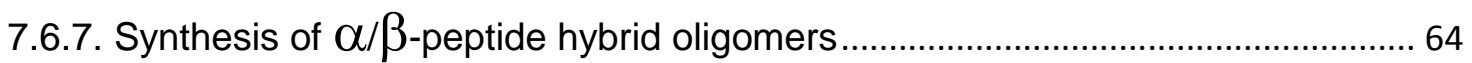

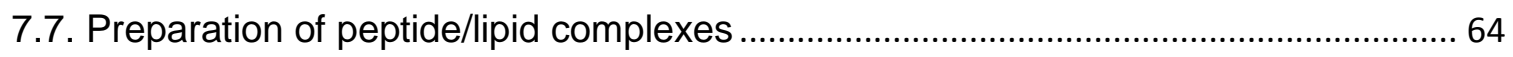

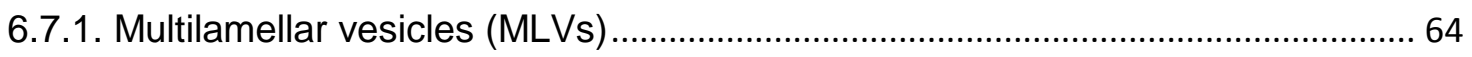

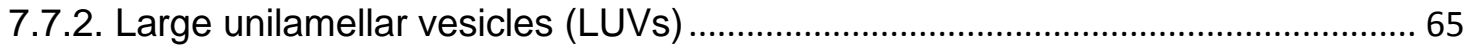

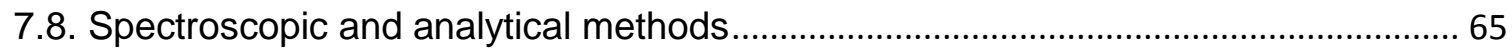

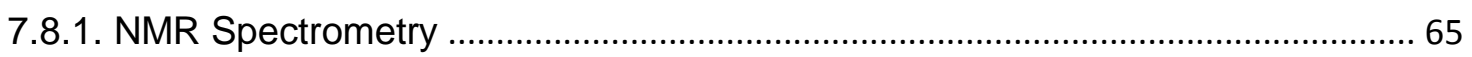

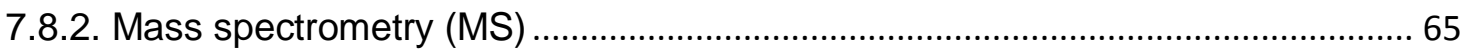

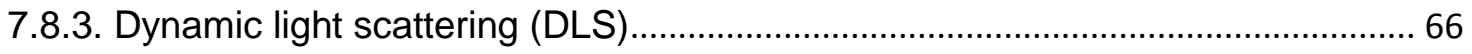

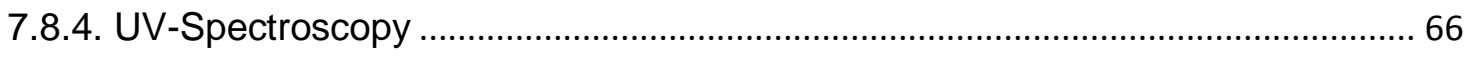

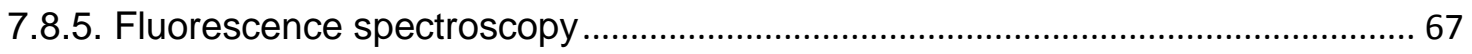

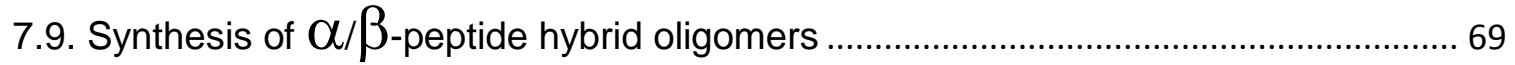

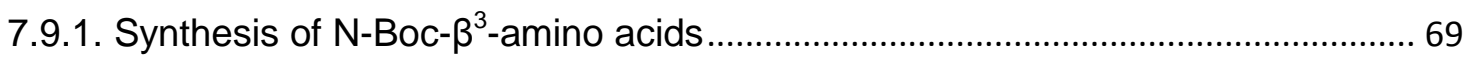

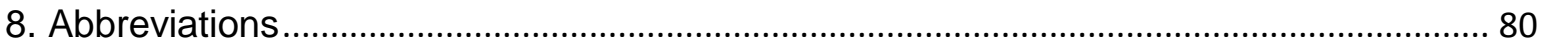

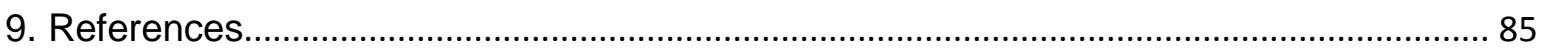





\section{Membrane fusion}

\subsection{Mechanism of membrane fusion}

Membrane fusion is an important part of all fundamental biological events under normal and pathological conditions and a complex process, in which two membranes merge together. A protein machinery controls membrane fusion in exo- and endocytosis, in intracellular trafficking, in enveloped virus infections and in many other lipid membrane related reactions. The prevailing mechanism of the fusion process is depicted in Figure 1.1. ${ }^{[1-3]}$

(a)

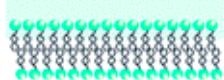

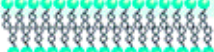

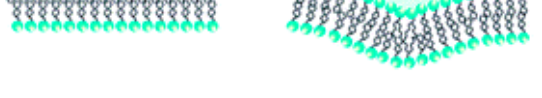

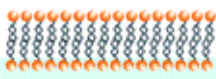

(b)

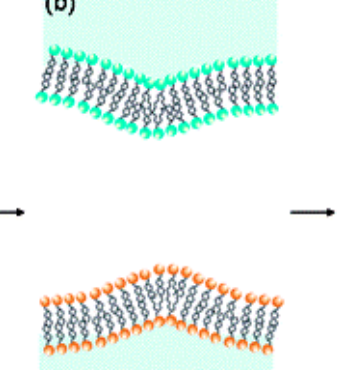

(c)

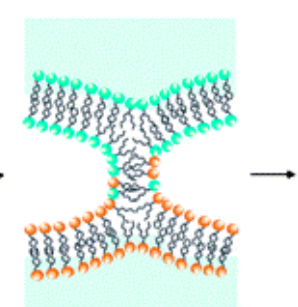

(d)

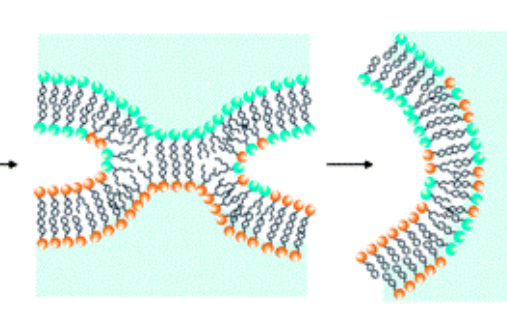

Figure 1.1. Fusion through a hemifusion pathway of the lipid bilayer. a) Pre-fusion contact. b) A point-like membrane protrusion (minimizes the energy of the hydration repulsion between the proximal leaflets of the membranes coming into immediate contact). c) A hemifusion stalk. d) Stalk expansion yields the hemifusion diaphragm. e) A fusion pore forms either from the hemifusion diaphragm bilayer or directly from the stalk. ${ }^{[4]}$

The fusion through a hemifusion pathway of membrane fusion (Figure 1.1) was first investigated theoretically and confirmed by experiments with merging of artificial protein-free bilayers, ${ }^{[5-7]}$ and then found for viral, ${ }^{[2]}$ intracellular, ${ }^{[8-11]}$ and cell fusion. ${ }^{[12]}$ The established mechanism involves hemifusion, a stalk-like connection between the outer membrane leaflets where the inner leaflets and the aqueous inner contents remain distinct (Figure 1.1, c). The hemifusion stage is then followed by fusion pore openning in order to complete the fusion process (Figure 1.1, e). 
Two important types of intermediates have been characterized: hemifusion structures and fusion pores. Hemifusion between two vesicles has usually been defined as lipid mixing without content mixing or as limited mixing within the outer leaflet and the inner leaflet not merging. ${ }^{[11,13,14]}$

Some electrophysiological measurements provided evidence for involvement of hemifusion intermediates. ${ }^{[6,15]}$ A hemifusion connection is often a transient structure that either dissociates to yield two separated membranes or transforms to a fusion pore. ${ }^{[3,15]}$ The latter one is a connection between merging membranes involving both, outer and inner leaflets (Figure 1.1, e). Fusion pore formation provides aqueous connections between the initially separated parts of the membranes. Various electrophysiological approaches and fluorescence assays, which monitor the mixing between aqueous contents and/or the lipids of the inner leaflets, have been employed for investigating fusion pore formation and expansion. ${ }^{[6,7,15]}$

The fusion between biological membranes is always mediated by different membrane-bound proteins. Notably, the mechanisms of natural membrane fusion processes mediated by viral, intracellular as well as developmental fusogens appear to be very similar. ${ }^{[16]}$

\subsection{Intracellular fusion}

The intracellular transport between plasma membrane and different organelles in eukaryotic cells involves vesicular intermediates that separate donor compartments and fuse with acceptor compartments. Vesicle budding and transferred cargo selection are known to be mediated by protein coats, ${ }^{[17,18]}$ while vesicle targeting and fusion are controlled by specific fusogenic proteins (Figure 1.2). ${ }^{[19]}$ The mechanism of vesicle budding has been extensively reviewed by BONIFACIO AND GLICK. ${ }^{[20]}$ 


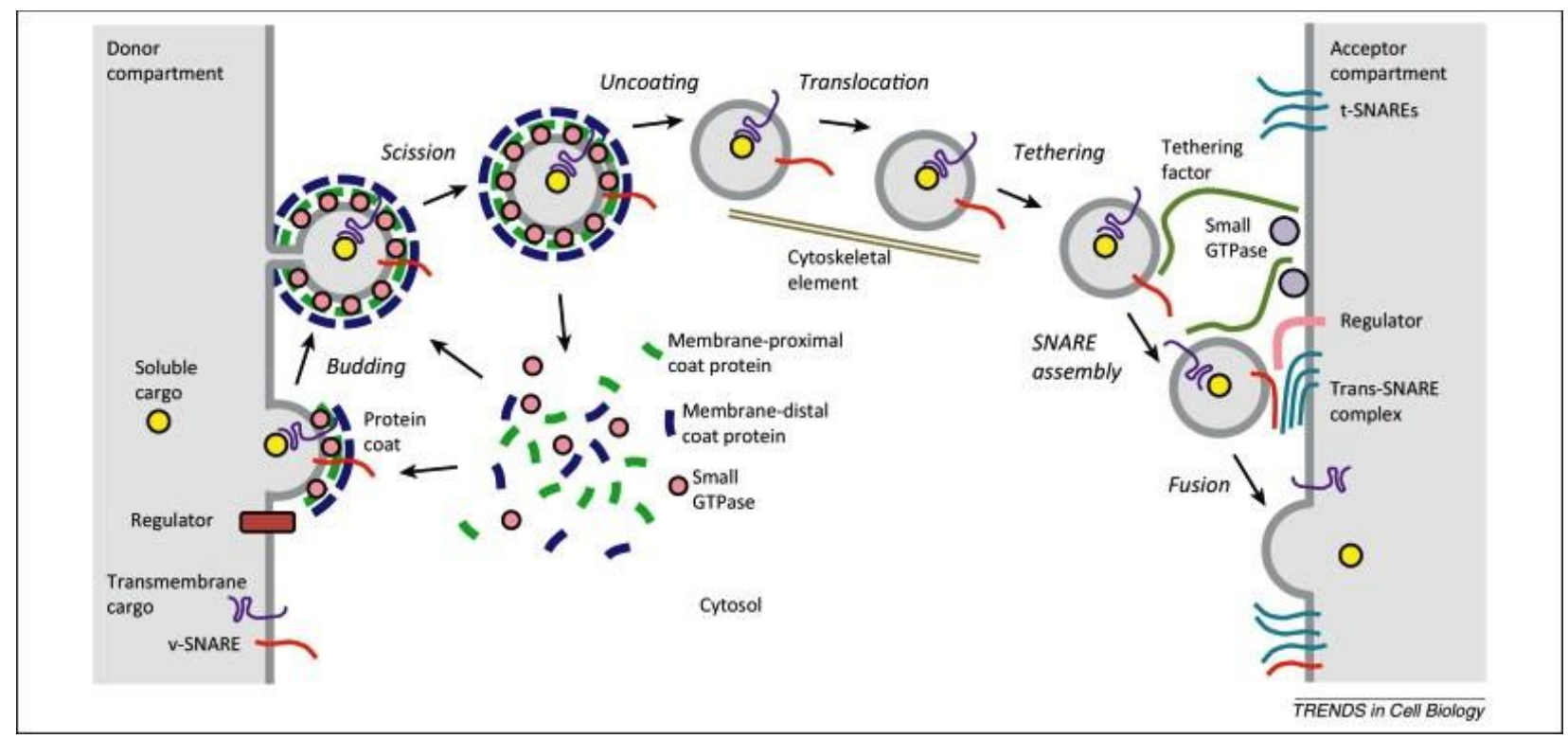

Figure 1.2. Intracellular transport by vesicle budding and fusion. ${ }^{[20]}$

In 1993, an important discovery concerning the mechanism of intracellular fusion was found; both, the intracellular transport (targeting and fusion steps) and the synaptic transmission are mediated by the same proteins. ${ }^{[21,22]}$ These so-called SNARE (Soluble N-ethylmaleimide-Sensitive Factor Attachment Protein Receptor) proteins turned out to mediate all transport steps of the secretory pathway in membrane fusion. However, the fusion events in mitochondria and peroxisomes involve proteins, which are completely different from the SNARE proteins. ${ }^{[23-25]}$ The SNARE superfamily of small proteins includes 24 known members in yeast and 35 in mammals. ${ }^{[26]} \mathrm{A}$ simple domain structure and the presence of an evolutionarily conserved SNARE motif (60-70 amino acids in heptad repeats) are characterizing all SNARE proteins. Most SNAREs have a single transmembrane domain at their $C$-termini, which is connected to the SNARE motif by a short linker. $N$-Terminal domains are not conserved and their structure considerably varies among diverse subgroups of SNAREs. ${ }^{[27,28]}$

Remarkable is the fact, that different sets of SNAREs from two opposing membranes were found to associate into complexes that are subsequently disassembled by the NSF protein. ${ }^{[29]}$ Originally, these proteins were designated as 
v-SNAREs (vesicle-membrane SNAREs) and t-SNAREs (target-membrane SNAREs). ${ }^{[29]}$ The formation of a complex from these proteins, typically containing two t-SNAREs and one v-SNARE protein, is mediated by the SNARE motifs, which form a parallel four-helix coiled-coil structure termed SNARE complex. ${ }^{[30]}$ The figure 1.3 described the assembly and disassembly of the SNARE complex.

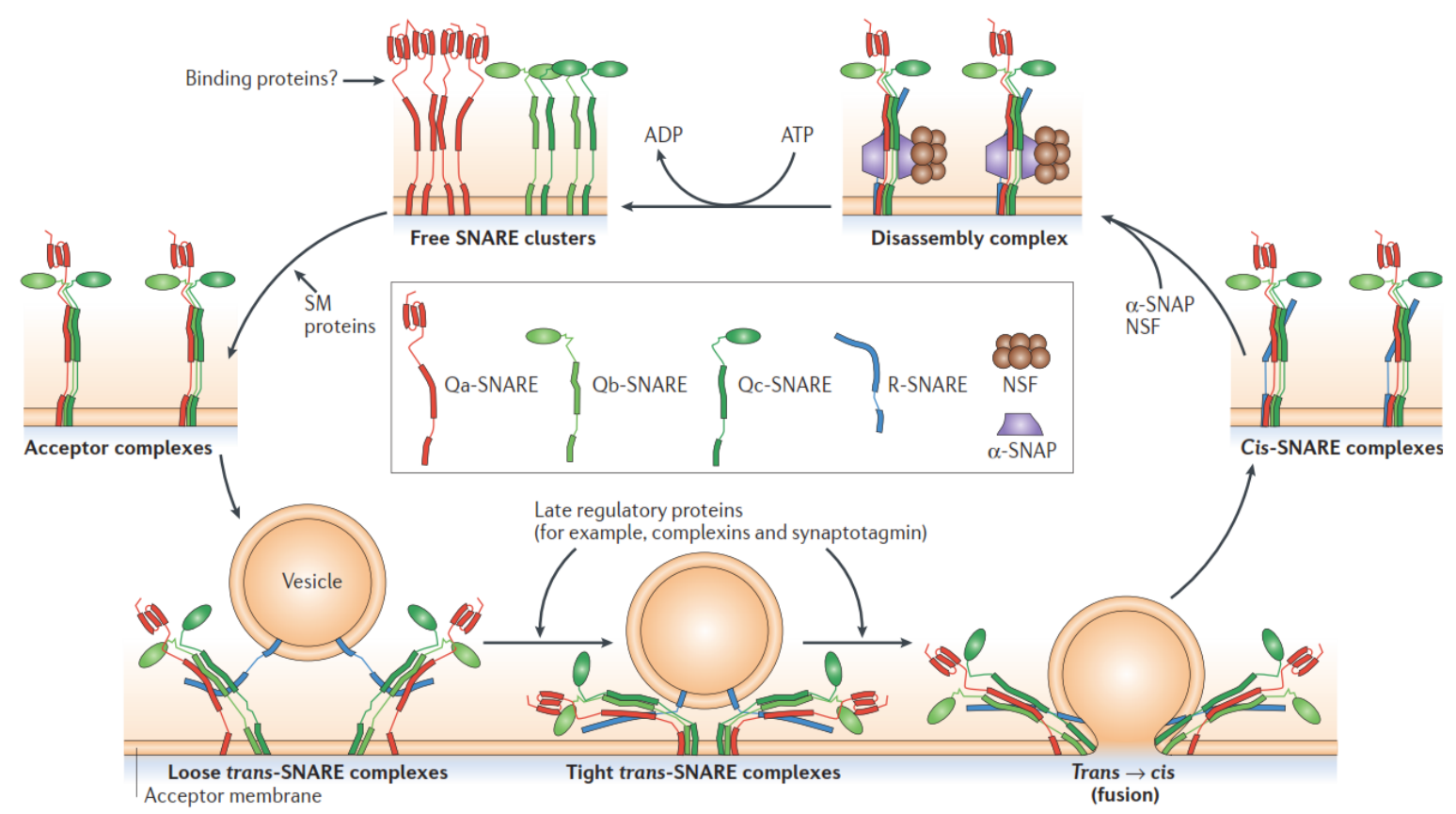

Figure 1.3. The SNARE conformational cycle during vesicle docking and fusion. Q-SNAREs, which are organized in clusters (top left), assemble into acceptor complexes, and this assembly process might require SM (Sec1/Munc18-related) proteins. Acceptor complexes interact with the vesicular R-SNAREs through the Nterminal end of the SNARE motifs, and this nucleates the formation of a four-helical trans-complex. Transcomplexes proceed from a loose state (in which only the N-terminal portion of the SNARE motifs are 'zipped up') to a tight state (in which the zippering process is mostly completed), and this is followed by the opening of the fusion pore. In regulated exocytosis, these transition states are controlled by late regulatory proteins that include complexins (small proteins that bind to the surface of SNARE complexes) and synaptotagmin (which is activated by an influx of calcium). During fusion, the strained trans-complex relaxes into a cis-configuration. Cis-complexes are disassembled by the AAA+ (ATPases associated with various cellular activities) protein NSF (N-ethylmaleimide-sensitive factor) together with SNAPs (soluble NSF attachment proteins) that function as cofactors. ${ }^{[19]}$ 
The crystal structures of two evolutionary distantly related SNARE complexes display a remarkable structural conservation. ${ }^{[30,31]}$ Thus, the core complex always contains 16 stacked layers of interacting side chains. These layers are all largely hydrophobic, except for a central "0" layer that contains three highly conserved glutamine $(Q)$ residues and one highly conserved arginine $(R)$ residue (Figure 1.4). The comparison of the primary sequences of closely or only distantly related homologues indicated the same structural features. ${ }^{[26,32]}$

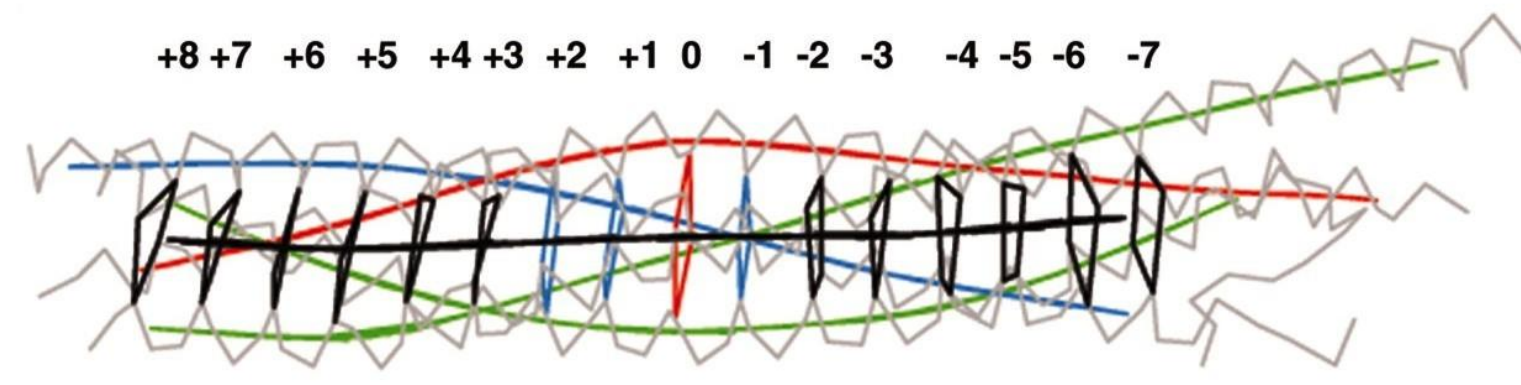

Figure 1.4. Scheme of a neuronal SNARE complex and skeleton diagram indicating the positions of the corresponding layers (numbered) in interacting side chains. The complex contains the SNARE motifs of syntaxin-1A (Qa-, depicted red), SNAP-25 (Qb- and Qc-, green) and VAMP/synaptobrevin (R-, blue). ${ }^{[32]}$

The characteristic motifs building SNARE structures are designated as Qa-, Qb-, Qc- and R- SNAREs (Figure 1.3). Functional SNARE complexes that drive membrane fusion are hetero-oligomeric, parallel four-helix bundles, and each bundle is invariant, requiring one of each of the Qa-, Qb-, Qc- and R-SNAREs. A phylogenetic analysis of SNARE sequences from $S$. cerevisiae, $A$. thaliana and mammals has been shown that these four SNARE subfamilies are highly conserved and diverged early in eukaryotic evolution. ${ }^{[26,27]}$

Due to their amphiphilic nature, SNARE motifs can also associate in other combinations that result in helical bundles that are less stable than core complexes. Particularly noteworthy are the complexes that are formed by the neuronal SNAREs. These include a Qaaaa complex (an antiparallel four-helix bundle) ${ }^{[127]}$, a Qabab complex (a parallel four-helix bundle) ${ }^{[128]}$, a Qaabc complex 
(a parallel four-helix bundle with some disordered regions ${ }^{[129,130]}$ and, surprisingly, an antiparallel QabcR complex. ${ }^{[131,132]}$ These complexes might not have the correct membrane topology or they might not contribute sufficient energy to drive membrane fusion. They probably represent 'off-pathway' reactions. ${ }^{[19]}$

The region surrounding the boundary membrane, termed as "vertex ring", initially becomes highly enriched with the fusion required Rab, Rab-effector complex, SNAREs, and "regulatory lipids" such as ergosterol and phosphoinositides. ${ }^{[33-35]}$ Subsequently, fusion occurs around the "vertex ring", joining the two boundary membranes and yielding a luminal vesicle within the larger fused organelle. After "vertex ring" formation, trans-SNARE complexes assembles and the additional regulatory proteins bind to trans-SNARE (Figure 1.3). ${ }^{[19]}$ The later include SMproteins and other proteins or domains that bind to $\mathrm{Ca}^{2+}$, to lipids or to SNAREs. ${ }^{[36]}$ SNARE proteins (usually $\mathrm{R}$ - and $\mathrm{Qa}$-) have transmembrane anchors in opposite bilayers ( $\mathrm{R}$ - in the vesicle and Qa- in the target membrane, respectively). Thus, the formation of a trans-SNARE complex by "zippering" starting from the N-terminal end to its C-terminal membrane anchor clamps the opposite membranes together and drives bilayer distortion, first hemifusion, and then, complete fusion of membranes. ${ }^{[37]}$ The full fusion converts trans-SNARE complexes to the corresponding post-fusion cis-SNARE complexes in which all SNAREs reside together in the resulting fused membrane. ${ }^{[19]}$ In the final step, a-SNAP displaces other SNARE-bound proteins and prepares the cis-SNARE complex for the ATPdependent disassembly by NSF. ${ }^{[38,39]}$

The mechanism of membrane fusion has been extensively investigated to unravel the aspects of this important life process. However, the specific physical forces and molecular mechanisms governing this process still remain unclear or not completely understood. Therefore, further studying of the whole fusion process as well as its individual steps is necessary. 


\subsection{Model systems for membrane fusion}

To shed light on the role of membrane apposition and the transmembrane domains of fusion proteins, fusion experiments have been carried out using vesicles reconstituted with fusion proteins. ${ }^{[40]}$ In addition, artificial model systems have been created that mimic the function of SNAREs in fusion reactions in vitro. ${ }^{[41-47]}$ Artificial SNARE analogues have the advantage of simplifying the complex SNARE assembly reaction such that systematic structural variations and system compositions can be used to study the influence of each segment on the fusion process.

SNARE analogues membrane fusion was successfully mediated by coiled-coil peptides, ${ }^{[47-49]}$ DNA double strand formation, ${ }^{[45,46]}$ aminoethylglycine peptide nucleic acids (aeg PNA), ${ }^{[50]}$ boronic acid/cis-diol, ${ }^{[51,52]}$ hydrogen bonding between cyanuric acid and melamine, ${ }^{[43,44]}$ and vancomycin/D-Ala-D-Ala recognition. ${ }^{[42,53]}$

Some similar fusogenic systems based on recognition of nucleo bases with a phospholipid chain as an anchor in membrane were designed. ${ }^{[54]}$ The influence of DNA binding geometry on the fusion probability was investigated. Thus, it was found that fusion events occured only when different DNAs were coupled to the lipid anchors with 5'- or 3'-ends, forming complementary duplexes (Figure 1.5). On the contrary, in case all complementary DNAs were bound with the 5 '-end, fusion was not observed, because the resulting duplex acted as a spacer between the membrane surfaces, inhibiting close contact between these surfaces necessary for a fusion event. Notably, the geometry of DNA/lipid conjugates containing 5'- and 3'coupled DNAs is more similar to that of the native SNARE complex (Figure 1.5). 

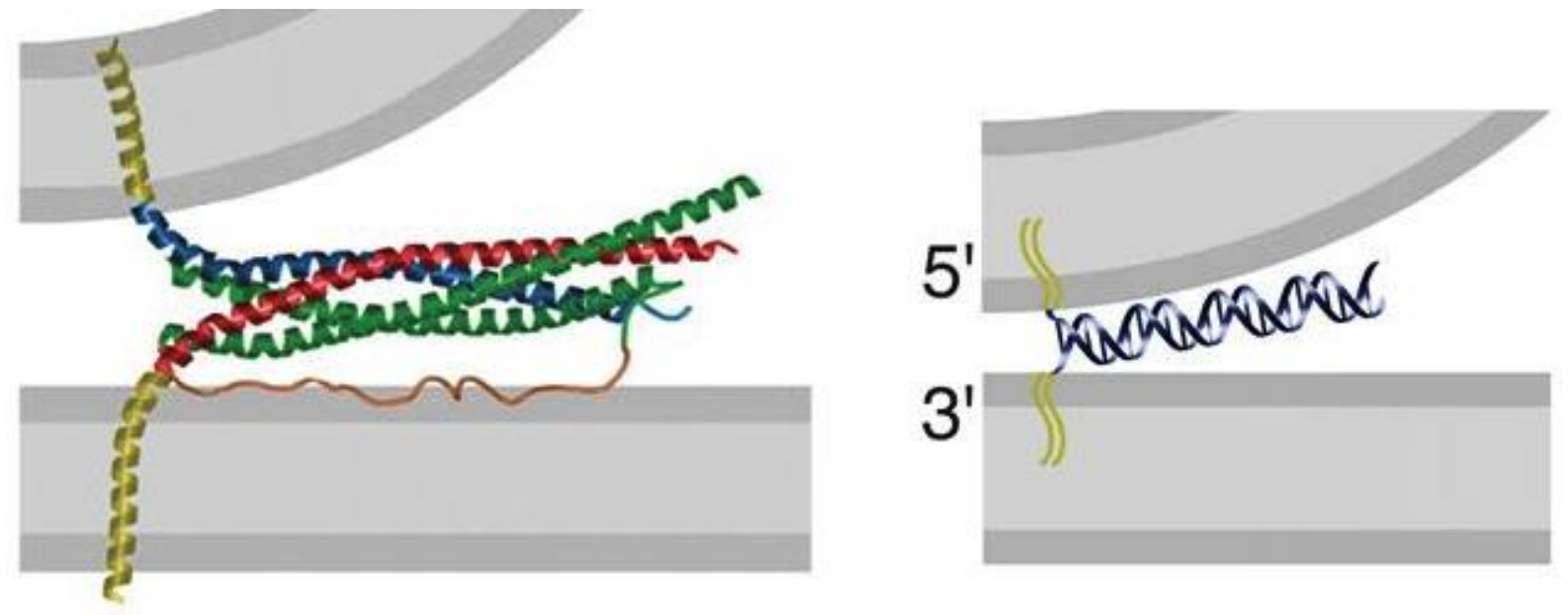

Figure 1.5. Schematic illustration of the binding of a vesicle to a planar membrane mediated either by SNARE (on the left) or complementary DNAs (on the right), which are anchored in a membrane via a lipid. ${ }^{[54]}$

KROS and coworkers presented a SNARE model system based on a coiled-coil forming a-peptide recognition motif. ${ }^{[47]}$ A complementary pair of coiled-coil forming peptides, $\mathrm{G}(\mathrm{EIAALEK})_{3}(\mathrm{E} 3)$ and $\mathrm{WWG}(\mathrm{KIAALKE})_{3}(\mathrm{~K} 3)$, interacting in parallel orientation was used as SNARE recognition motif (Figure 1.6). The peptides were conjugated with 1,2-dioleoyl-sn-glycero-3-phosphoethanolamine lipid (DOPE) through a $P E G_{12}$ linker, followed by incorporating this lipid into membrane bilayer. The anchored peptides E3 and K3 in the vesicles form a stable heterodimer complex, which bring two membranes in close proximity leading to fusion. The elongation of the coiled-coil motif to four repeating units ( $E 4$ and K4) increased the rate of fusion. ${ }^{[47]}$ Furthermore, more hydrophobic anchors such as cholesterol and DOPE increased the fusion rate while less hydrophobic linkers such as palmitoleic acid, decanoic acid, and adamantine carboxylic acids decreased the fusion efficiency. ${ }^{[47]}$ This study suggests that the lipid anchor and the efficient incorporation of the anchor into the vesicles are important factors in the fusion process. 
a)

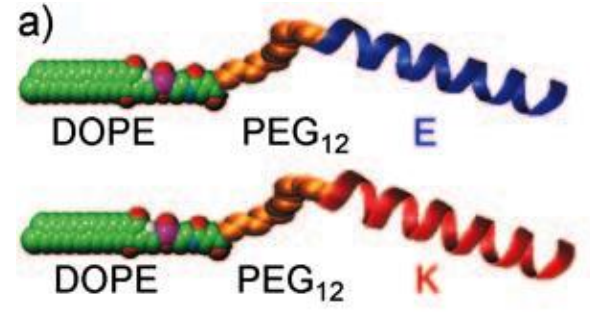

b)

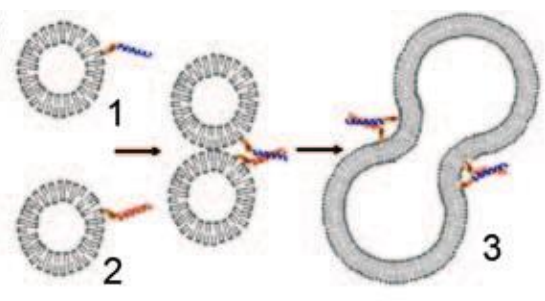

Figure 1.6. a) $E$ and $K$ coiled-coil domains anchored to DOPE lipid through a $P E G_{12}$ linker. b) Schematic illustration of the fusion when vesicle carrying $\mathrm{E}$ construct mixed with vesicle bearing $\mathrm{K}$ construct. ${ }^{[47]}$

The coiled-coil recognition were proved to be an excellent replacement for the SNARE motif in terms of achieving leakage-free efficient and full fusion of the vesicles with content mixing. Therefore, the coiled-coil recognition motif has been further investigated as SNARE recognition motif anchored to TMDs and linkers of native SNARE proteins (Figure 1.7) ${ }^{[48]}$. Thus, coiled-coil forming helices of E3 and K3 were directly linked to the TMDs of VAMP2 and syntaxin-1A. Lipid mixing and content mixing assays showed full fusion of the vesicles bearing TMD VAMP2 E3 with the vesicles carrying TMD syntaxin K3.

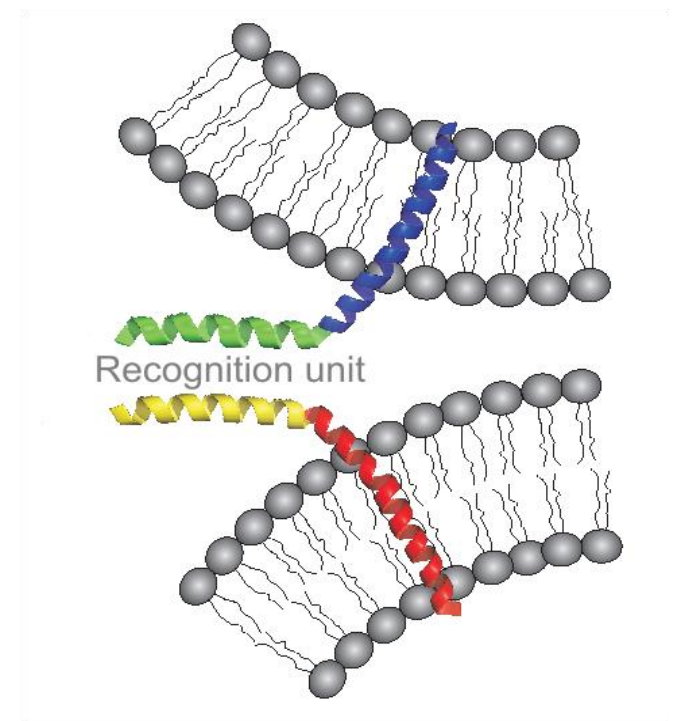

Figure 1.7. SNARE fusion model system based on native TMD and linker domains of syntaxin (blue helix) binding to E3 peptide (green helix) and native TMD and linker domains of VAMP2 (red helix) binding to K3 peptide (yellow helix). ${ }^{[48]}$ 
Peptide nucleic acids or PNA recognition has been used as SNARE motif analog because antiparallel and parallel duplexes can be formed dependent on nucleobase sequence (Figure 1.8). ${ }^{[50]}$ PNA sequences were chosen that ensure duplex formation at room temperature and provide orientation of the connected TMDs on opposite sides (antiparallel orientation, PNA1 gtagatcact and PNA2 agtgatctac) or on the same side of the recognition complex (parallel orientation, PNA1 and PNA3 catctagtga). For both combinations, lipid mixing between reacting vesicles can be observed. However, in accordance with the native SNARE complex, fusion initiated by parallel PNA strand recognition is more efficient than by antiparallel PNA duplex formation. Because the PNA recognition motif is quite small, spacing between opposed TMDs and vesicle membranes is not sufficient to suppress lipid exchange even in case of the antiparallel recognition motif. Content mixing fusion assays with the PNA-based model system reveals that a significant amount of vesicles is arrested in hemifusion stage preceding the full membrane fusion only providing outer leaflet lipid mixing.

The roll of transmembrane domain has been investigated using aeg-PNA peptides. The results showed that effective fusion events take place only if full-length TMDs (SyxTMD and SbTMD) pull together the outer and the inner leaflets of both merging vesicle membranes. The fusion efficiency decreases significantly when any TMD segment is reduced or deleted (Figure 1.8). ${ }^{[50]}$ 


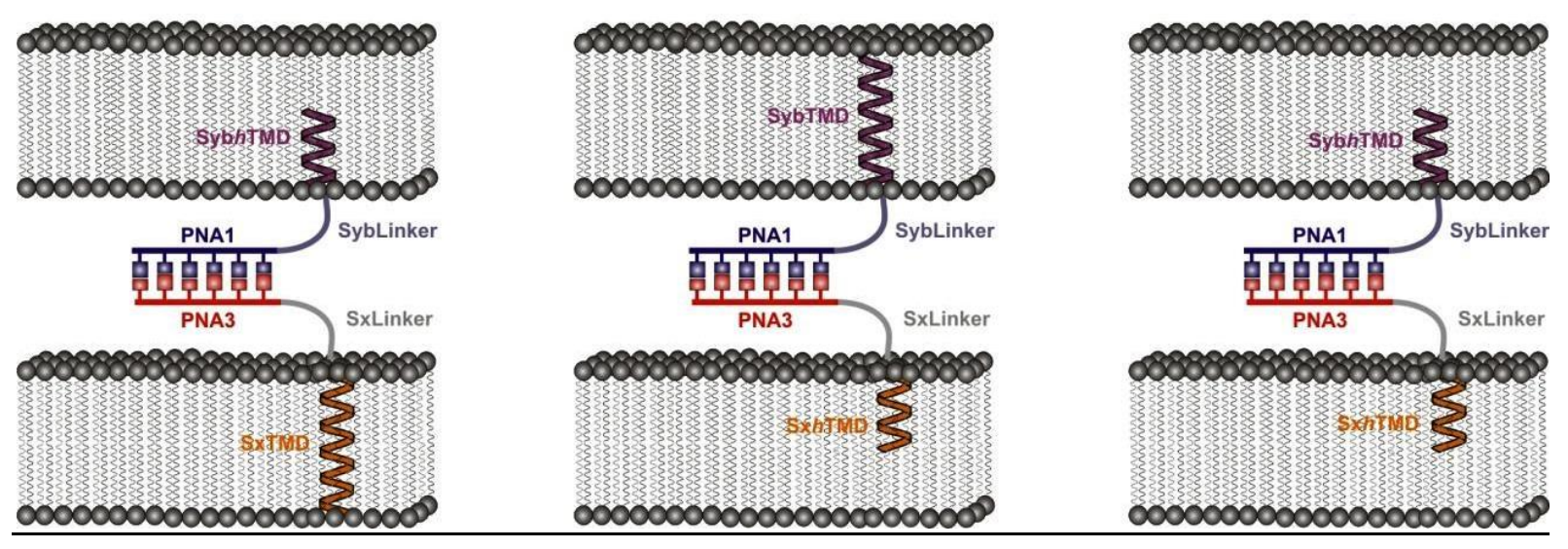

Figure 1.8. Simplified PNA/peptide models with complementary parallel strand orientation of PNA1 (blue) and PNA3 (red). (A) Model system containing a part of Sb-TMD (Syb, violet). (B) Model system containing a part of Syx-TMD (Sx, orange). (C) Model system containing TMD parts of syntaxin-1A and synabtobrevin $2 .{ }^{[50]}$

The transmembrane anchors in the native SNARE complex are linked at the same side of the SNARE recognition motif corresponding to a parallel orientation of recognizing oligomers. The mechanistic requirement of this parallel organization for vesicle fusion was investigated using DNA, aeg-PNA and the coiled-coil peptides clearly indicate that membrane anchors attached to opposite sides of the recognition motif (antiparallel orientation) inhibit or at least reduce fusogenicity. Nevertheless, vesicle fusion can be obtained also with antiparallel attached TMDs in a mechanism, which obviously differs from SNARE mediated fusion. 


\subsection{Goals of this Study}

The study of the relevant literature concerning the known mechanisms of membrane fusion and previously employed artificial fusogens indicated, that further development of the new model systems for membrane fusion and improvement of already available ones, is a challenging task. The usage of a well defined recognition unit with a special topology instead of native SNARE motif would potentially clarify the molecular mechanisms governing membrane fusion and open new attractive ways for drug delivery. The nucleobase-functionalized $\beta$-peptides or $\beta$-PNA are potential candidate to use as SNARE recognition units.

Thus, the main goal of this study is to develop novel model systems for specific membrane fusion and distance regulated vesicle fusion based on $\beta$-PNA. The following aspects are to be addressed:

$>$ synthesis of the corresponding model systems for membrane fusion;

$>$ investigation of the behavior of synthesized fusogens in membranes;

$>$ investigation of a vesicle-vesicle distance by modifying the model system. 


\section{Bases and design of the $\beta$-peptide}

\section{1. $\beta$-Peptides}

A foldamer is defined as an oligomer that folds into a conformationally ordered state in solution, a structure that is stabilized by a collection of noncovalent interactions between nonadjacent monomeric units. ${ }^{[56]}$ There are two major types of foldamers: single-stranded foldamers and multiple-stranded foldamers. Recently, several peptidomimetic foldamers have attracted a lot of attention because of their unique conformations and interesting bioactivities. ${ }^{[56]}$ The family of $\beta$-peptides is a major class of foldamers, studied over the years due to their unique folding behavior in solution. ${ }^{[55,57]}$ In comparison to $\alpha$-peptides, $\beta$-peptides are more flexible because of the presence of an additional methylene group. $\beta$-Peptides have received considerable attention due to their structural diversities. ${ }^{[55,57-59]}$ At least 15-20 $\alpha$-amino acids are required to form a stable $\alpha$-helical secondary structure. Considering the higher conformational flexibility of $\beta$-peptides, one might expect that even a longer backbone would be required to obtain a stable helical secondary structure. However, it has been shown that $\beta$-peptides composed of as few as six $\beta$-amino acid residues form surprisingly stable helices. ${ }^{[57]}$ The $\beta$-peptide oligomers are resistant towards enzymatic degradation and have little tendency for the $H / D$ exchange of the central amide protons. ${ }^{[60]} \beta$-Peptides are shown also to have versatile biological activity. ${ }^{[61]}$ Furthermore, it was shown that $\beta$-amino acids have a significant potential to function as powerful peptidomimetics. ${ }^{[62]}$ In the recent years, several research groups have contributed in this field and have concluded that short $\beta$-peptide oligomers form stable helices in solution and in solid state. SEEBACH'S group has focused on the $\beta$-peptides composed of conformationally flexible acyclic $\beta$-amino acids. ${ }^{[57,63]}$ Whereas, GeLLMAN and coworkers have focused on conformationally constrained cyclic residues with limited degree of freedom along the $\mathrm{C}_{\alpha}-\mathrm{C}_{\beta}$ bond. ${ }^{[55]}$ 
Several helical secondary structures are known for $\beta$-peptides including the 14helix, 12-helix, 10/12-helix, and 10-helix. The nomenclature of the $\beta$-peptide helices is based on the pattern of hydrogen bonding and the number of atoms in the hydrogen-bonded rings as shown in Figure 2.1.

A

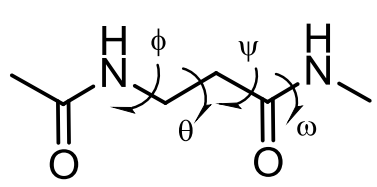

$\beta$-peptide

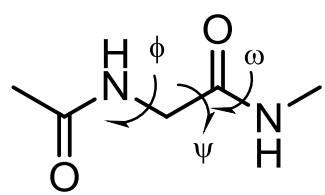

$\alpha$-peptide

B<smiles>CCC(CCCNC)(CCC(=O)NCCCNC(=O)CCNC(=O)CCNC(=O)CCNC)NC(=O)CCNC</smiles><smiles>CNCCC(=O)NCCCCCCC(=O)NCCC(=O)NCCC(=O)NC</smiles>

Figure 2.1. A) The main chain torsional angles of a $\beta$-peptide and an $\alpha$-peptide; B) nomenclature for $\beta$-peptide helices based on different possible hydrogen-bonding patterns. ${ }^{[56]}$

Although helical conformations are most common structural motifs for a-peptides, they are significantly different from $\beta$-peptide helices. A comparison of a $\alpha$-helix with the $\beta$-peptide helices is represented in Figure 2.2.

All three helical structures differ from each other significantly by polarities with respect to their $\mathrm{C}$ - and $\mathrm{N}$-termini, radius, and number of residues per turn. The 14- 
helical structure is stabilized by hydrogen bonding between an amide proton $(\mathrm{N}-\mathrm{H})$ at position $\mathrm{i}$ and a main chain carbonyl group $(\mathrm{C}=\mathrm{O})$ at position $\mathrm{i}+2$, forming a series of intercatenated 14-membered rings (Figure 2.1).

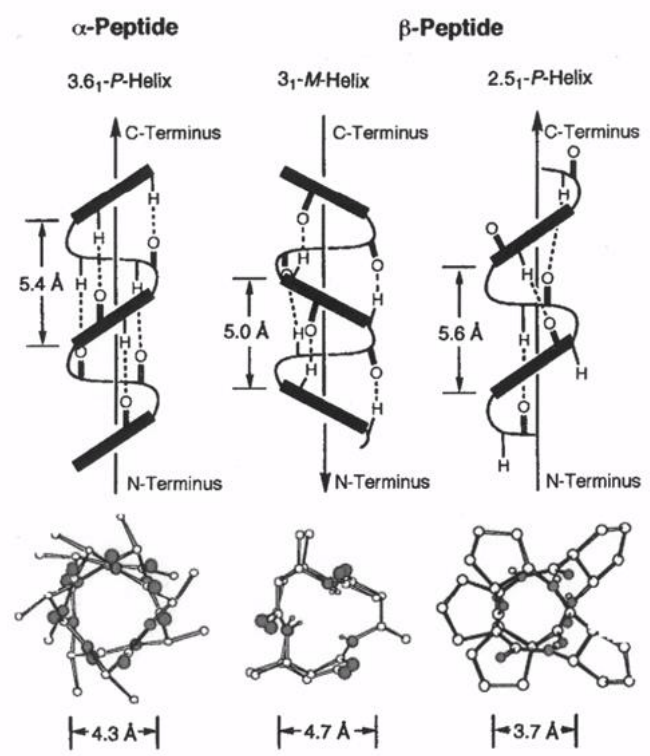

Figure 2.2. Schematic representation of three helices: regular $\alpha$-helix (left), $3_{1}$-helix (14-helix) (middle) and $\beta$ peptide 2.51-helix (12-helix) (right). This figure shows the polarities, pitches and diameters of the helices and their views along the axis. ${ }^{[57]}$

The overall structure of the 14-helix differs from that of the a-helix in many aspects like radius, polarity, and overall dipole. The net dipole of the 14-helix is opposite to that of a $\alpha$-helix as the amide carbonyl and $\mathrm{NH}$ groups project towards the $\mathrm{N}$ - and C-terminus, respectively. Furthermore, a $\beta$-peptide 14-helix has approximately three residues per turn, which positions the side chains of every third residue on the same side of the helix with linear orientation. GELLMAN and coworkers have shown that a short $\beta$-peptide composed of trans-2-aminocyclohexanecarboxylic acid $(\mathrm{ACHC})$ adopts a 14 -helical conformation in solid state and in solution. ${ }^{[64,65]}$ $\beta$-Peptides are able to adopt various stable secondary structures (helix, turn, and sheet) which indicates that it should be possible to design functional mimics of natural peptides and proteins. Several $\beta$-peptides were shown to exhibit interesting 
biological activities. ${ }^{[59]} \beta$-Peptides are extremely stable towards all common proteolytic enzymes in vivo and in vitro. ${ }^{[66-67]}$ It has been recently shown that $\beta$ amino acids offer useful structural diversity in designing peptidomimetics. ${ }^{[62]}$ Amphiphilic $\beta$-peptides are shown to mimic the amphiphilic a-helices involved in lipid uptake and transport in human apolipoproteins. ${ }^{[68]}$ They are also known to function as potential antimicrobial agents. Antimicrobial agents can kill bacteria by interacting and disrupting the integrity of the cellular membranes. So far antimicrobial $\beta$-peptides have been prepared with either 14-helical or 12-helical conformations. Several amphiphilic oligomers with 14-helical conformation have been studied to function as antimicrobial agents. ${ }^{[69]}$ Cyclic $\beta$-peptides and mixed $\alpha$ and $\beta$-peptides are known to self-assemble in tubular architectures, which can be used as ion-conducting channels in phospholipid bilayers. ${ }^{[70-71]}$ Therefore, it is clear that $\beta$-peptides which adopt several novel secondary structures, should be used to understand the fundamental implications of molecular assembly as well as in the field of designing pharmaceuticals and molecular devices.

\subsection{Nucleobase-functionalized $\beta$-peptides ( $\beta$-PNA)}

The most prominent helical secondary structure in $\beta$-peptides is the 14-helix with three amino acids per turn orienting every third side chain ( $i$ and $i+3)$ on the same side of the helix. ${ }^{[65,69,72-77]}$ This helix is obtained with $\beta$-amino acids that have lateral substituents in $\beta$-position. Nevertheless, the helix propensity can be even improved by incorporation of conformationally constrained cyclic amino acids like trans-(1R,2R)-2 aminocyclohexanecarboxylic acid (ACHC). ${ }^{[65,}$ 69, 72-75] The combination of stable helix formation and the uniform orientation of every third amino acid side chain offers the unique opportunity to use $\beta$-peptides for molecular architecture with peptide helical secondary structures (Figure 2.3). One possibility for using $\beta$-peptide helices for molecular architecture, the self-association of amphiphilic $\beta$-peptide 14-helices driven by hydrophobic interactions has already been reported. ${ }^{[78]}$ In addition, specific helix interactions might be obtained by using 
the recognition potential of hydrogen bonding. The nucleobase pair recognition known from oligonucleotides seems especially well suited for specificity and stable dimerization, since stacking interactions contribute to the overall stability. As already reported for a-peptides, the modification of amino acid side chains with nucleobases can be used for specific and reversible helix recognition and threedimensional organization. ${ }^{[79-81]}$ Furthermore, nucleobase-functionalized a-helices can recognize DNA ${ }^{[82-83]}$ or a complementary $\alpha$-helix. ${ }^{[84-86]}$ Base pairing provides an excellent driving force and selectivity for self-assembling $\beta$-peptide 14-helices. The principle design and first evidence for specific recognition of nucleobasefunctionalized $\beta$-peptides with respect to tertiary structure formation has been reported. $^{[87]}$

A

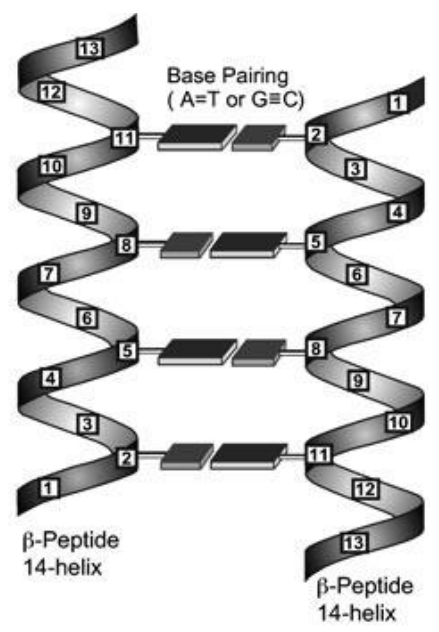

B

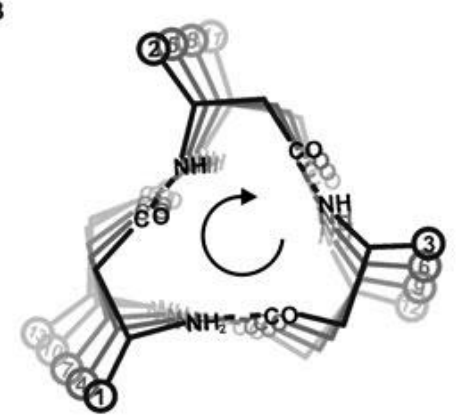

Figure 2.3. A) Model of antiparallel $\beta$-peptide helix association mediated by nucleobase pairing; B) top view of the right-handed 14-helix. ${ }^{[88]}$ 
The synthesis and recognition of a variety of $\beta$-peptide helices in order to investigate the stability of double-strand formation by comparison of the A-T and G-C pairing contributions has been reported. ${ }^{[88]}$ Furthermore, geometrical parameters like the preferred strand orientation, the positioning of $\beta$-homolysine within the $\beta$-peptide helix, and the influence of the helix content on duplex formation have been evaluated. The functionalization of one helical face with three nucleobases already leads to very stable complexes in case of $\mathrm{G}-\mathrm{C}$ recognition, ${ }^{[87]}$ whereas $A-T$ pairing $\beta$-peptides with the same oligomer length are significantly less stable. $\beta$-Peptide helices with four nucleobases in order to obtain defined double strands based on the four canonical pairing possibilities $A-T, T-A, G-C$, and $C-G$ have been investigated. ${ }^{[88]}$ The peptides, which contain 13 amino acids, were presented with the nucleo- $\beta^{3}$-amino acids $(S)-\gamma$-(guanine-9-yl)- $\beta$-homoalanine $(\mathrm{H}-\beta-\mathrm{HalG}-\mathrm{OH}), \quad(S)-\gamma-($ cytosine-1-yl)- $\beta$-homoalanine $\quad(\mathrm{H}-\beta-\mathrm{HalC}-\mathrm{OH}), \quad(S)-\gamma-$ (adenine-9-yl)- $\beta$-homo-alanine (H- $\beta-\mathrm{HalA}-\mathrm{OH})$ and (S)- - -(thymine-1-yl)- $\beta$ homoalanine $(\mathrm{H}-\beta-\mathrm{HalT}-\mathrm{OH})$ incorporated in every third position as a recognition unit. For the remaining two positions per turn, $\beta$-homolysine was incorporated to increase the solubility in aqueous media and $\mathrm{ACHC}$ was introduced to achieve conformationally stable 14-helices (Figure 2.4). ${ }^{[88]}$ 
A

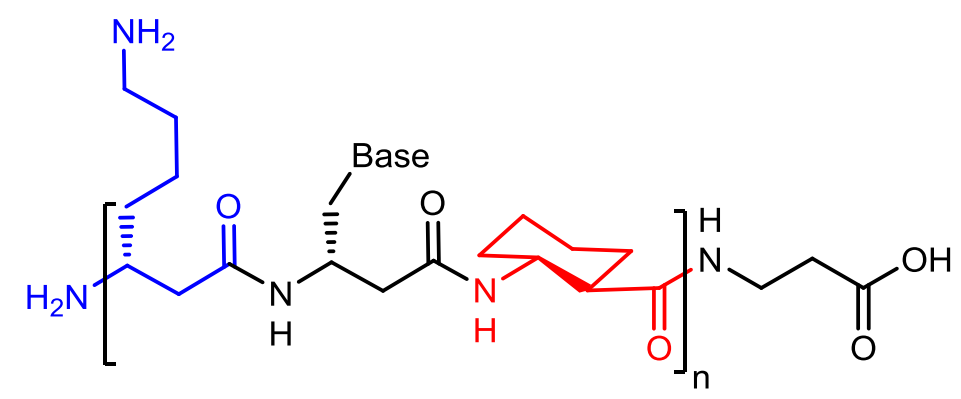

B<smiles>Cc1cn(C[C@H](CC(=O)O)NC(=O)OC(C)(C)C)c(=O)[nH]c1=O</smiles>

Boc-HalT-OH<smiles>[Z]Nc1ccn(C[C@H](CC(=O)O)NC(=O)OC(C)(C)C)c(=O)n1</smiles>

Boc-HalC(Z)-OH<smiles>CC(C)(C)OC(=O)N[C@@H](CC(=O)O)Cn1cnc2c(N)ncnc21</smiles>

Boc-HalA-OH

Figure.2.4. A) Triplet sequences of the $\beta$-peptide with ACHC, nucleobase and $\beta$-homolysein; B) The used nucleobase- $\beta^{3}$-amino acids in the previous right-handed 14-helix sequence.

The strand orientation has been investigated with several nucleo- $\beta^{3}$-amino acid sequences of the $\beta$-peptide 14-helix ( $\beta$-PNA). ${ }^{[88]}$ The sequence TAGT (5) and ACTA (6) or ATCA (7) and TGAT (8) are two pairs of oligomers that are complementary with antiparallel-strand orientation. In contrast, oligomers TAGT (5) and ATCA (7) or ACTA (6) and TGAT (8) are two complementary pairs designed to form a heterodimer, if parallel-strand orientation is preferred (Figure 2.5). All thermal denaturation studies with UV and CD spectroscopy have been proven to be reversible. There is a clear preference of $\beta$-PNA helices to undergo base-pairmediated organization with stable antiparallel helix orientation. Such unexpected stability for only four base pairs most likely arises from the preorganization of the $\beta$ PNA helices. Other reason could be the additive effect of WATSON-CRICK and HOOGSTEEN pairing, which contributes to the overall stability of the pairing complexes. ${ }^{[88]}$ 


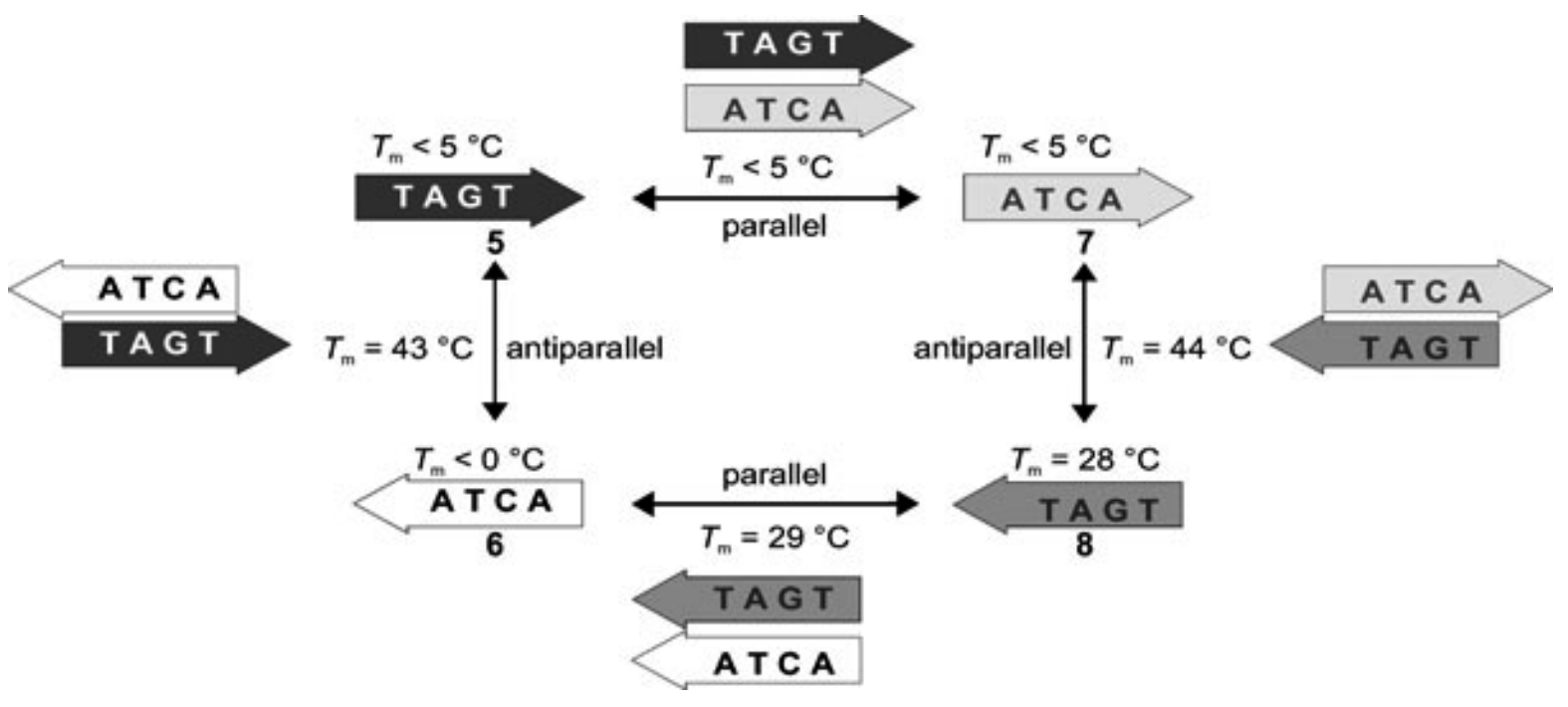

Figure 2.5. $\beta$-PNA sequences designed to prove a preference for antiparallel or parallel helix orientation. ${ }^{[8]}$

The oligomers (5) TAGT and (6) ATCA are very interesting due to their thermal stability $\left(T_{m}=43^{\circ} \mathrm{C}\right)$ in antiparallel double strands and none self-pairing. Therefore, those sequences have been chosen to be used as recognition units for the SNARE protein. The oligomers ATCA and TAGT are bounded to the native linker and transmembrane domains of the syntaxin- $1 \mathrm{~A}$ and synaptobrevin respectively. 


\section{Design and synthesis of new artificial model systems for SNARE proteins}

\subsection{Design of model systems}

Membrane fusion, one of the most fundamental processes in life, occurs when two separate lipid membranes merge into a single continuous bilayer. ${ }^{[4]}$ This process is triggered by the specific action of fusion proteins like neuronal SNARE proteins in the case of synaptic transmission. ${ }^{[19]}$ In order to promote exocytotic fusion of synaptic vesicles in presynaptic nerve endings, a coiled-coil four-helix bundle between two SNARE proteins residing in the plasma membrane (syntaxin-1A and SNAP-25) and a SNARE protein residing in the membrane of synaptic vesicles (synaptobrevin 2 or VAMP2) is formed, forcing the two merging membranes in close proximity (Figure 3.1). ${ }^{[19]}$ However, the precise mechanism by which SNARE proteins execute the merger of the lipid bilayers is still unclear. ${ }^{[89]}$

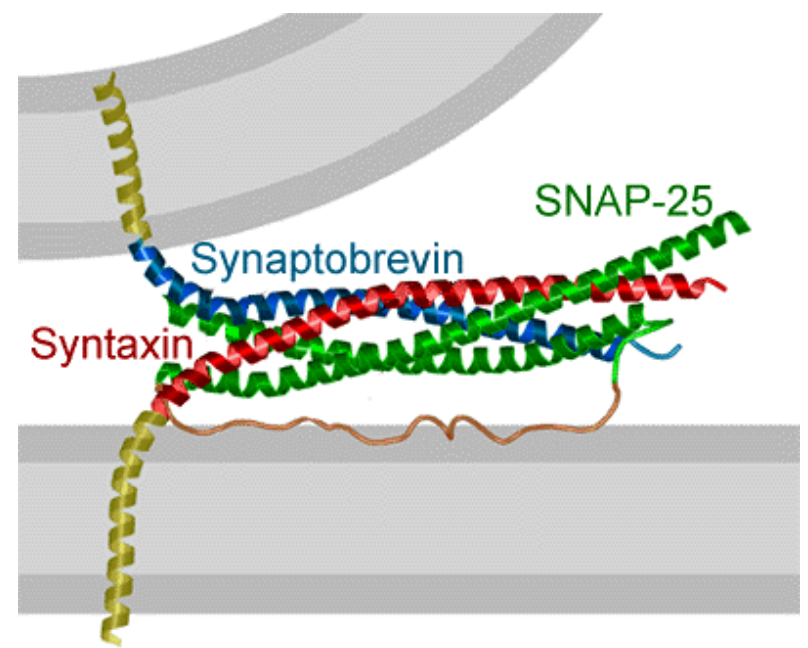

Figure 3.1. Depiction of the SNARE complex consisting of VAMP (blue), syntaxin (red) and SNAP-25 (green). ${ }^{[30]}$ 
There are two ways to study membrane fusion processes: 1) investigation of the native fusogenic proteins, ${ }^{[33,40]}$ or 2 ) designing various artificial model systems with reduced complexity. ${ }^{[90,91]}$ Artificial model systems simplify the complex natural systems and allow the systematical variation of the chemical structure and composition of these systems, in order to study the influence of each segment on the fusion process. Accordingly, design and synthesis of novel model systems for synaptic SNARE proteins is the major goal of this study. The tansmembrane domain showed to have an important role in the fusion process. Therefore, it was decided to use membrane anchors based on native transmembrane domains and linker regions of syntaxin-1A (Sx) or synaptobrevin $2(\mathrm{Sb})$ in our new model systems (Figure 3.2).

\section{Syntaxin-1A}

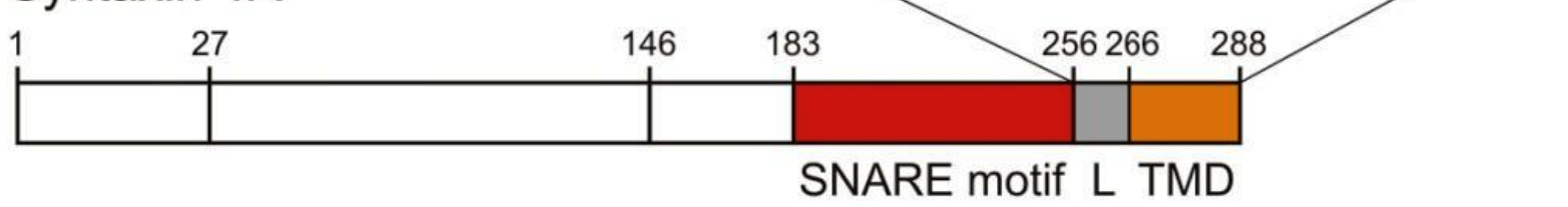

\section{Synaptobrevin 2}

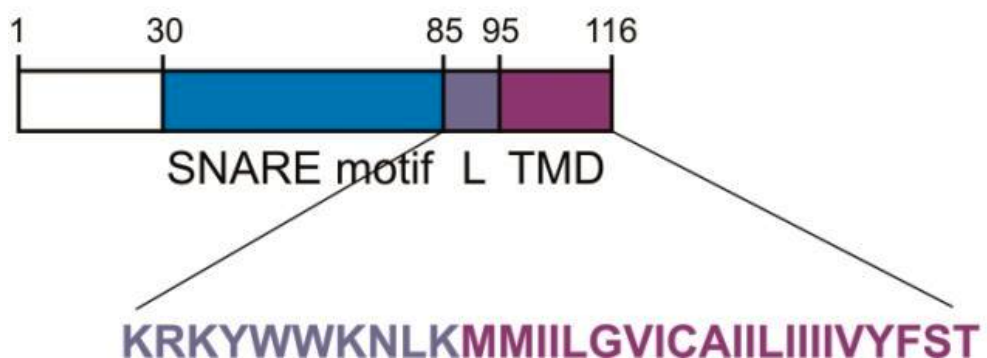

Figure 3.2. Schematic structure of syntaxin-1A (SNARE motif-red; linker region-grey; TMD-orange) and synaptobrevin 2 (SNARE motif-blue; linker region-light violet; TMD-violet). ${ }^{[97]}$

The SNARE recognition motif was replaced by $\beta$-PNA oligomers TAGT and ACTA (Figure 3.3), which are known to form a stable antiparallel duplex. ${ }^{[88]} \beta$-PNA offers 
a conformational rigid linear topology as a stable 14-helix and can be obtained with six $\beta$-amino acids (two helix turns). They have a high thermal stability and resistance towards enzymatic degradation. Therefore, $\beta$-PNA was implemented in the SNARE analogs with distance regulating properties for studying the vesicle membrane docking and fusion.
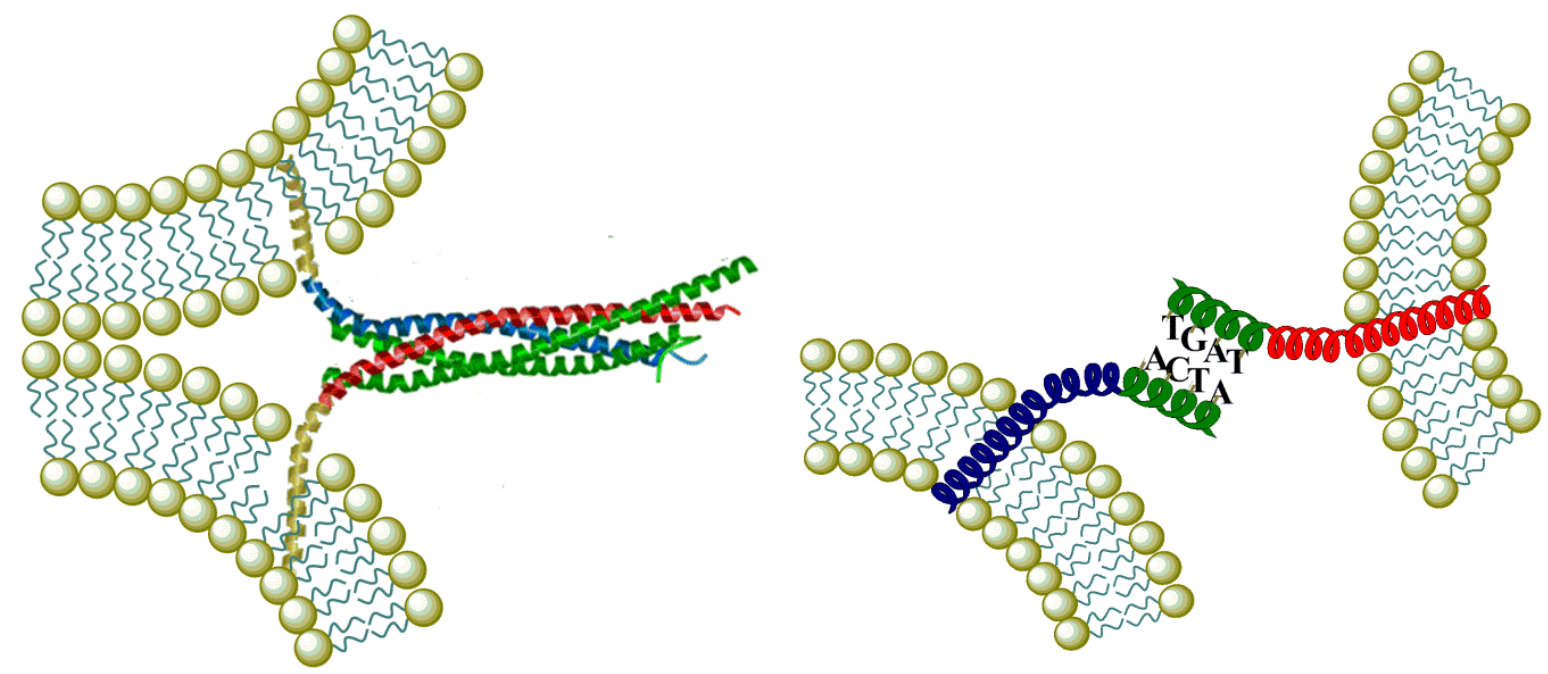

Figure 3.3. SNARE protein mediated membrane fusion (left) in comparison to fusion mediated by a TMD/linker/ $\beta$-PNA construct (right).

Initially, the $\beta$-PNA-peptide model system (ACTA-Syx and TAGT-Sb) with the transmembrane and linker domains of the natural SNARE and $\beta$-PNA sequences as recognition units was designed (Figure 3.4, up). $\beta$-PNA consists of two strands, each of them has four helix turns (about $20 \AA$ ), which play the role as distance regulator between the opposite membranes. Later, the model system has been modified to investigate the influence of elongated $\beta$-PNA recognition units on the vesicle fusion. Thus, the constructs ACTA-ext-Syx and TAGT-ext-Sb were designed so that the hybrids contain an extended $\beta$-peptide 14-helix within the linker region (Figure 3.4, down). The last $\mathrm{N}$-terminal six $\alpha$-amino acids before the $\beta$-PNA starts were exchanged for $\beta$-amino acids. Therefore, a continuous rigid 14helix can be formed extending the $\beta$-PNA strand into the linker region. This 
extension was provided on both sides of the $\beta$-PNA recognition motif, thereby, extending the linear 14-helix $\beta$-peptide from 20 to $40 \AA$. The sequences for the six $\beta$-amino acid extensions were adapted from the linker sequences of syntaxin and synaptobrevin including $\mathrm{ACHC}$ units to ensure the $\beta$-peptide 14-helix propensity (Figure 3.4, down).

TMD Sb

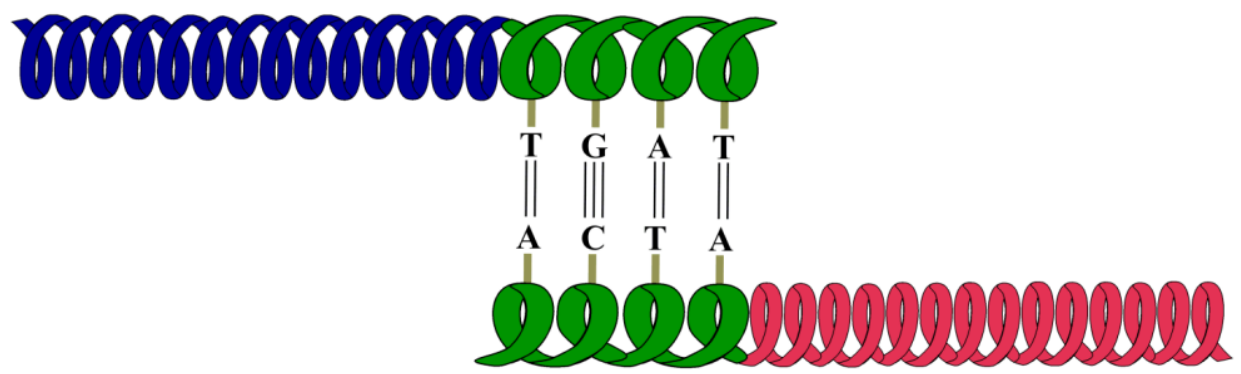

TMD Syx

TMD Sb

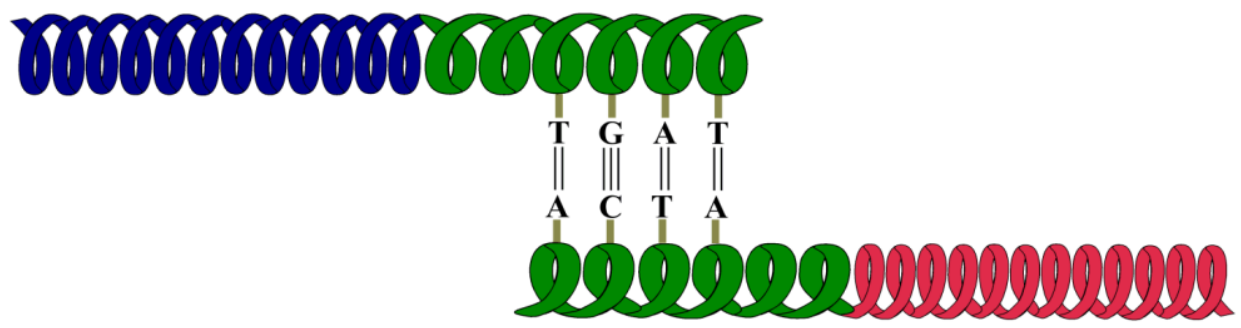

TMD Syx

Figure 3.4. up) Nucleobase functionalized $\beta$-peptide SNARE derived fusion system containing the native transmembrane domains (TMD) and linker sequences of synaptobrevin (Sb, blue) and syntaxin-1A (Syx, red) connected to $\beta$-peptide nucleic acid recognition units (green). Down) $\beta$-PNA SNARE analogs with extended $\beta$ peptide 14-helices in the linker region (green). TMDs and most of the linker sequences are derived from synaptobrevin (Sb, blue) and syntaxin-1A (Syx, red).

Thus, two artificial model systems for SNARE proteins with different length of the 14-helix $\beta$-peptide are designed and investigated in this work. Those $\beta$-PNA SNARE model systems can deliver further insight into the antiparallel fusion mechanism and the effect of the distance between the membranes. 


\subsection{Synthesis of $\beta$-PNA-peptides}

\subsubsection{Manual solid phase peptide synthesis}

Peptide synthesis is largely based on the solid phase method developed in 1963 by R. B. MeRRIFIELD. ${ }^{[92,93]}$ The C-terminal amino acid of the peptide is linked via a cleavable linker to an insoluble polymer support (resin). The side-chain functional groups and $\mathrm{N}$-a-amino group of the amino acids are protected with orthogonal protecting groups. The $\mathrm{N}-\alpha$-amino protecting group (9-fluorenylmethoxycarbonyl (Fmoc), tert-butyloxycarbonyl (Boc)), is then cleaved and the growing peptide chain is extended stepwise towards the $\mathrm{N}$-terminus by repeating the coupling/capping/deprotection cycles, until the protected target peptide has been assembled (Figure 3.5). All soluble reagents can be removed from the peptidesolid support by filtration and washed out at the end of each coupling step. Cleavage of the peptide from resin, and concurrent removal of all side-chain protecting groups is usually conducted by acidolysis. Depending on the nature of the used linker, the product can be a peptide acid, amide or include other Cterminal functionalities.

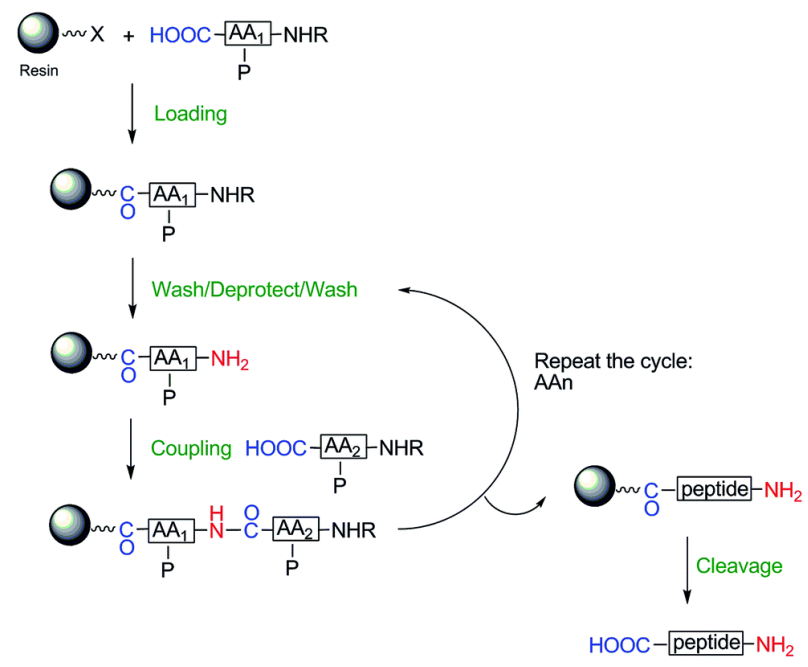

Figure 3.5. Schematic representation of SPPS. ${ }^{[98]}$ 
Change of protection group strategy, solid support and development of more efficient coupling reagents leads to higher yields and suppression of side reactions ${ }^{[99]}$ However, particular difficulties arise due to intermolecular aggregation, steric hindrance of protecting groups and premature termination of the sequence.

Peptide bond formation is a condensation reaction between two amino acids when the amino group of one amino acid reacts with the carboxylic group of the other amino acid, releasing a molecule of water. The carboxylic acid should be activated by making its hydroxyl group, a better leaving group. Quite a number of compounds activating carboxylic acids (coupling reagents) have been employed in peptide synthesis. In a recent review, a variety of such coupling reagents for amide bond formation has been comprehensively discussed. ${ }^{[94]}$ The most-widely used coupling reagents are carbodiimides on one hand, and phosphonium and aminium salts on the other hand (Figure 3.6).

$$
\mathrm{R}-\mathrm{N}=\mathrm{C}=\mathrm{N}-\mathrm{R}
$$

Carboiimide

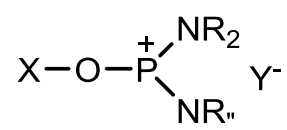

Phosphonium salts<smiles>[Y]N[C+]([R2])O[Y]</smiles>

Aminium salts

Figure 3.6. Coupling reagents.

Dicyclohexylcarbodiimide (DCC) is a classic member of carbodiimides family of coupling reagents, which has been used as carboxylic acids activator since 1955. ${ }^{[95]}$ But it has some limitations in use, e.g. these reagents cause dehydration of Asn and Gln residues. The other group of coupling reagents is the uronium/aminium (HATU/HBTU) and their salts are presented in Figure 3.7. 
<smiles>[Y]c1[X]c2c(cc1)nnn2O</smiles>

HOBt: $\mathrm{X}=\mathrm{CH}, \mathrm{Y}=\mathrm{H}$ HOAt: $X=N, Y=H$<smiles>[Y]c1ccc2c(c1[X])n(C(N(C)C)N(C)C)n[n+]2[O-]</smiles>

HBTU: $X=\mathrm{CH}, Y=\mathrm{H}$ HATU: $X=N, Y=H$

Figure 3.7. HATU, HBTU, HOBt and HOAt coupling reagents.

Coupling reagents derived from HOAt or HOBt react with a carboxylic acid to form reactive acyluronium (in case of HATU/HBTU) species which are then immediately transformed into $\mathrm{R}(\mathrm{CO}) \mathrm{OAt}$ or $\mathrm{R}(\mathrm{CO}) \mathrm{OBt}$ esters in the presence of $\mathrm{HOAt}$ or $\mathrm{HOBt}$, respectively. A tertiary amine (e.g. DIEA) is usually added in order to deprotonate the carboxylic acid prior to activation (Figure 3.8).

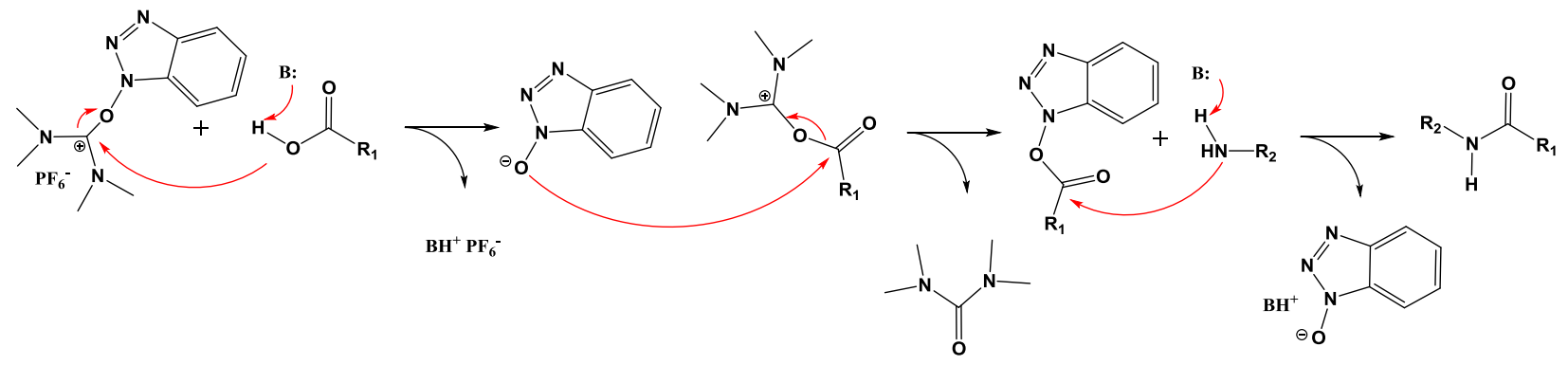

Figure 3.8. Mechanism of amide bond formation using HATU $\left(R_{1}, R_{2}\right.$ are side chains and $B$ is a Base).

A direct attack of an amino group on the uronium/aminium coupling reagent to form guanidinium salt as a by-product is a very important side-reaction. Coupling reagents based on HOAt have several important advantages over the HOBt-based compounds. They have been shown to dramatically shorten the reaction time and to give target products in higher yields with less racemization. ${ }^{[96]}$ 
There are two strategies for peptide synthesis Fmoc and Boc strategies and the most commonly used one is Fmoc strategy. In addition, the Fmoc method is easy to use and Fmoc group can be cleaved under mild basic condition, in contrast, the Boc method requires strong acidic conditions for the cleavage (usually neat trifluoroacetic acid TFA). The removal of side-chain protecting groups and the cleavage of the peptide from the resin at the final stage of the synthesis are achieved by incubating in hydrofluoric acid or trifluoromethanesulfonic acid, which makes the Boc chemistry generally disfavored. Nevertheless, Boc strategy is suited to synthesize difficult, hydrophobic and unnatural peptide chains and reduce peptide aggregation. Therefore, the synthesis of $\beta$-PNA-peptide oligomers has been carried out by using Boc-SPPS.

The general scheme which outlines the strategy of peptide synthesis was shown in Figure.3.5. Initially, the first Boc amino acid is attached covalently to an insoluble support resin on a HF or TFMSA cleavable linker. Deprotection of Boc, is accomplished by treatment of the peptide with TFA (Figure 3.9). The second Boc amino acid is coupled utilizing a pre-activated species or in situ activation. After the synthesis of the desired peptide, the resin bound peptide is deprotected and detached from the solid support via HF or TFMSA cleavage.

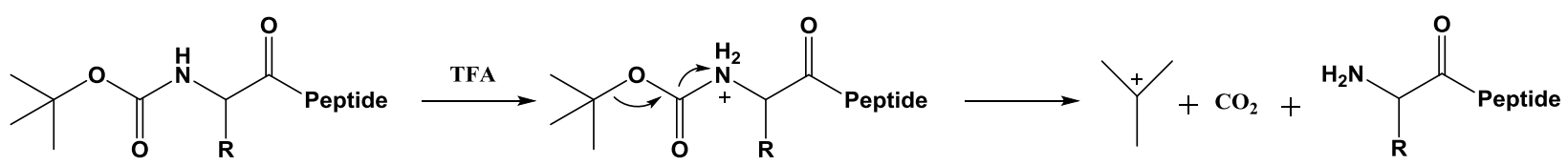

Figure 3.9. Mechanism of Boc deprotection.

\subsubsection{Manual SPPS of TMDs of syntaxin-1A and synaptobrevin 2}

The synthesis of TMD/linker sequences of syntaxin-1a (Syx-linker-TMD) and synaptobrevin 2 (Sb-linker-TMD) is difficult due to the high content of hydrophobic 
amino acids (Figure 3.10). Hence, to increase the yield and make the method efficient for continuous coupling of the $\beta$-amino acids, in situ neutralization SPPS for assembly of Syx-linker-TMD and Sb-linker-TMD was used starting from PAM resin. ${ }^{[100]}$ The standard reagents and procedures (see section 7.6.3) were employed for these syntheses.

a)

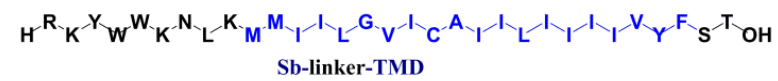

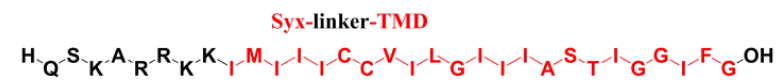

b)

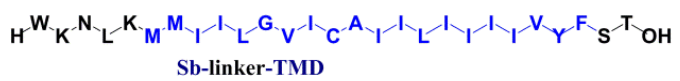

$$
\begin{aligned}
& \text { Syx-linker-TMD }
\end{aligned}
$$

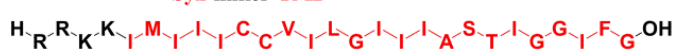

Figure 3.10. TMD and linker sequences of syntaxin-1A (Syx-linker-TMD) and synaptobrevin 2 (Syb-linkerTMD).a) TMD and Linker domains of (ACTA-Syx and TAGT-Sb); b) TMD and Linker domains of ACTA-ext-Syx and TAGT-ext-Sb.

The synthesized Syx-linker-TMD and Sb-linker-TMD were soluble in 2,2,2trifluoroethanol (TFE). Unfortunately, the strong hydrophobic sequences and the poor solubility in water, methanol and acetonitrile were making the purification of these peptides by reversed phase HPLC impossible. However, the proof of successful formation of Syx-linker-TMD and Sb-linker-TMD could be only achieved by LC-MS. This proof allowed us to continue the synthesis of $\beta$-PNA-peptide hybrids directly, without cleavage from the solid support and further purification of the TMD part.

\subsubsection{Synthesis of $\beta$-amino acids}

Due to the increased number of possible configurational isomers of $\beta$-amino acids, a number of synthetic strategies are available. The preparation of enantiopure $\beta$ amino acids has been extensively reviewed by many authors and several synthetic strategies have been already developed. ${ }^{[101-104]}$ The most classical and conventional pathway is the ARNDT-EISTERT homologation of $\alpha$-amino acids. ${ }^{[105]}$ 
The N-protected amino acids can be converted to the corresponding diazoketones via reaction of the mixed anhydride derivatives with diazomethane which undergo WOLFF rearrangement to give the desired $\beta$-amino acids (Figure 3.11).<smiles>[R]C(NC(=O)OC(C)(C)C)C(=O)O</smiles>

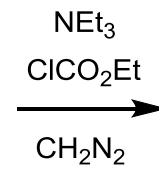<smiles>[R]C(NC(=O)OC(C)(C)C)C(=O)C=[W]</smiles>

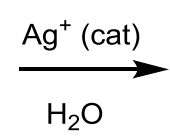<smiles>[R]C(CC(=O)O)NC(=O)OC(C)(C)C</smiles>

Figure 3.11. Reaction route to synthesis $\beta$-amino acids

The $\beta$-amino acids Boc- $\beta$-HLys(Z)-OH, Boc- $\beta$-HTyr(2-Br-Z)-OH, Boc- $\beta-H \operatorname{Trp}$ (For)$\mathrm{OH}$, Boc- $\beta-\mathrm{HAla}-\mathrm{OH}$, Boc- $\beta-\mathrm{HSer}(\mathrm{BzI})-\mathrm{OH}$ and Boc- $\beta-\mathrm{HGln}-\mathrm{OH}$, were synthesized by using the above mentioned strategy starting from the corresponding $\alpha-D$-amino acid. $^{[106]}$

\subsubsection{Synthesis of nucleo- $\beta$-amino acids}

In the previous section it was shown, that several methods are available for the synthesis of enantiomerically pure $\beta$-amino acids. Several methods known for the preparation of $\beta$-amino acids with proteinogenic side chains are not applicable to the synthesis of nucleo- $\beta$-amino acids. The ARNDT-EISTERT homologation of aromatic a-amino acids as a standard procedure is expected to proceed with partial racemization. ${ }^{[105]}$ Therefore, this pathway is not suitable for the preparation of enantiomerically pure nucleo- $\beta$-amino acids.

$\beta$-Homoserine derivatives are used as a starting material to access the synthesis of nucleo- $\beta$-amino acids. Reduction of the commercially available Boc-LAsp(OBzl)-OH leads to the required $\beta$-homoserin derivative which reacts with $\mathrm{N}^{3}$ benzoyl pyrimidine (thymine) to give the desired nucleo- $\beta$-amino acid. The MitsunOBU reaction is the key step in the synthesis of pyrimidinyl-nucleo- $\beta$-amino acid (S)-N-Boc- $\beta$-HalT-OH (Figure 3.12$) \cdot{ }^{[107]}$ The (S)-N-Boc- $\beta-H a l C-O H$ is 
synthesized from the corresponding mesylate of the $\beta$-homoserine derivative by nucleophilic substitution (Figure 3.12). ${ }^{[107]}$

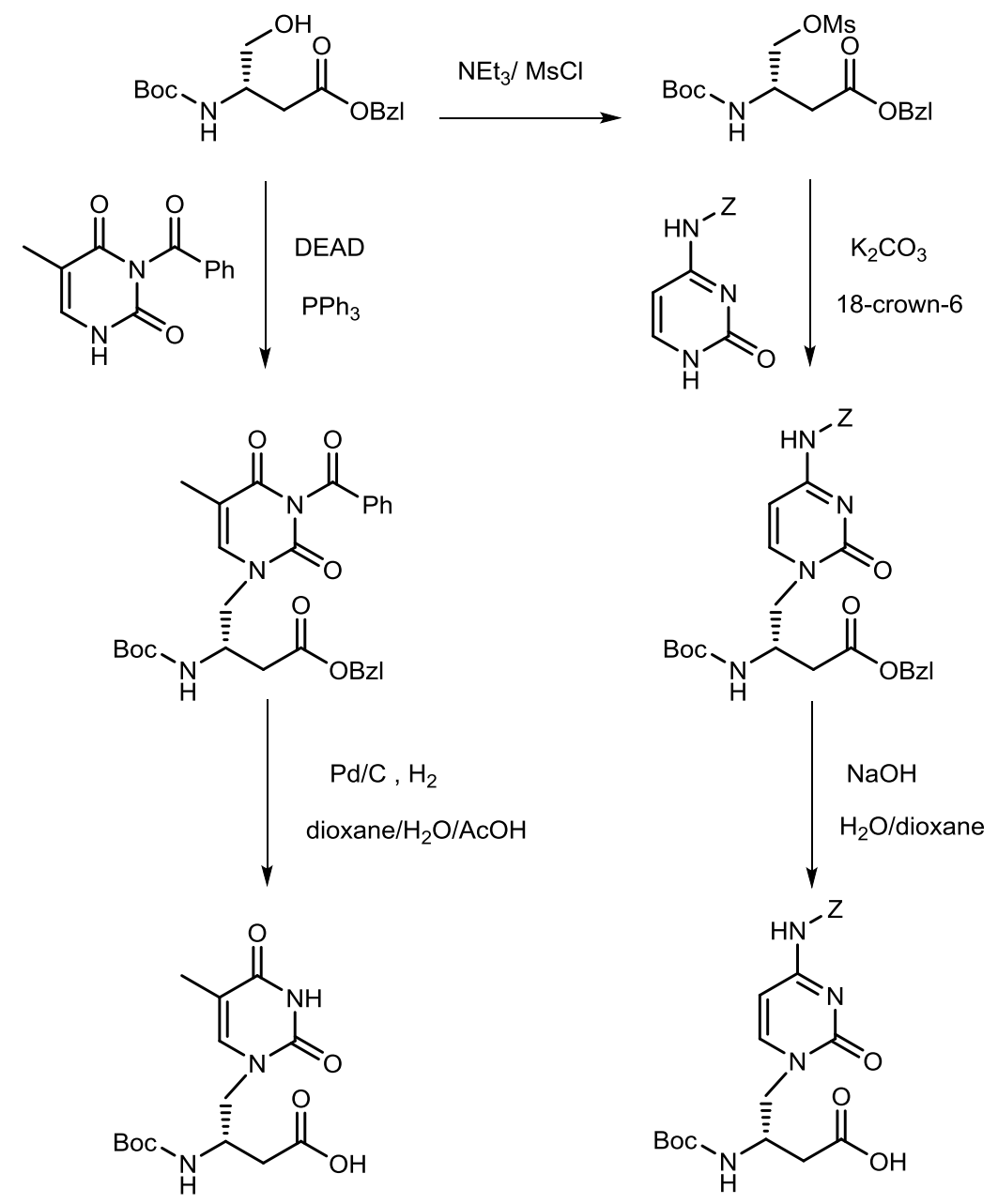

(S)-N-Boc- $\beta$-HalT-OH

(S)-N-Boc- $\beta$-HalC-OH

Figure.3.12. Synthesis of Boc- $\beta-\mathrm{HalT}-\mathrm{OH}$ and $\mathrm{Boc}-\beta-\mathrm{HalC}-\mathrm{OH}$ starting from $\beta$-homoserin derivative.

In case of the purine nucleobases ( $A$ and $G$ ), the $\beta$-homoserine derivative strategy gives very low yields. Since $\beta$-amino acids are well-known precursors of $\beta$-lactams, the reverse route ( $\beta$-lactam $\rightarrow \beta$-amino acid) is one of the simplest pathways used for the synthesis of enantiomerically pure $\beta$-amino acids and is more suitable for purine nucleobases adenine and guanine. ${ }^{[108]}$ The $\beta$-lactam mesylate is obtained 
from the L-aspartic acid in four steps according to the procedure of SALZMANN et al. $^{[107]}$ Reaction of $\beta$-lactam mesylate with 2-amino-6-chloropurine under basic conditions furnishes guaninyl- $\beta$-lactam. ${ }^{[107]}$ After selective hydrolysis of the $\beta$ lactam ring, followed by Boc- protection, the guaninyl- $\beta^{3}$-amino acid is obtained. Similarly, adenine is selectively alkylated with $\beta$-lactam mesylate providing exclusively adeninyl- $\beta$-lactam. The desired adeninyl- $\beta^{3}$-amino acid is obtained after hydrolysis of adeninyl- $\beta$-lactam followed by Boc-protection under basic conditions. $^{[110]}$

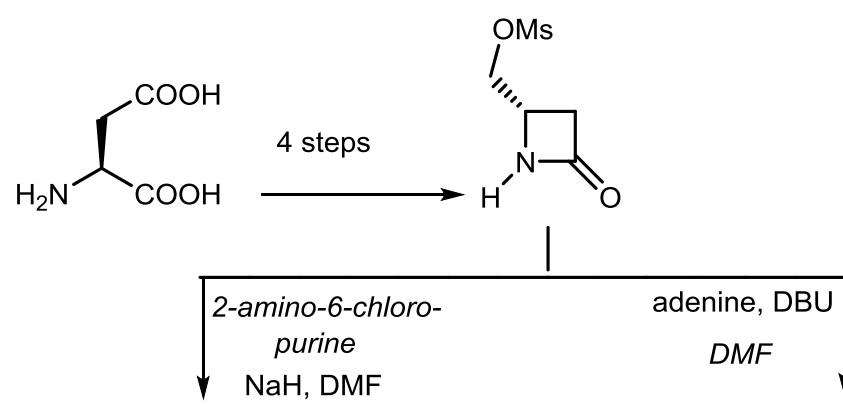

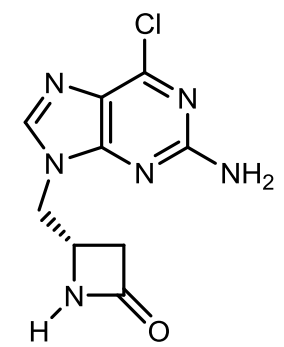
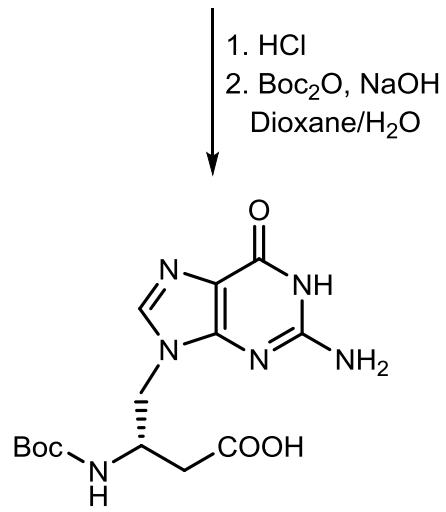

(S)-N-Boc- $\beta$-HalG-OH<smiles>Nc1ncnc2c1ncn2C[C@H]1CC(=O)N1</smiles>

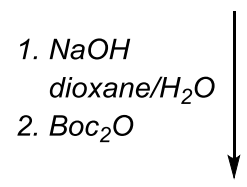<smiles>CC(C)(C)OC(=O)N[C@@H](CC(=O)O)Cn1cnc2c(N)ncnc21</smiles>

(S)-N-Boc- $\beta-\mathrm{HalA}-\mathrm{OH}$

Figure 3.13. Synthesis of Boc- $\beta-\mathrm{HalG}-\mathrm{OH}^{[109]}$ and Boc- $\beta-\mathrm{HalA}-\mathrm{OH}{ }^{[110]}$ starting from the mesylated $\beta$-lactam. 
The nucleo- $\beta$-amino acids (S)-N-Boc- $\beta$-HalA-OH and (S)-N-Boc- $\beta$-HalG-OH have been synthesized starting from $\beta$-lactam as it is shown in Figure 3.13. ${ }^{[109,110]}$

\subsubsection{Continuous SPPS of PNA/TMD hybrids}

The transmembrane domain and linker regions of native syntaxin-1A and synaptobrevin 2 were synthesized by manual Boc-SPPS. The peptides (Syx-TMD and $\mathrm{Sb}-\mathrm{TMD}$ ) and shortened linker analogs were synthesized in the same way on the PAM resin. The following assembly of $\beta$-PNA recognition units (ACTA for syntaxins and TAGT for synaptobrevins) was performed manually on $25 \mu \mathrm{mol}$ scale as described in section 7.6.4. Finally, the synthesized hybrids were cleaved from a solid support under very strong acidic conditions with simultaneous deprotection of all side chain protecting groups. Unfortunately, the purification was impracticable due to very poor solubility of the oligomers. Thus, the hybrids (ACTASyx, TAGT-Sb, ACTA-ext-Syx and TAGT-ext-Sb) were applied without further purification in previously designed model systems for synaptic SNARE proteins (section 3.1) (Figure 3.14).

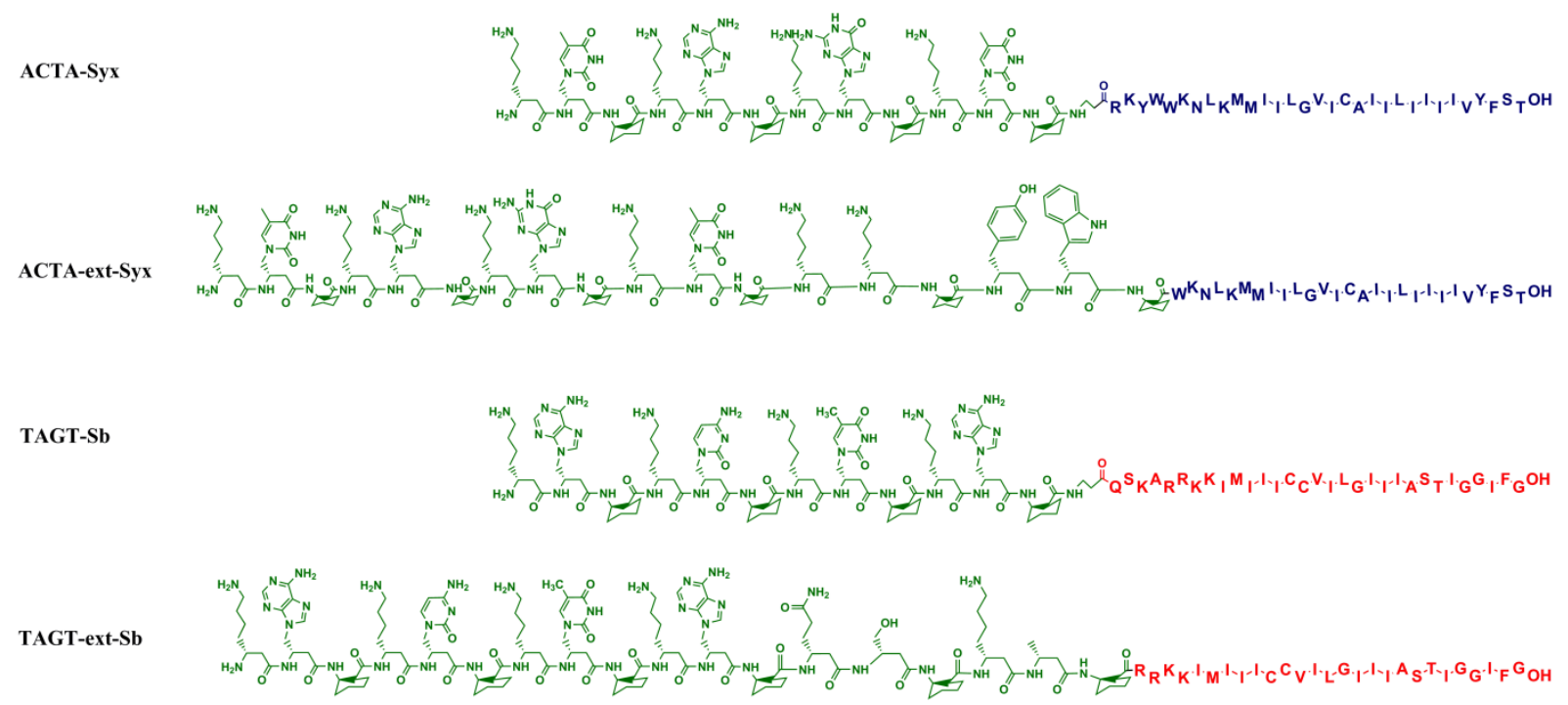

Figure 3.14. The synthesized and employed $\beta$-PNA/peptide hybrids in this work. 


\section{4. $\beta$-PNA/peptide hybrids in membranes}

\subsection{Insertion of $\beta-P N A / T M D$ hybrids in membranes}

The analysis of $\beta$-PNA/peptide hybrids distribution in vesicle membranes was performed in unilamellar vesicle systems consisting of DOPC/DOPE/cholesterol lipids (50/25/25). These large unilamellar vesicles (LUVs) with a diameter of $100 \mathrm{~nm}$ were obtained using an extrusion technique following literature protocols. ${ }^{[111]}$ The peptide/lipid complexes were formed at an early stage of vesicle preparation by mixing stock solutions of the highly hydrophobic $\beta$-PNA/peptide constructs in TFE and the lipid species in chloroform. The following evaporation of solvents and treatment of the residue with aqueous buffer solution (20 mM HEPES, $100 \mathrm{mM} \mathrm{KCl}, 1 \mathrm{mMEDTA}, 1 \mathrm{mM}$ DTT $\mathrm{pH}=7.4$ ) led to the formation of multilamellar vesicles and final extrusion through a polycarbonate membrane (pore diameter 50 or $100 \mathrm{~nm}$ ) providing unilamellar vesicles of corresponding size. HEPES buffer is widely used in physiological studies and maintaining the physiological pH while DTT can reduce the disulfide bond.

\subsection{Distribution of the fluorophores in lipid membranes}

Fluorescent lipid derivatives containing 7-nitrobenz-2-oxo-I, 3-diazol (NBD) have a bright yellowish-green fluorescence and high quantum yields. The electronwithdrawing nitro group at position 7 of NBD participates in delocalization of electrons in the conjugated ring system (Figure 4.1). The reduction of the nitro group to an electron-donating amino group changes the electronic transitions of this molecule and its fluorescence dramatically. ${ }^{[12]}$ In aqueous solutions, a dithionite ion $\left(\mathrm{S}_{2} \mathrm{O}_{4}{ }^{2-}\right)$ is in an equilibrium with a $\mathrm{SO}_{2}^{-}$radical anion. This radical, by a single-electron transfer pathway, is involved in the reduction of a nitro group. ${ }^{[113,114]}$ 
$1 / 2 \mathrm{~S}_{2} \mathrm{O}_{4}{ }^{2-}$

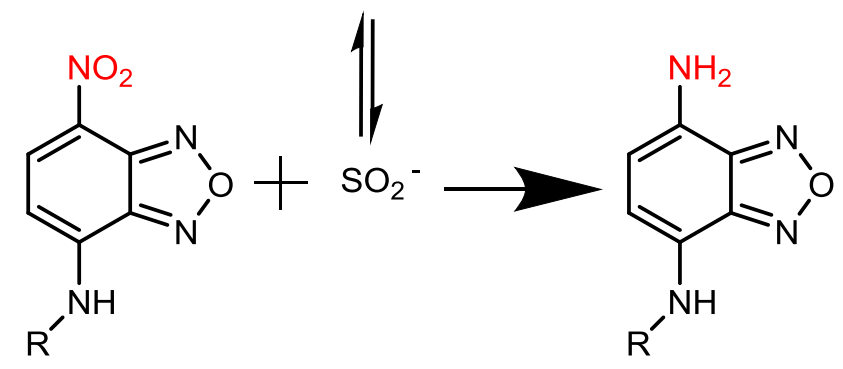

Figure 4.1. Reduction of NBD with sodium dithionite.

For measuring membrane lipid asymmetry, a simple fluorescence assay based on the reduction of NBD-fluorophores with sodium dithionite is employed. ${ }^{[12]}$ This assay has been used to distinguish between hemifusion (merging of the outer leaflets of membranes only) and full fusion (merging of both outer and inner leaflets) of vesicles. Both charged dithionite ions $\left(\mathrm{S}_{2} \mathrm{O}_{4}{ }^{2-}\right)$ and the corresponding radical anions $\left(\mathrm{SO}_{2}{ }^{-}\right)$are unable to penetrate the hydrophobic vesicle membranes, and therefore, the NBD-fluorescence from the outer leaflet can be eliminated by treatment with sodium dithionite selectively. Sodium dithionite has previously been used to reduce nitrotyrosine residues to the corresponding aminotyrosins without affecting the overall protein structure. ${ }^{[115,116]}$ Therefore, this reagent was employed for reduction in fluorescence studies with synthesized $\beta$-PNA/peptide conjugates. In order to estimate the distribution of the labled DOPE lipid with NBD-fluorophore between outer and inner leaflets of the vesicles, the vesicle was treated with sodium dithionite. The decrease of the NBD-emission up to $40 \%$ from the starting value was observed (Figure 4.2). That means that about $60 \%$ of NBD-DOPE was initially allocated in the outer leaflets and about $40 \%$ in the inner leaflets of vesicles. 


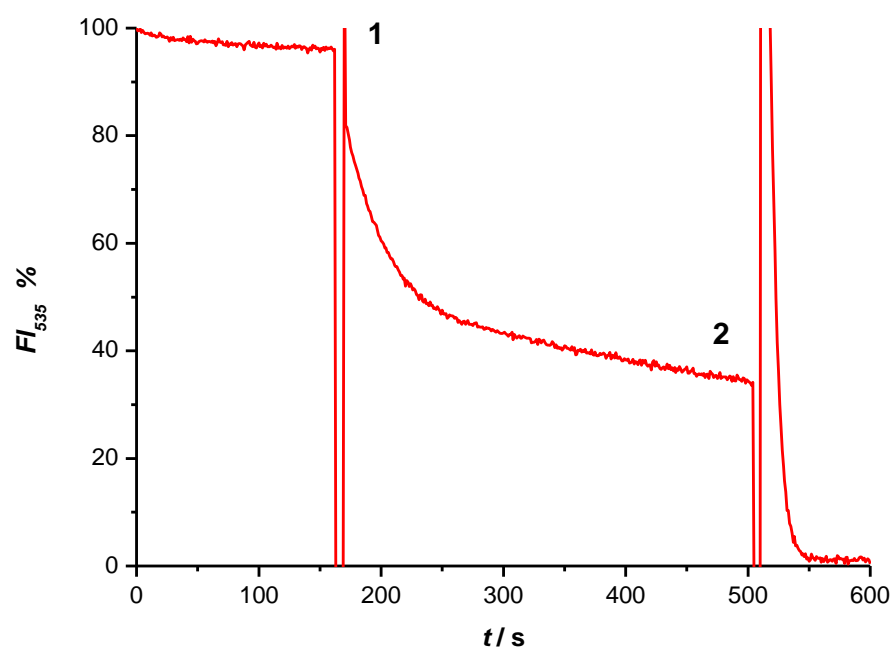

Figure 4.2. Fluorescence change after treatment of NBD labeled lipid vesicles containing with sodium dithionite (1) and complete elimination of fluorescence after destruction of the vesicles with $0.1 \%$ TritonX-100 (2). 


\section{Fusion activity of PNA/TMD model systems}

\subsection{Vesicle fusion conditions}

The membrane fusion mediated by native fusogenic proteins as well as by synthetic model analogues has predominantly been studied in liposomes. Liposomes are subdivided into small unilamellar vesicles (SUVs, diameter $<100 \mathrm{~nm}$ ), large unilamellar vesicles (LUVs, diameter 100-1000 nm) and giant unilamellar vesicles (GUVs, diameter $>1000 \mathrm{~nm}$ ). The lipid composition, size, surface charge and peptide/lipid ratio of such liposomes can be easily controlled. In this study, LUVs with an average diameter of $100 \mathrm{~nm}$ were employed for investigating fusion activity of synthesized PNA/TMD hybrids.

The LUVs with a lipid composition of DOPC/DOPE/cholesterol (50/25/25) were prepared by extrusion through a polycarbonate membrane with a nominal pore size of $100 \mathrm{~nm}$. The radius distribution of the prepared vesicles containing TAGT-Sb and ACTA-Syx was determined by dynamic light scattering (DLS) and the average diameter was found to be $140 \mathrm{~nm}$ (Figure 5.1). The average diameter of prepared vesicles was determined for each population and was always in the same range.
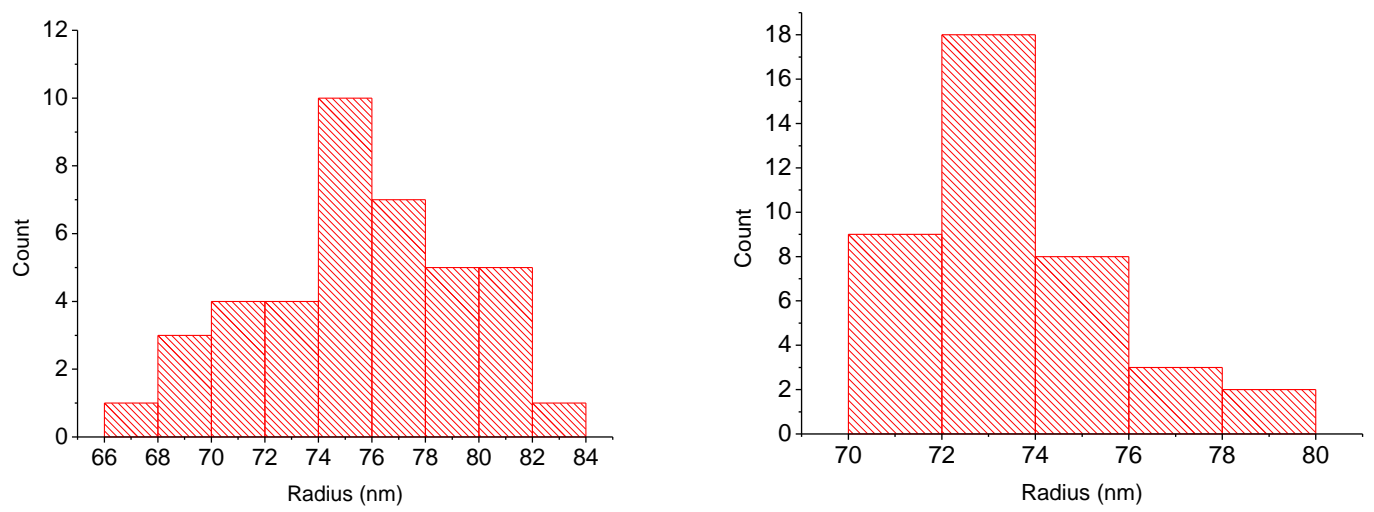

Figure 5.1. DLS Measurements of the vesicles radius after extrusion; vesicle size with TAGT-Sb (left) and vesicles with ACTA-Syx (right). 
Two populations of vesicles, the labeled ones (doped with $1.5 \%$ of NBD-DOPE as a donor dye and $1.5 \%$ of Rh-DOPE as an acceptor dye, with an overall concentration of DOPE $25 \%$ ), and the unlabeled ones were prepared for the lipid mixing assay experiments. First TAGT-Sb and ACTA-Syx were incorporated in these labeled and unlabeled vesicles, respectively. It has been found, that the peptide to lipid ratio (P/L) 1:200 shows maximal increase in the NBD fluorescence. ${ }^{[97]}$ By mixing both vesicle populations in different proportions, the highest increase in the donor fluorescence has been also found to occurs at a 1 to 4 ratio of labeled to unlabeled vesicles, respectively. ${ }^{[97]}$ Therefore, this ratio was employed for all following lipid mixing and content mixing experiments.

Thus, all following fusion experiments for the seven different model systems were carried out in $100 \mathrm{~nm}$ LUVs with a lipid composition of DOPE/DOPC/cholesterol of $50 / 25 / 25$ and a peptide/lipid ratio of 1/200.

\subsection{Membrane fusion study assays}

\subsubsection{Lipid mixing assay}

The lipid mixing assay is the most frequently used technique to monitor membrane fusion. ${ }^{[17]}$ This method is based on the physical phenomenon of fluorescence resonance energy transfer (FRET). When the fluorescence donor (e.g NBD) and acceptor (e.g. lissamine rhodamine $(\mathrm{Rh})$ ) are located in one population of vesicles, the distance between both dyes is appropriate for an efficient FRET (Figure 5.2, A). If the membranes of fluorophore-labelled and non-labelled vesicles merge together, the average distance between donor and acceptor dyes increases, leading to a decrease of FRET efficiency and increase of donor emission (Figure 5.2, C). Notably, the change in FRET is not observed when vesicles aggregate without fusion. 
A

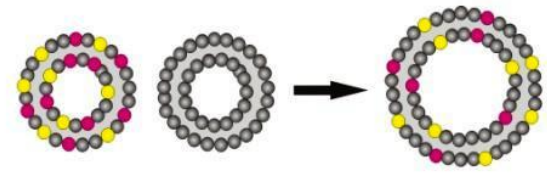

B

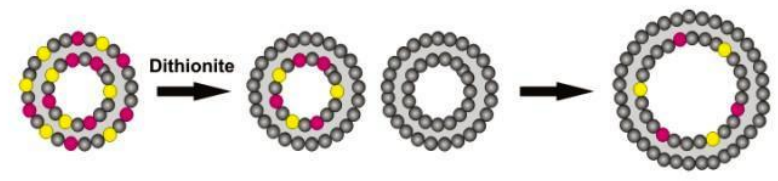

C

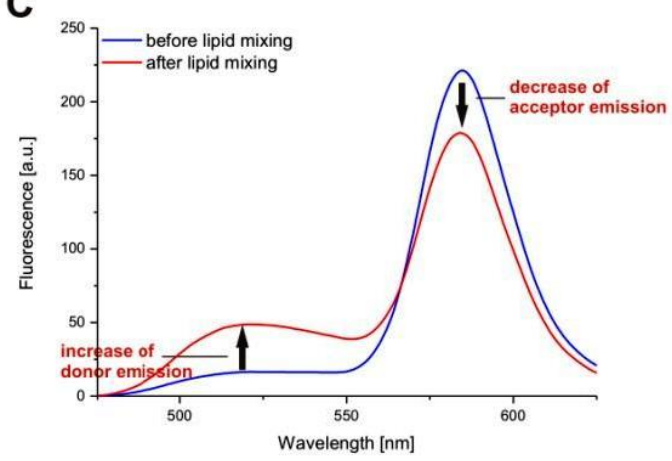

Figure 5.2. Sketch of the fusion techniques. A. Lipid mixing assay; B. Inner leaflet lipid mixing assay. Fluorescent donor (NBD) and fluorescence acceptor (Rh) are depicted yellow and pink, respectively; C. Fluorescence spectra of vesicles containing donor (NBD) and acceptor (Rh) dyes before the lipid mixing (blue curve) and after it (red curve). ${ }^{[50]}$

As already mentioned, the NBD-fluorophores from the outer leaflet of the vesicles can be selectively reduced with sodium dithionite. ${ }^{[112]}$ This feature can be exploited to assess mixing of the inner leaflets of the membranes. If the mixing of fluorophore-labeled vesicles pretreated with sodium dithionite and non-labeled vesicles results in an increase of NBD-emission, it can only occur due to mixing of the inner leaflets of the membranes (Figure 5.2, B). Thus, the inner leaflet lipid mixing assay allows to distinguish between hemifusion (merging of the outer leaflet of membrane only) and full fusion (merging of both outer and inner leaflet of membrane).

Both lipid mixing assays were performed using unilamellar vesicle systems comprised of DOPC/DOPE/cholesterol (50/25/25) lipids. NBD-DOPE (1.5 mol \%) and Rh-DOPE (1.5 mol \%) were used as donor and acceptor fluorescence dyes, respectively. The peptide/lipid complexes were formed by mixing stock solutions of the highly hydrophobic PNA/TMD hybrids in TFE and those of the lipid species in chloroform prior to formation of large unilamellar vesicles (LUVs). These LUVs with a diameter of $100 \mathrm{~nm}$ were obtained via extrusion techniques following literature protocols. ${ }^{[111]}$ 


\subsubsection{Content mixing assay}

The most frequently used content mixing assay is based on the formation of a fluorescent complex of $\mathrm{Tb}^{3+}$ with dipicolinic acid (DPA). ${ }^{[118,119]}$ In this method, vesicle populations containing encapsulated $\mathrm{Tb}^{3+}$ or DPA are prepared separately. Upon fusion of vesicles of these two kinds, a $\mathrm{Tb}^{3+} / \mathrm{DPA}$ complex is formed that leads to an increase of the observed fluorescence emmission.

Alternatively, self-quenching assays with fluorescein, calcein or sulforhodamine B (SRB) dyes can be applied to this method. ${ }^{[120-122]}$ In this study, the advantage of using SRB as a fluorescent dye in self-quenching assays was used. Thus, the fluorescence of SRB disappears almost completely due to the self-quenching at concentration higher than $30 \mathrm{mM}$, while for calcein and fluorescein these threshold concentrations are significantly higher $(80 \mathrm{mM}$ and $100 \mathrm{mM}$, respectively). Furthermore, SRB induces a very low osmotic pressure to the membrane compared to calcein. Thus, osmotic pressures of $50 \mathrm{mM} \mathrm{SRB}$ and calcein in $20 \mathrm{mM} \mathrm{HEPES}$ are $0.066 \mathrm{Osmol} / \mathrm{kg}$ and $0.239 \mathrm{Osmol} / \mathrm{kg}$, respectively. Due to the low osmotic pressure, the unspecific leakage for SRB is also lower than for calcein. The self-quenching content mixing assay was carried out in $100 \mathrm{~nm}$ LUVs with a lipid composition of DOPC/DOPE/cholesterol (50/25/25). Two populations of vesicles, the one with encapsulated $20 \mathrm{mM}$ of SRB (self-quenching $\approx 80 \%$ ) and another one containing no dye (Figure.5.3, A) were prepared separately. If the mixing of vesicle contents (the fusion process) takes place upon mixing of both vesicle populations, the dilution of SRB dye occurs that leads to the observed increase of SRB-emission (Figure 5.3, B). 
A
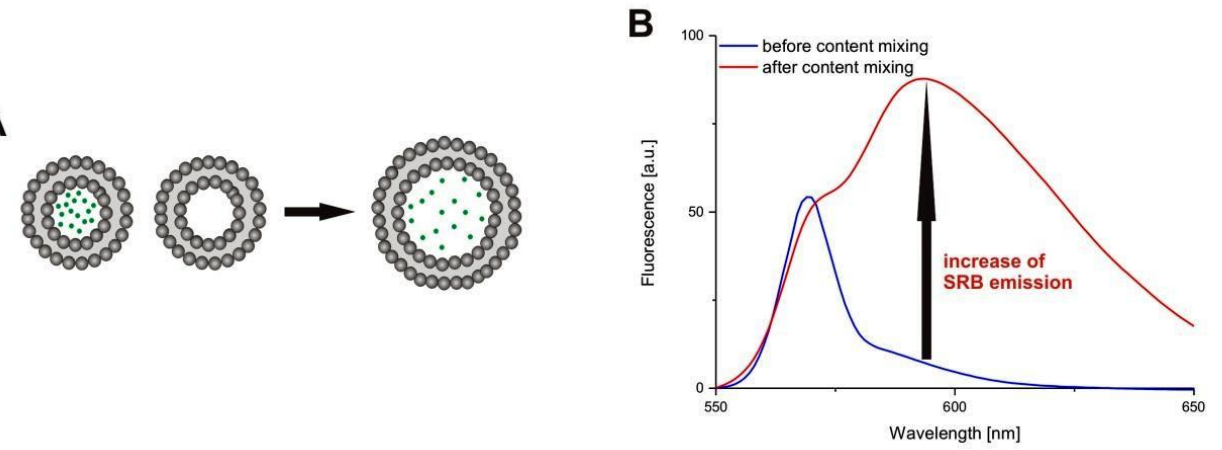

Figure 5.3. Sketch of fusion techniques. A. Self-quenching content mixing assay. Sulforhodamine B is depicted in green; B. Fluorescence spectrum of vesicles containing sulforhodamine B (SRB) dyes before content mixing (blue curve) and after it (red curve). ${ }^{[50]}$

\subsection{Fusogenic activity of $\beta$-PNA-peptide model system}

The SNARE-mimicking systems include TMD/linker segments from natural SNARE proteins, synaptobrevin $2(\mathrm{Sb})$ and syntaxin-1A (Syx), and $\beta$-peptide nucleic acid ( $\beta$-PNA) recognition motifs (Figure 5.4). Such synthesized SNARE complex analogs can be assembled in antiparallel manner (Figure 5.4, up). Two different $\beta$ PNA/TMD oligomers (Figure 5.4, down) were synthesized for this purpose by continuous SPPS. 
TMD Sb

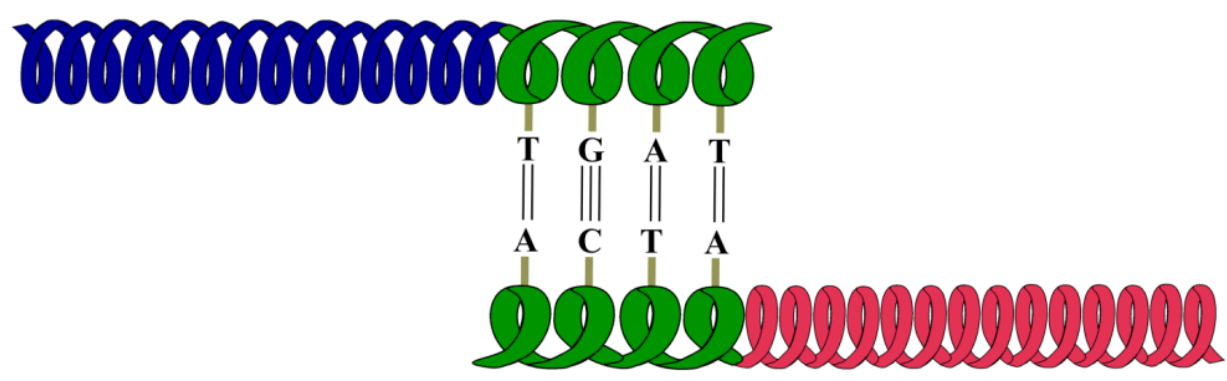

TMD Syx

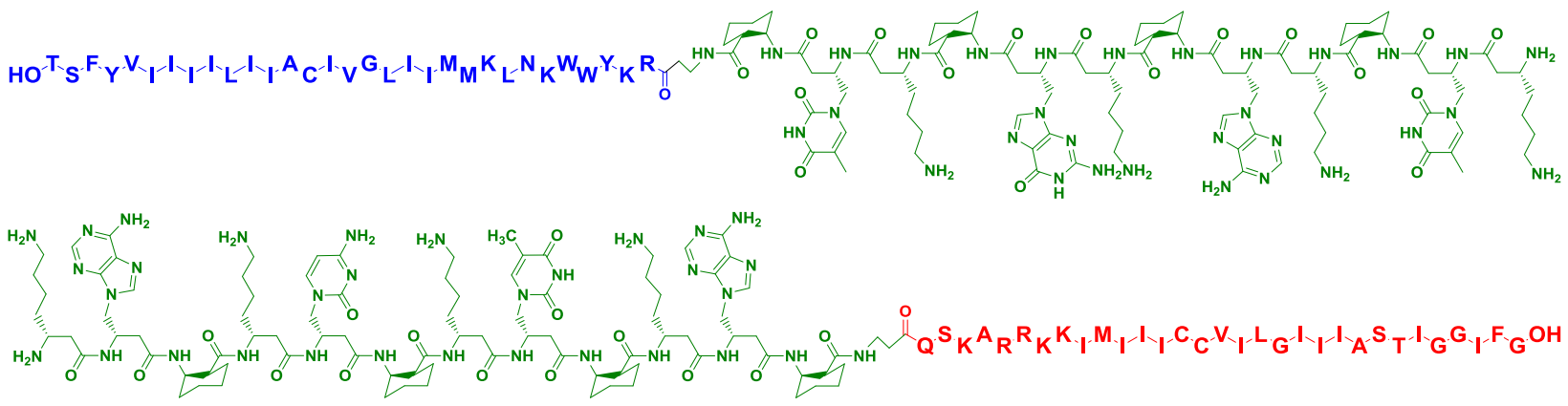

Figure 5.4. schematic (up) and structural (down) SNARE simplified fusion system with $\beta$-PNA.

Fusion experiments were performed using vesicles with diameter of (100 $\pm 20 \mathrm{~nm})$, as determined by dynamic light scattering (see section 5.1). Vesicles containing TGAT-VAMP2 were prepared with nitrobenzofuran (NBD) as a donor dye and lissamine rhodamine $(\mathrm{Rh})$ as an acceptor dye; both dyes were attached to the head group of the (DOPE) lipid while the other vesicle population containing ACTASyx was unlabelled. During the fusion the distance between the dyes increase which can be indicated by a lower fluorescence resonance energy transfer (FRET) efficiency and higher donor emission (see section 5.2.1). Indeed, upon mixing of vesicles containing ACTA-Syx with vesicles containing TAGT-Sb, an increase in the NBD emission was observed and no changes have been detected by mixing the vesicles containing the same peptide TAGT-Sb (Figure 5.5). 


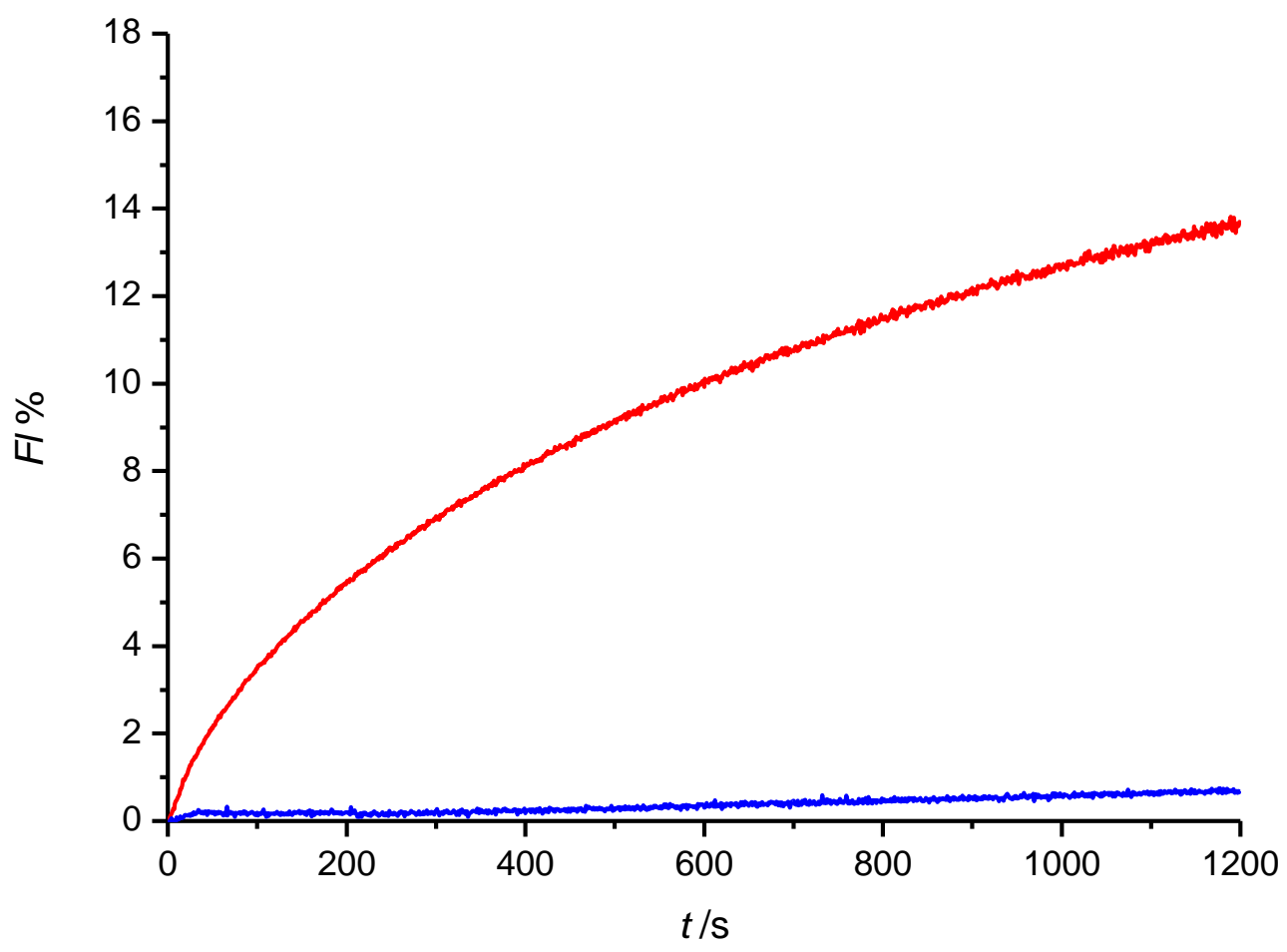

Figure 5.5. Total lipid mixing detected by NBD emission of ATCA-Syx and TGAT-Sb vesicles (red); total lipid mixing assay of TGAT-Sb and TGAT-Sb vesicles (blue).

The fusion of lipid bilayer requires merging of the inner and outer lipid leaflets of the membrane; therefore it is necessary to investigate whether the inner leaflet also merges. The previous experiment has been repeated after treating the labelled vesicle with sodium dithionite, thereby the NBD fluorescence in the outer leaflet is eliminated. Since the sodium dithionite is not able to penetrate the membrane, the emission from the inner leaflet stays intact. ${ }^{[123]}$ An $56 \%$ overall decrease in the NBD emission is expected for $100 \mathrm{~nm}$ vesicles and indeed we could measure about $62 \%$ decrease upon addition of sodium dithionite. By indicating the NBD emission, an efficient lipid mixing was also observed by the sodium dithionit pre-treated vesicles, which proves that not only the outer leaflets fuses (hemifusion) but also the inner leaflets (full fusion) (Figure 5.6). 


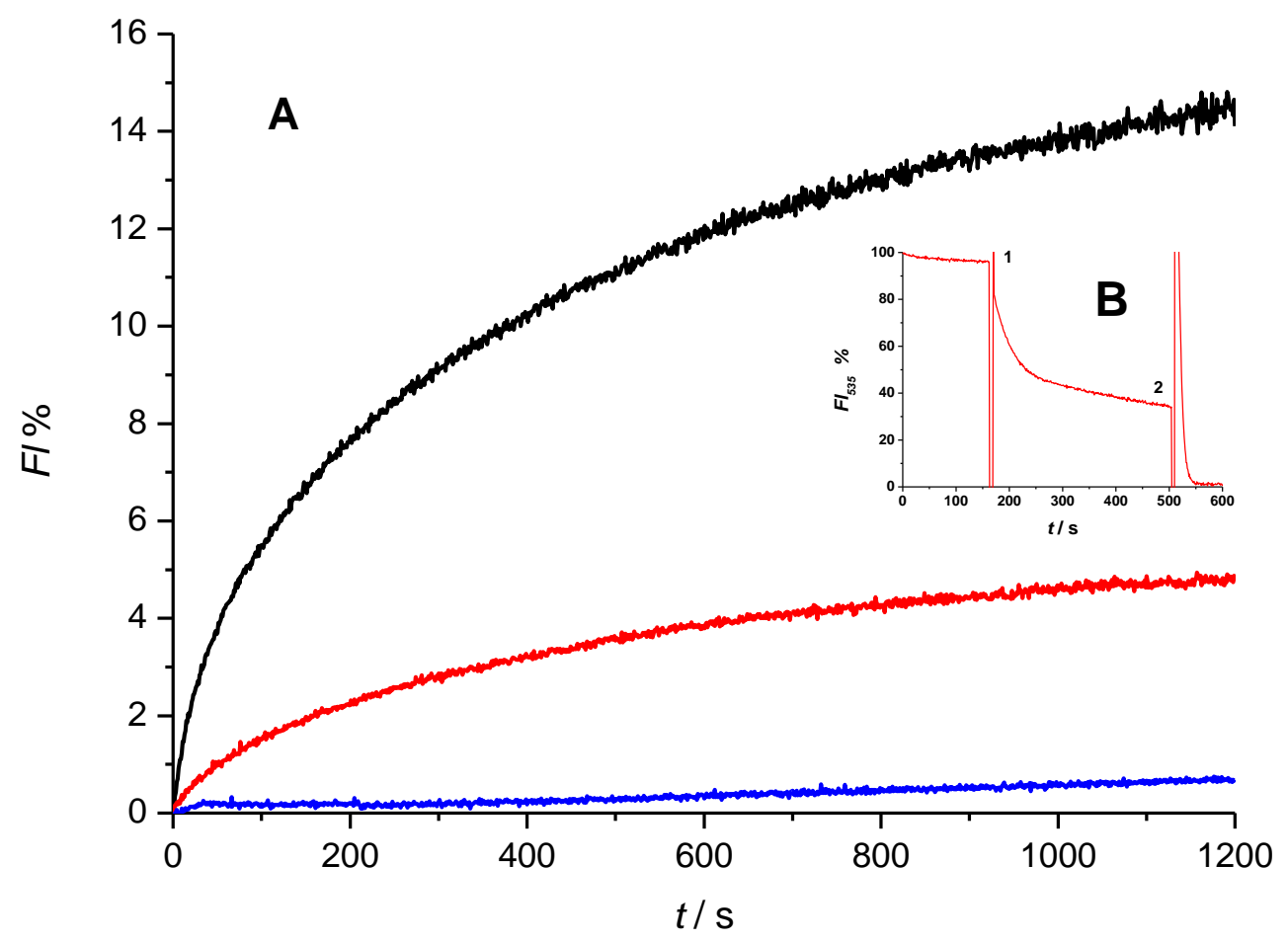

Figure 5.6. A) Total lipid mixing detected by NBD emission of ATCA-Syx and TGAT-Sb vesicles (black); inner leaflet lipid mixing (with dithionite) of ATCA-Syx and TGAT-Sb vesicles (red); total lipid mixing assay of TGAT$\mathrm{Sb}$ and TGAT-Sb vesicles (blue). B) NBD intensity upon addition of sodium dithionite (1) and complete elimination of fluorescence after destruction of the vesicles with $0.1 \%$ TritonX-100 (2).

In order to prove that this system induces full fusion, we performed content-mixing experiments (Section 5.2.2). Sulforhodamine B (SRB) has fluorescence selfquenching at high concentrations $(>10 \mathrm{mM})$ and is used in content-mixing experiment. Two vesicle populations were prepared, one encapsulates the SRB and the other is not labelled. By a fusion process it is expected to see an increase in the fluorescence caused by dilution of SRB. The leakage experiment has been also performed as a control experiment by using only the labelled vesicles (with SRB) and indicating the fluorescence over the same time period. Here we were able to see an increase in the SRB fluorescence in comparison to the leakage 
experiment. This experiment proves that the system induces full fusion where the outer and inner leaflets merge (Figure 5.7).

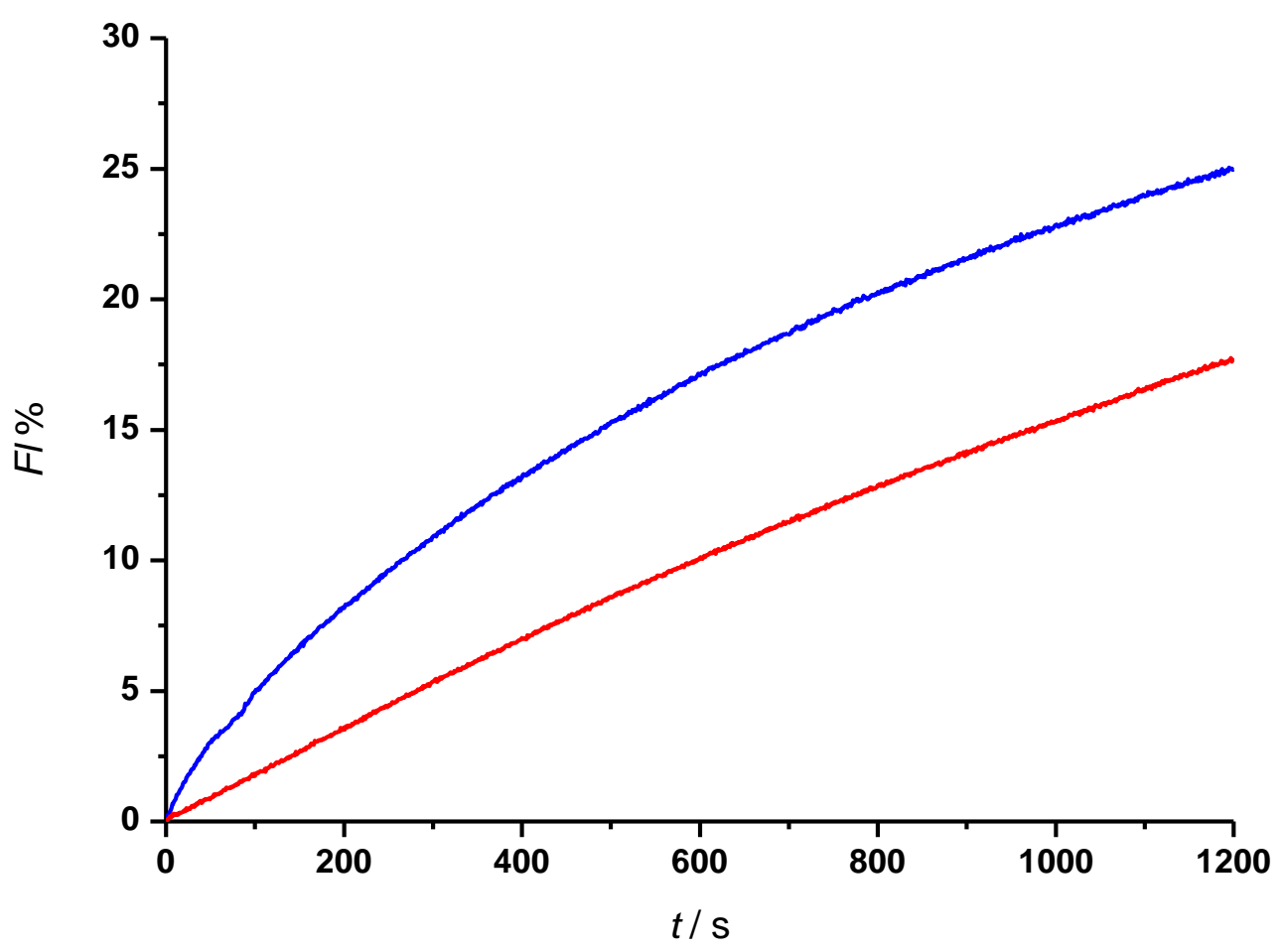

Figure 5.7. Content mixing assay by using sulforhodamine $B$ encapsulated in vesicles containing TGAT-Sb mixed with unlabelled vesicles containing ACTA-Syx (blue); leakage obtained with only labelled vesicles without mixing with unlabelled one (red).

Lipid-mixing experiments were conducted at various temperatures to investigate whether the formed duplex is also stable as recognition unit. At $35{ }^{\circ} \mathrm{C}$ the fusion efficiency is higher than at $25{ }^{\circ} \mathrm{C}$ where the duplex is mostly paired and at $45^{\circ} \mathrm{C}$ the efficiency has the same value as before, which is close to the melting temperature $T_{M}=44{ }^{\circ} \mathrm{C}$. Obviously, after reaching the melting point, the $\beta$-PNA still partly form a duplex. At $55^{\circ} \mathrm{C}$ most of the duplex is unpaired and therefore the efficiency of the fusion is dramatically decreased (Figure 5.8).

Thus, the lipid mixing experiments carried out with $\beta$-PNA/TMD SNARE analogs at various temperatures are in good agreement with the stability of the corresponding 
$\beta$-PNA duplexes and therefore, can be predictably influenced by changing the temperature.

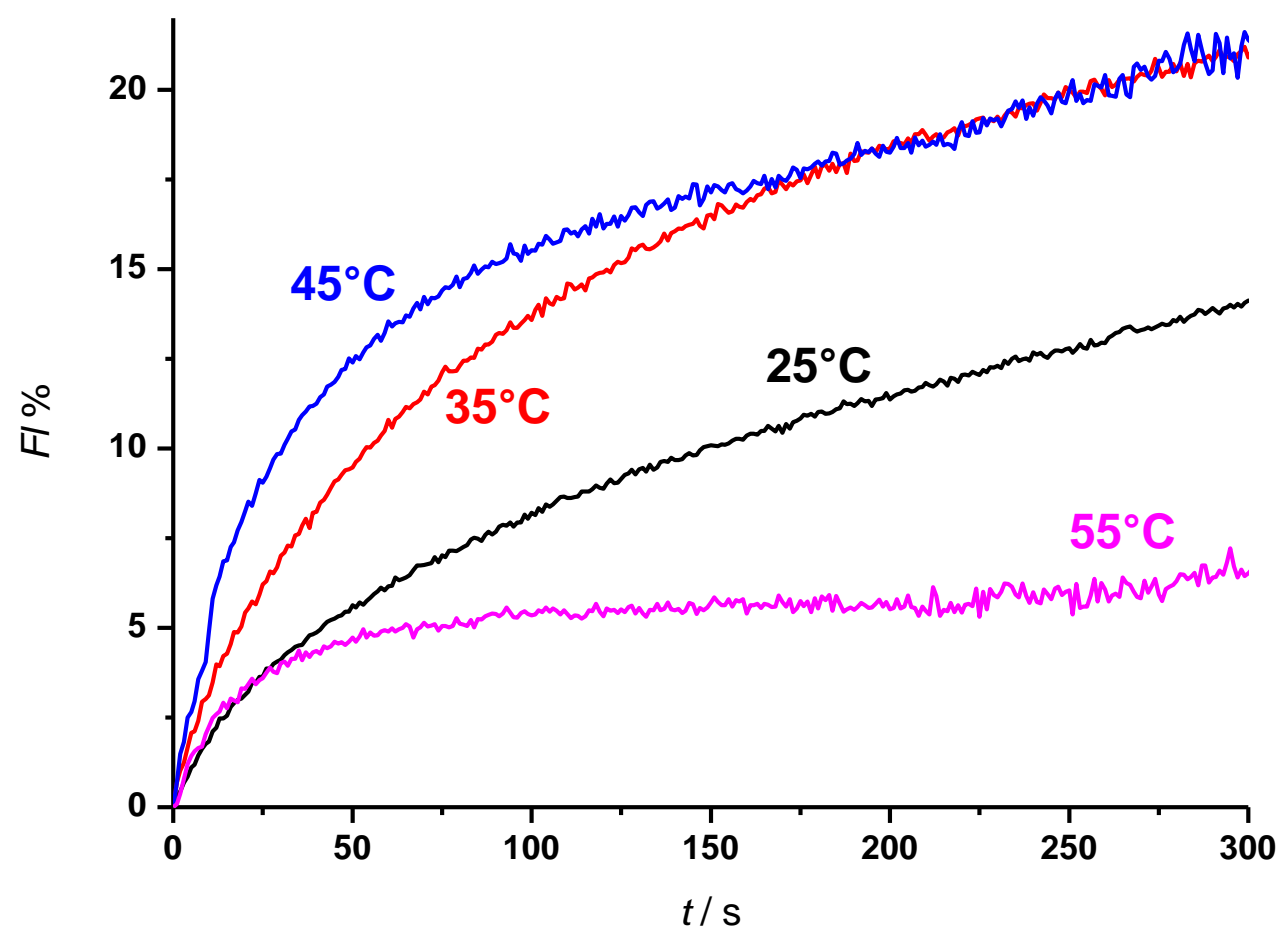

Figure 5.8. Temperature-dependent lipid-mixing experiment of vesicles containing ACTA-Syx and TAGT-Sb at various temperatures.

The last experiments have been shown clearly the fusogenic activity of the $\beta$-PNA SNARE model system where the $\beta$-PNA duplex in an antiparallel orientation was able to induce merging between the two different vesicles bilayers and mixing the aqueous content of the vesicles. Based on the hypothesis that the recognition motif with antiparallel strand orientation and opposed TMD linkers needs to be flexible or short to enable the interaction between vesicle membranes, we have investigated elongated $\beta$-peptide helices. Therefore, TMD/linker/ $\beta$-PNA hybrids were synthesized that contain an extended $\beta$-peptide 14 helix within the linker region. The last $\mathrm{N}$-terminal six $\alpha$-amino acids before the $\beta$-PNA starts were exchanged for 
$\beta$-amino acids. A continuous rigid 14-helix can be formed by extending the $\beta$-PNA strand into the linker region. This extension was given on both sides of the $\beta$-PNA recognition motif, thereby extending the linear 14-helix $\beta$-peptide from 20 to $40 \AA$. The resulting TMD/linker/ $\beta$-PNA constructs containing extended 14-helices ACTAext-Syx and TGAT-ext-Sb (Figure 5.9) were prepared in analogy to the other peptide $\beta$-PNA hybrids.

TMD Sb

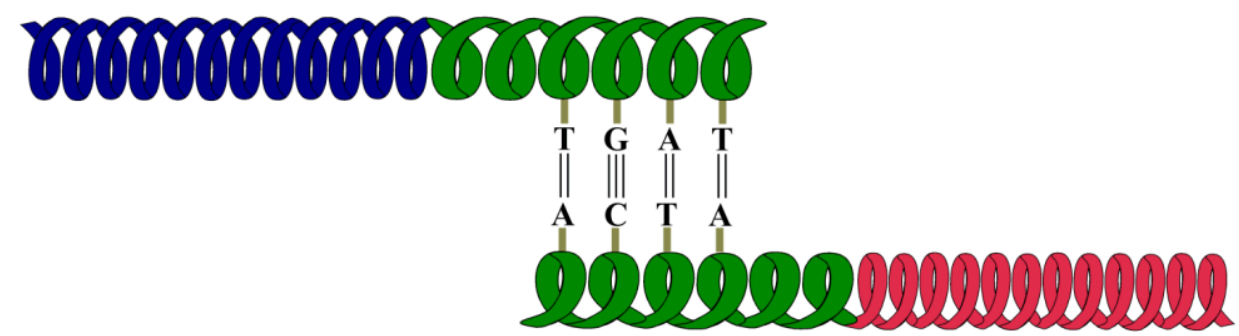

TMD Syx

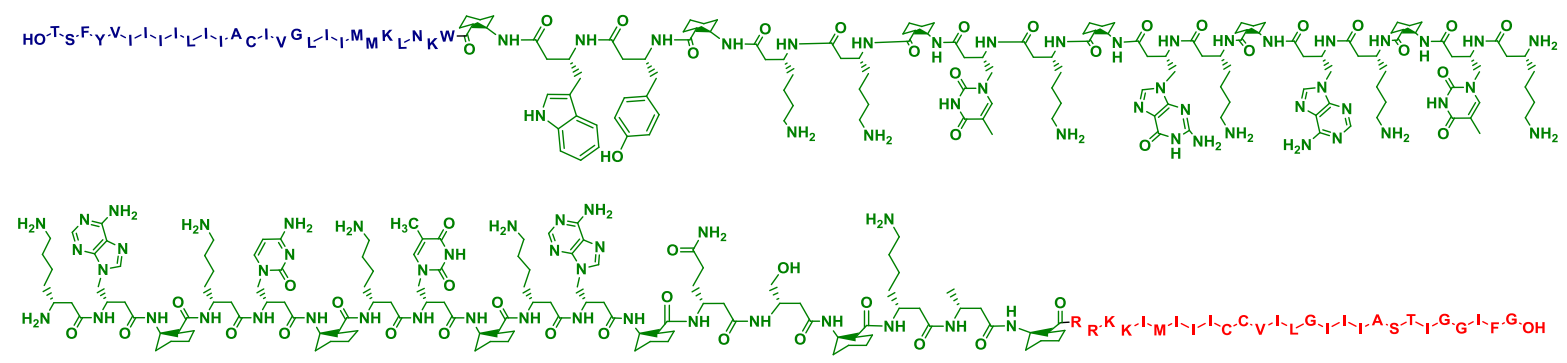

Figure 5.9. schematic (up) and structural (down) SNARE simplified fusion system with extended $\beta$-PNA peptides.

Lipid-mixing experiments were carried out with the 14-helix extended $\beta$-PNA peptides ACTA-ext-Syx and TGAT-ext-Sb. In comparison with fusion of ACTA-Syx and TAGT-Sb the extended $\beta$-peptides showed less fluorescence increase and by that a significantly reduced fusogenicity (Figure 5.10, up). Studying the ACTA-extSyx and TGAT-ext-Sb mediated vesicle fusion after treatment of the fluorophore labeled vesicles with dithionite, showed that lipid mixing was almost irrelevant and similar to the level of the control experiment mixing two TGAT-ext-Sb modified 
vesicles. In order to prove that only hemifusion is induced by using the extended $\beta$ peptides, the content mixing assays were performed (Figure 5.10, down). The SRB Fluorescence increase was almost identical with the leakage experiment. This leads to the conclusion that lipid mixing mediated by the extended $\beta$-PNA-peptides provides hemifusion involving only the outer leaflet instead of full fusion of both leaflets. 

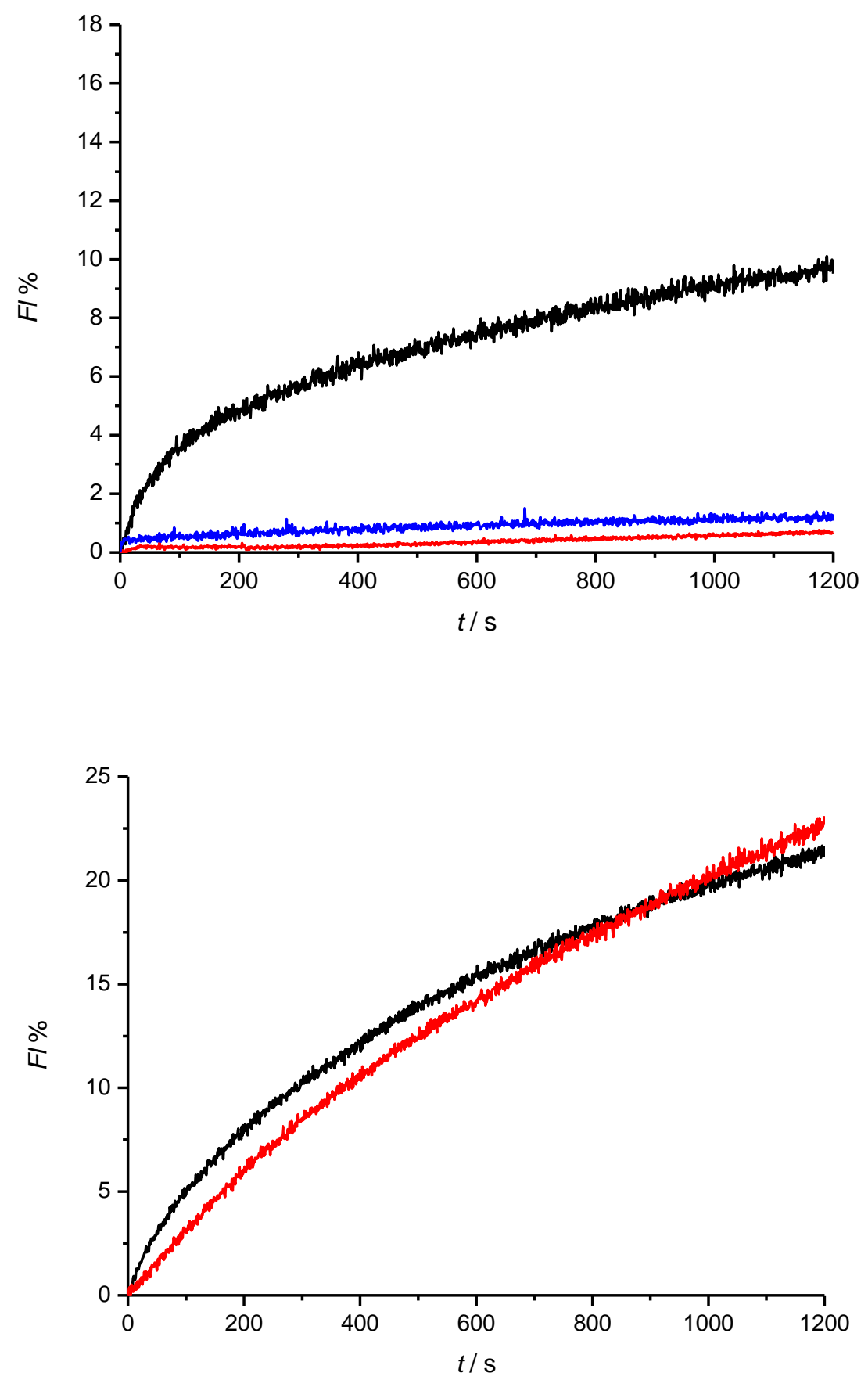

Figure 5.10. Up) ATCA-ext-Syx and TGAT-ext-Sb fusion assay: total lipid mixing (black) and inner leaflet lipid mixing (with dithionite, blue). Total lipid mixing between TGAT-ext-Sb and TGAT-ext-Sb (red). Down) Content mixing assay with SRB encapsulated vesicles containing TGAT-ext-Sb and empty vesicles containing ACTAext-Syx (blue), leakage obtained with only labelled vesicles without mixing with unlabelled one (red). 
This explication is supported by the content mixing assay. Fusing of an empty vesicle filled with a SRB, mediated by ACTA-ext-Syx and TGAT-ext-Sb, was not indicated since the fluorescence increase is in the range obtained by leakage (Figure $5.10, \mathrm{~B}$ ). The different results obtained from vesicle membrane fusion mediated by $\beta$-PNA recognition, leads to mechanistic conclusions. In spite of the rigid $\beta$-PNA duplex structure and the restriction to pair with antiparallel stand orientation, membrane fusion is still efficient. The valuable aspect is the high duplex affinity for $\beta$-PNA with only four base pairs which reaches the release of energy in the SNARE mediated fusion process. In addition, the antiparallel orientation of the recognition motif is not SNARE protein like and roughly is not favorable for fusogenicity. Notwithstanding, the short $20 \AA \beta$-PNA recognition motif permits overcoming the unbeneficial orientation, brings the membranes in approximately close distance and promotes fusion (Figure 5.11). The TMD/linker/ $\beta$ PNA constructs are likely to end up in the fused vesicle in a bridged form anchored twice by TMDs with the $\beta$-PNA on the membrane surface. By prolongation of the $\beta$ PNA in the linker region the length of the rigid linear duplex structure will be longer and the distance of TMDs becomes large enough to hold the $100 \mathrm{~nm}$ vesicles away from each other, but still enables the interaction only with the outer leaflet leading to hemifusion (Figure 5.11). 


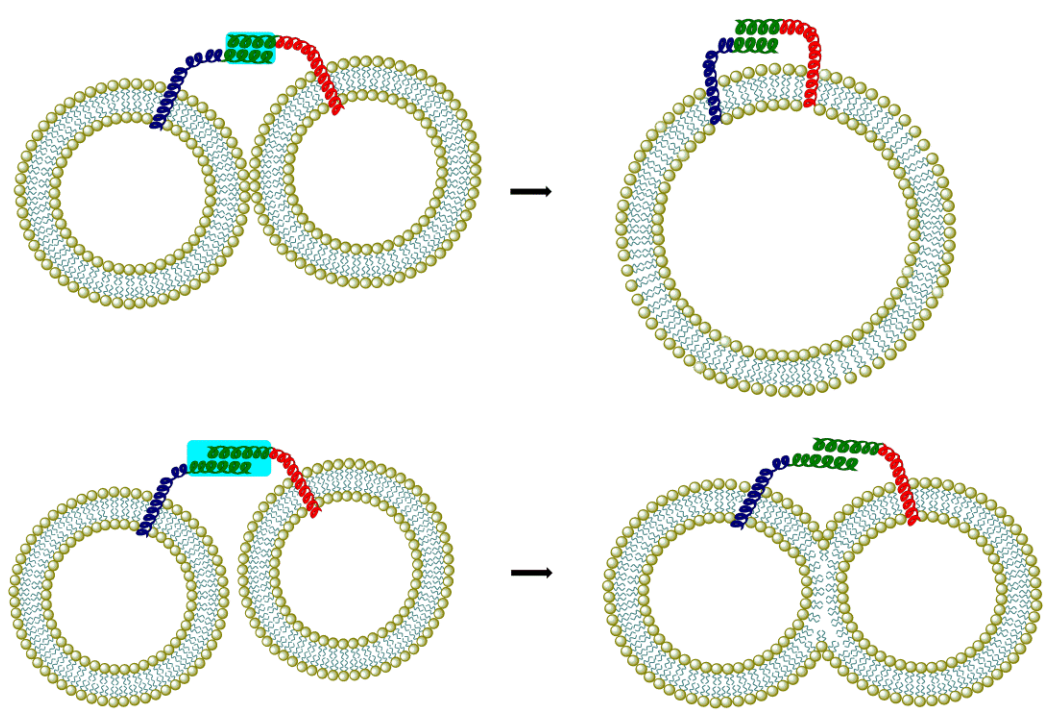

Figure 5.11. Lipid mixing of vesicle membranes mediated by antiparallel recognition: short recognition motif (20 A) allows vesicle overlap resulting in fusion (upper line); extended recognition motif (40 $\AA$ ) keeps vesicles on distance resulting in hemifusion (lower line).

\subsection{Parallel oriented $\beta$-PNA/peptide hybrid model system}

As it is known, two complementary nucleobase-functionalized $\beta$-peptides ( $\beta$-PNAs) favor an antiparallel orientation over a parallel one, regardless of the nucleobases sequence (see section 2.2). But synthesizing such a parallel model enables an interesting comparison with native SNARE complex and the other artificial recognition units such as PNA and coiled-coil. Therefore, we have designed a new model system and a possible strategy was developed to synthesize parallel $\beta$-PNA recognition units (Figure.5.12). 

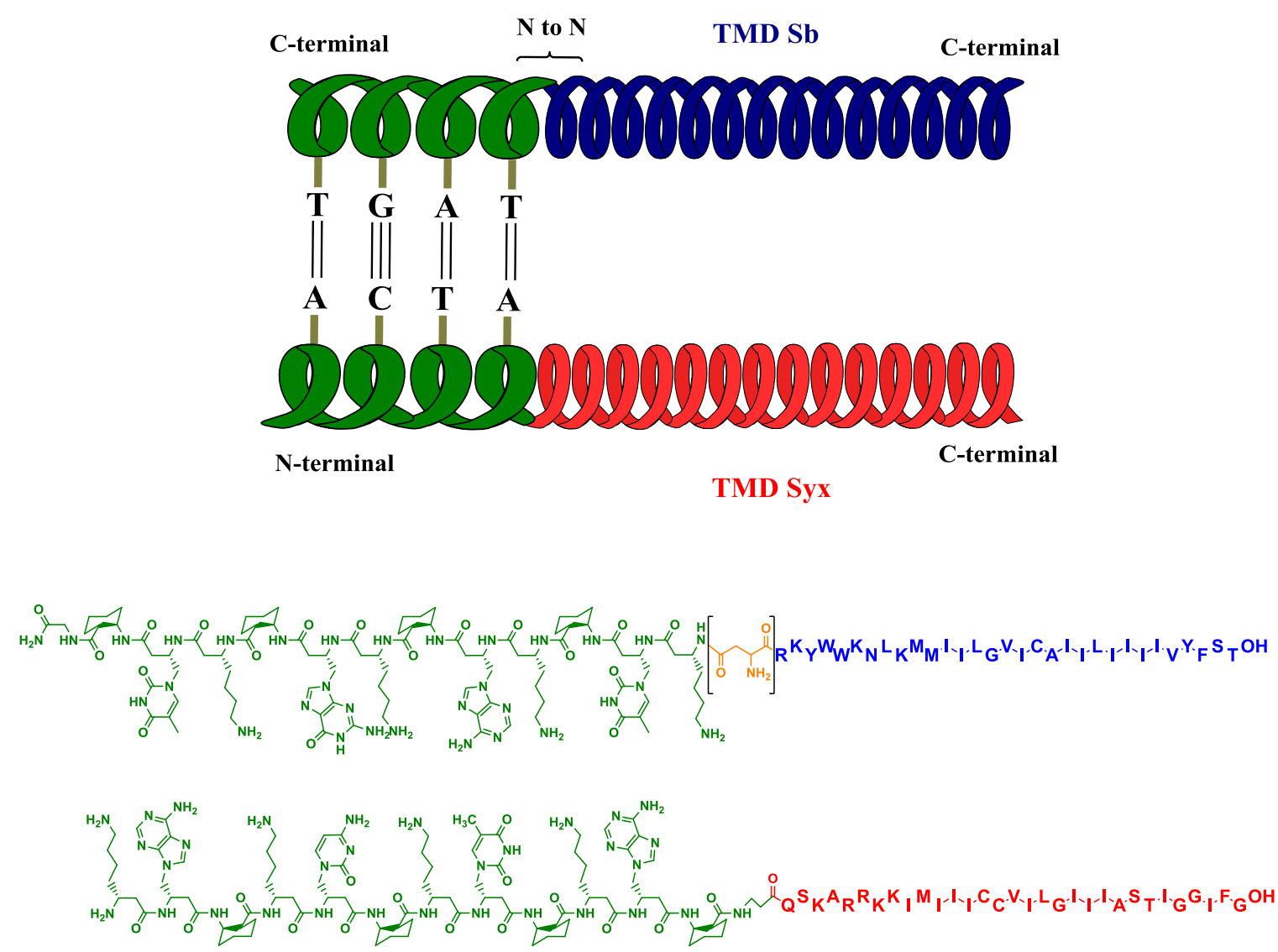

Figure 5.12. schematic (up) and structural (down) SNARE simplified fusion system with parallel $\beta$-PNA.

The suggested strategy included synthesizing the TMD and linker domains of the synabtobrevin 2 using Boc-SPPS and coupling aspartic acid on the N-terminus then keeping the peptide on the resin with its protecting groups. The synthesis of the $\beta$-PNA recognition unit on MBHA resin should be performed using Boc-SPPS with Fmoc protecting groups on all amine groups and followed by the cleavage of the peptide from the resin, which has only one free amino group. A coupling reaction should be carried out between the free amino group of the cleaved peptide and the carboxyl group ( $\mathrm{COOH}$ of Glu) of the peptide on the resin. In order to prove the validity of the mentioned method, two model peptides (Pep1 and Pep2) were synthesized (Figure 5.13). 


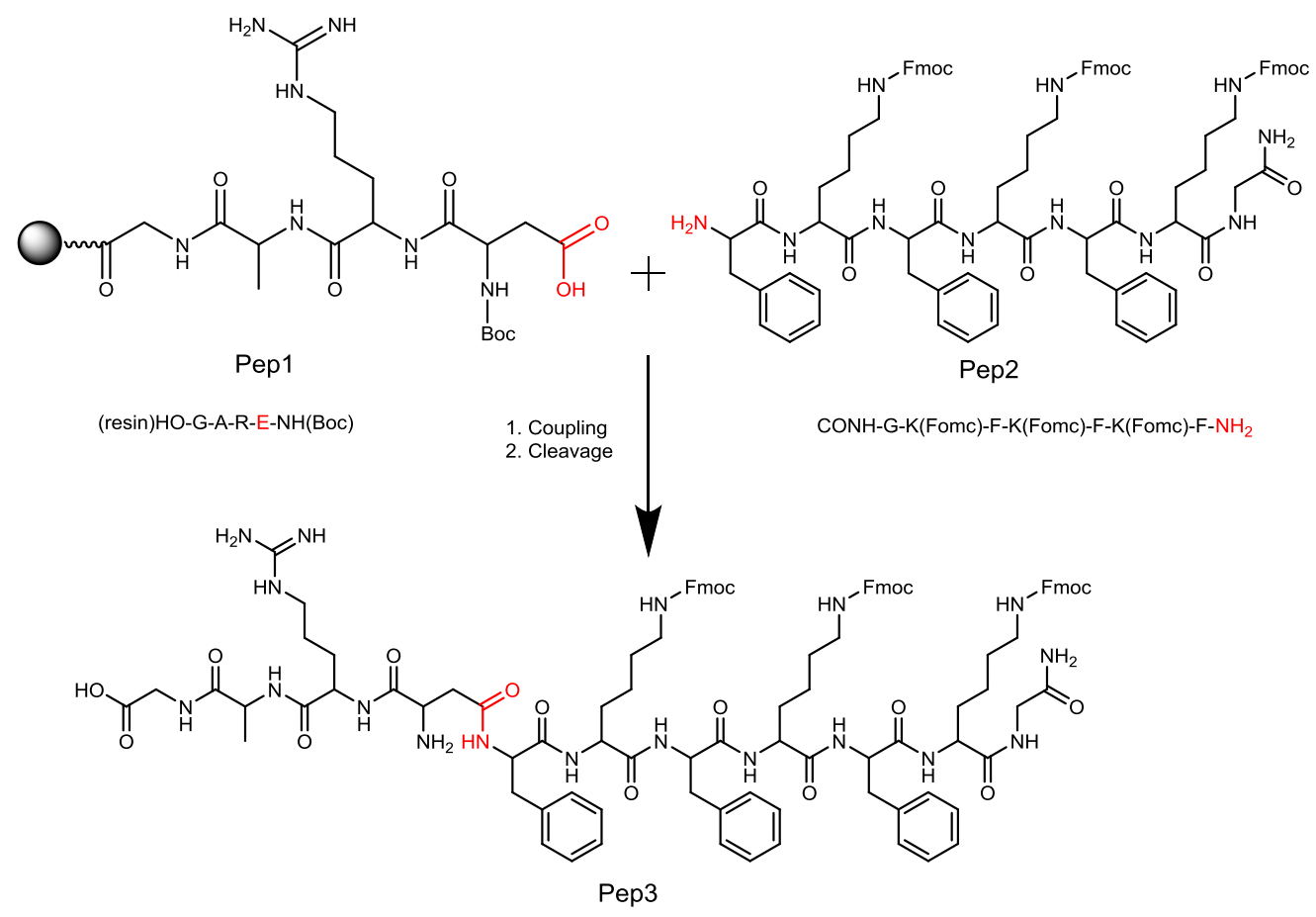

HO-G-A-R-E-F-K(Fmoc)-F-K(Fmoc)-F-K(Fmoc)-G-CONH

Figure 5.13. Synthetic strategy of the simplified model system.

The coupling reaction was successfully performed by using HATU, HOAt as activator and DIEA as activator base and the formation of the peptide (Pep3) was proven by mass spectroscopy. Therefore, this strategy can be applied to obtain the parallel recognition unit. The TMD-Sb and TAGT peptides were synthesized following the previous strategy and the coupling reaction was carried out (Figure $5.14)$. 


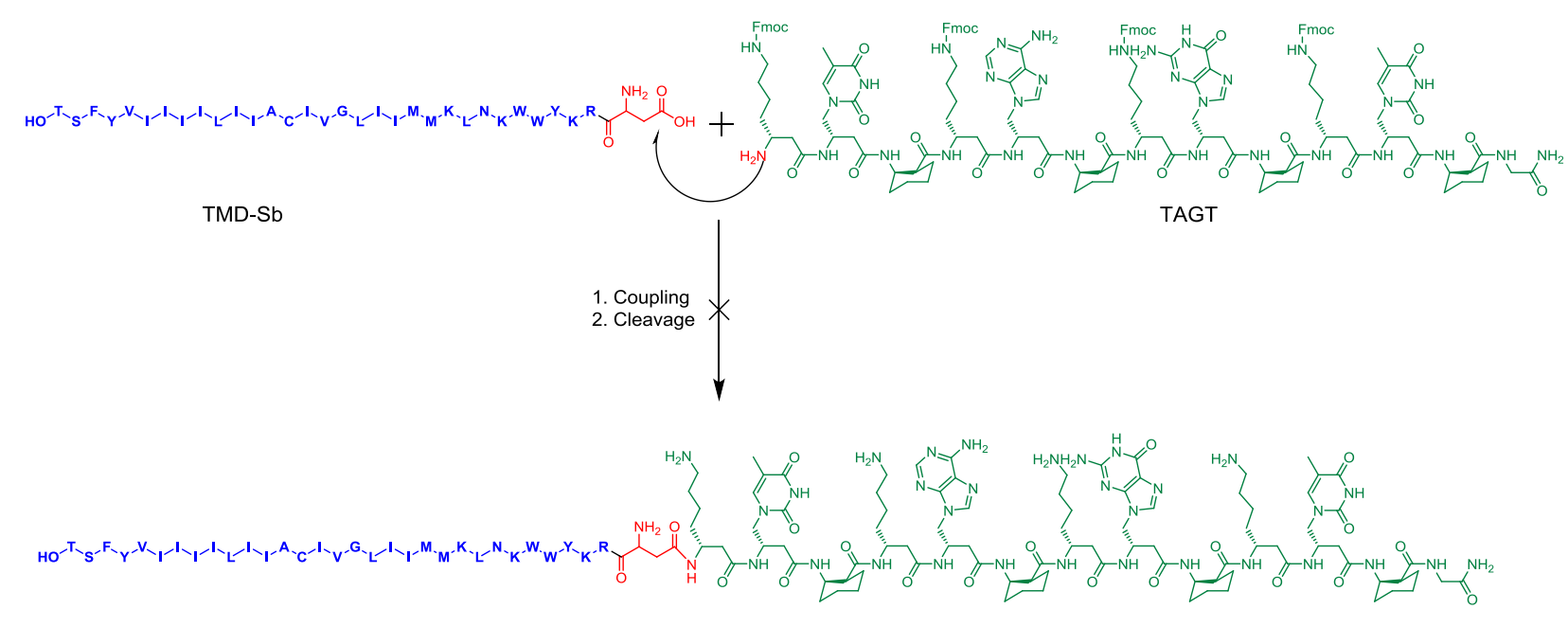

Figure 5.14. Synthetic strategy of the parallel model system.

The reaction could not be achieved and the product was not been detected. The sterical hindrance could play a major role through preventing the product formation. Probably, the free amino group does not have access to the carboxyl group on the strong hydrophobic peptide, which is anchored to the resin. 


\section{Summary}

Membrane fusion is a central process in biological systems. Despite intensive research in this field, many mechanistical questions remain unanswered. Therefore, model systems have been developed allowing in vitro investigation of the processes with reduced system complexity. Such systems allow simplification of the complex natural systems and systematic variation of the chemical structure and composition for understanding the fusion mechanism in detail. This extremely useful information would provide a chance to ultimately design artificial fusion systems with prescribed properties. Therefore, the fusogenic activity of new artificial model systems with varied structures and chemical properties is being constantly investigated.

In this work, the novel simplified SNARE-mimicking systems consisting of TMD/linker segments of the natural membrane-bound SNARE proteins (syntaxin$1 \mathrm{~A}$ and synaptobrevin 2) with a nucleobase functionalized $\beta$-peptide ( $\beta$-PNA) recognition motif were designed and synthesized (Figure 6.1 A). The $\beta$-PNA oligomers can form the 14-helix with three amino acids per turn orienting every third side chain ( $i$ and $i+3$ ) on the same side of the helix. The $\beta$-PNA/TMD model system allows for creating artificial SNARE complexes which assemble preferentially in an antiparallel orientation (Figure 6.1 D).

The synthesized $\beta$-PNA/TMD hybrids were shown to efficiently incorporate in vesicle membranes and after that, the corresponding recognition units remain available for interactions. The fusion experiments show that antiparallel orientation of the recognition motifs of the model systems turned out to be effective for fusion. The new PNA/peptide hybrids allow controlling fusion of vesicles depending on the temperature considering the duplex melting stability. The inner leaflet lipid mixing assay and content mixing assay experiments showed clearly, that the system induces full fusion where the outer and inner leaflets merge together.

Derived from the previous model systems and the hypothesis that the antiparallel recognition units should be flexible, TMD/linker/ $\beta$-PNA hybrids were synthesized 
which contains an extended $\beta$-peptide 14 helix within the linker region (Figure 6.1 B). The fusion assay experiments indicated that the extended $\beta$-PNA-peptides provide hemifusion involving only the outer leaflet with reduced efficiency.

In this study the model system with a parallel $\beta$-PNA recognition motif was designed (Figure $6.1 \mathrm{C}$ ). The synthesis of a simplified peptide model was presented to examine the ability of the coupling between two different peptide segments without any exchange of amino acids. Unfortunately, the application of this strategy on the complete parallel $\beta$-PNA peptides was not successful.

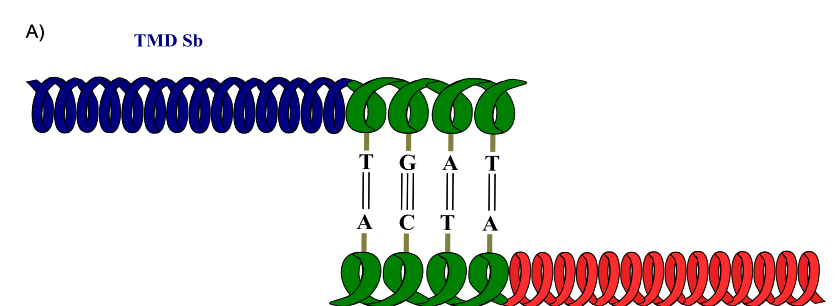

B)

TMD Sb
C)

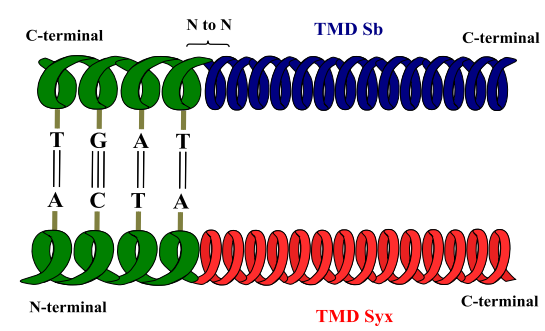

D)

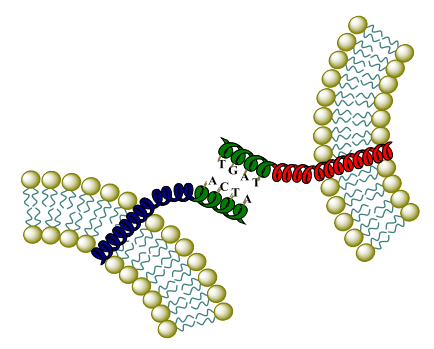

Figure 6.1. A) Schematic SNARE simplified fusion system with $\beta$-PNA. B) Schematic SNARE simplified fusion system with extended $\beta$-PNA. C) Schematic SNARE simpli fied fusion system with parallel $\beta$-PNA. D) Fusion process mediated by a TMD/linker/ $\beta$-PNA construct (right).

The short recognition motif $(20 \AA)$ permits bringing the vesicles in close spatial proximity and induces full fusion. While the extended recognition motif (40 $\AA$ ) keeps vesicles on distance and leads to hemifusion. The $\beta$-PNAs allow antiparallel orientation and therefore, a fusion mechanism is addressed, that differs from the 
native SNARE situation. Nevertheless, the artificial TMD/linker/ $\beta$-PNA constructs are surprisingly efficient in mediating membrane fusion. The $\beta$-PNA recognition motif with the linear and conformational rigid 14-helix backbone offers an especially interesting option of distance control.

In conclusion, this system offers a powerful tool to control the fusion state by using different length of $\beta$-PNA. The extended $\beta$-PNA leads to hemifusion state while the shortened one induces full fusion.

Thus, the designed and synthesized $\beta$-PNA/TMD hybrids emerged as very attractive and promising artificial fusogenic systems, which is capable of inducing efficient fusion. Importantly, their structure elements such as membrane-anchored TMDs, linker regions and recognition units can be easily systematically modified on demand and the $\beta$-PNA recognition duplex formation is very selective and stable. Furthermore, the mechanism of an antiparallel model system could be shown as another possible fusion route and a distance depending fusion mechanism. 


\section{Materials and general methods}

\subsection{Solvents}

All technical solvents were distilled prior to use. Anhydrous DMF, diethyl ether, TFE, THF, DCM and NMP were obtained from Aldrich, Fluka, Acros or Carl Roth $\mathrm{GmbH}$, controlled by GS and used without additional purification. Piperidine was obtained from Riedel de Haen and used as supplied. Acetonitrile and methanol were of HPLC grade. Demineralized water (MiliQ) was processed from Simplicity system of Millipore (Bredford, UK).

\subsection{Reagents}

All chemicals were of the highest grade available and used as supplied. Bocprotected amino acids were purchased from NovaBiochem, GL Biochem (Shanghai) Ltd., ACM Research Chemicals or PANAGENE Inc. (Daejeon):

- Boc-Gly-OH

- Boc-Phe-OH

- Boc-lle-OH

- Boc-Ala-OH

- Boc-Val-OH

- Boc-Leu-OH

- Boc-Asn-OH

- $\mathrm{Boc}-\mathrm{Thr}(\mathrm{Bzl})-\mathrm{OH}$

- $\mathrm{Boc}-\mathrm{Ser}(\mathrm{Bz} \mathrm{l})-\mathrm{OH}$

- Boc-Cys(pMeOBzl)-OH

- $\operatorname{Boc}-\operatorname{Met}(\mathrm{O})-\mathrm{OH}$

- Boc-Arg(MTS)-OH 
- Boc-Lys(2-Cl-Z)-OH

- Boc-Trp(For)-OH

- Boc-Tyr(2-Br-Z)-OH

Resins for SPPS Boc-Gly-Pam-resin (loading $0.75 \mathrm{mmol} / \mathrm{g}$ ) and Boc-Thr(Bzl)-Pamresin (loading $0.45 \mathrm{mmol} / \mathrm{g}$ ) were purchased from Novabiochem (Merck). Boc- $\beta$ amino acids and nucleobase functionalized $\beta$-amino acids ( $A, T, C$ and $G$ ) have been synthesized as described earlier. ${ }^{[87]}$ Lipids and fluorophores were obtained from the Avanti Polar Lipids (Alabaster, USA).

\subsection{Lyophilization}

A Christ Alpha-2.4-lyophilizer equipped with a high vacuum pump was used to liberate dry substances from water.

\subsection{High performance liquid chromatography (HPLC)}

HPLC was performed on a Pharmacia Äkta basic system (pump type P-900, variable wavelength, detector of type UV-900) using the following columns:

Analytical HPLC: Phenomenex, synergi, Max-RP $(150 \times 4.6 \mathrm{~mm}, 5 \mu \mathrm{m})$

Phenomenex, RP C-18 (250 x $4.6 \mathrm{~mm}, 5 \mu \mathrm{m})$

All HPLC runs were performed by using a linear gradient of solvents $A(0.1 \%$ aq. TFA) and B (100\% Methanol, $0.1 \%$ aq. TFA) within $30 \mathrm{~min}$. For analysis and purification, HPLC grade acetonitrile and ultra pure water were used. Flow rates were taken as $1 \mathrm{~mL} / \mathrm{min}$ for the analytical runs. All crude samples were dissolved in TFE-formic acid mixtures and filtered prior to injection. UV detection was conducted at $215 \mathrm{~nm}$ for fully deprotected peptides and at $260 \mathrm{~nm}$ for $\beta$-PNA containing peptides. 


\subsection{Further chromatographic methods}

Flash chromatography was performed using Merck silica gel 60. Thin layer chromatography (TLC) was carried out using Merck aluminum sheets of silica gel $60 \mathrm{~F} 254$ with detection under UV light at $254 \mathrm{~nm}$ or development with solution of ninhydrin in ethanol $(2.0 \mathrm{~g}$ ninhydrin, $100 \mathrm{~mL} \mathrm{EtOH}$ and $1 \mathrm{~mL} \mathrm{AcOH}$ ) followed by heating using a heat-gun.

\subsection{Solid phase peptide synthesis (SPPS)}

\subsubsection{Handling of solid support and building blocks}

Amino acid building blocks were stored at $-18{ }^{\circ} \mathrm{C}$. For the storage of resins for SPPS the temperature did not exceed $4 \stackrel{\circ}{\circ} \mathrm{C}$. Before opening, chemicals were warmed to room temperature. If necessary, both resins and amino acids were additionally dried in high vacuum.

\subsubsection{Kaiser test}

The Kaiser test was used to confirm the successful coupling step by detecting the free amino groups on the resin. The solutions of ninhydrin in ethanol $(5 \mathrm{~g} / 100 \mathrm{~mL})$, phenol in ethanol $(80 \mathrm{~g} / 20 \mathrm{~mL})$ and aq. $\mathrm{KCN}(1 \mathrm{mM}, 2 \mathrm{~mL})$ in pyridine $(98 \mathrm{~mL})$ were prepared. A few beads of the resin were washed several times with ethanol and placed in a small glass tube. Two drops of each solution described above were added to the sample of resin. The resulting suspension was heated at $120 \stackrel{\circ}{\circ} \mathrm{C}$ for $5 \mathrm{~min}$. Blue color of resin beads indicated positive test result (presence of free amino groups on the resin), whereas a yellow color (negative test) confirmed the absence of the free amino groups and, therefore, completeness of the corresponding coupling step. It is worth to note, that the Kaiser test is not accurate 
(can provide false negative results) in the case of peptides containing proline, asparagine or serine residues.

\subsubsection{Manual SPPS for $\alpha-P e p t i d e s$}

The SPPS of peptide conjugates was carried out manually at $25 \mu \mathrm{M}$ scale using the Pam- resins. ${ }^{[100]}$ The resins were suspended in the minimal amount of DMF and allowed to swell for $2 \mathrm{~h}$. After the swelling was completed and the solvents were removed, the following procedure was repeated for each coupling cycle:

1. Boc-deprotection with TFA ( $\geq 99.9 \%$ ), 2 times for 1 min each.

2. Coupling: The corresponding building blocks (11 eq.) were dissolved in the minimal amount of DMF; HBTU (10 eq.) and DIEA (29 eq.) were added before he mixture was given to the resin gently shaking for $12 \mathrm{~min}$.

3. Capping: The unreacted amino groups were "capped" by shaking resins with the mixture of $\mathrm{Ac}_{2} \mathrm{O}(2 \mathrm{M})$, DIEA (0.6 M), HOBt $(60 \mathrm{mM})$ in DMF, 2 times for $5 \mathrm{~min}$ each.

4. Washing: After each step (deprotection, coupling, capping), the resin was washed with DMF and DCM at least three times using approximately $2 \mathrm{~mL}$ of solvent per $100 \mathrm{mg}$ of resin.

5. Final washing: Before final assembly of the synthesized constructs or before cleavage from solid support, the resin was washed with DMF (at least 3 times), $\mathrm{DCM}$ (at least 3 times) and $\mathrm{MeOH}$ or diethyl ether (at least 2 times) and then dried in vacuo. 


\subsubsection{Manual SPPS for $\beta$-peptides}

After the synthesis of the TMD and Linker, the following $\beta$ amino acids were synthesized for the recognition units:

Boc-ACHC-OH

Boc- $\beta-A l a-O H$

Boc- $\beta-G l n-O H$

Boc- $\beta-\operatorname{Tyr}(2-\mathrm{Br}-\mathrm{Z})-\mathrm{OH}$

Boc- $\beta$-Trp(For)-OH

Boc- $\beta$-Lys(CBZ)-OH

Boc- $\beta-\operatorname{Ser}(\mathrm{Bzl})-\mathrm{OH}$

Boc- $\beta$-Guanin-OH

Boc- $\beta$-Adenin-OH

Boc- $\beta-$ Cytosin-OH

Boc- $\beta$-Thymin-OH

After coupling of the last $\alpha$-amino acids the coupling protocol for $\beta$-amino acids was applied. ${ }^{[88]}$ The coupling cycle started with Boc-deprotection applying 95\% TFA and $5 \%$ m-cresol twice within 2 min, followed by washing with DMF (5 times). For each coupling, an excess of $\beta$-amino acid building block of five equivalents was used; the $\beta$-amino acids were dissolved in stock solutions of coupling reagents within 5 min before the base was added. For activation of coupling HATU/HOAt (4.5 eq./5 eq.) in DMF were used. DIEA (14 eq.) was used as activator base. $A$ $0.25 \mathrm{M}$ concentration was used as the final reaction mixture for the building blocks and HOAt. The HATU concentration was adjusted to $0.225 \mathrm{M}$. Standard coupling 
time was $60 \mathrm{~min}$ at $50^{\circ} \mathrm{C}$. $\beta$-Amino acid building blocks were introduced by double coupling. The reaction time for the second coupling was kept as 60 min at $50{ }^{\circ} \mathrm{C}$ but the amino acids and activators concentrations were reduced (amino acid 3 eq./ HATU 2.5 eq./ HOAt 3 eq.). After washing with DMF (5 times) and DCM (5 times) capping was fulfilled with $\mathrm{Ac}_{2} \mathrm{O}(2 \mathrm{M})$, DIEA $(0.6 \mathrm{M})$ and $\mathrm{HOBt}(60 \mathrm{mM})$ in DMF within 30 min. Washing with DMF (10 times), DCM (10 times) completed the coupling cycle. The resin was dried in vacuo.

\subsubsection{Cleavage}

Peptides were cleaved from the solid support simultaneously removing the side chain protecting groups; standard TFMSA cleavage was applied using the mixture

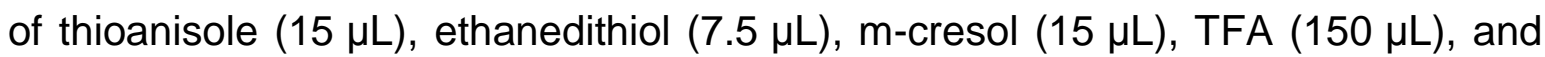
TFMSA $(15 \mu \mathrm{L}) .{ }^{[124,125]}$ In case the sequences contained a sensitive Trp residue the resin was pretreated with $10 \%$ piperidine in DMF for $3 \mathrm{~h}$; afterwards the previous mixture with additional DMS $(15 \mu \mathrm{L})$ was applied. Cleavage reactions were carried out for $3 \mathrm{~h}$ at ambient temperature starting with $0^{\circ} \mathrm{C}$ for $5 \mathrm{~min}$.

\subsubsection{Post-cleavage work up}

After cleavage, the resin was filtered and the resulting solution was concentrated under reduced pressure. The crude product was precipitated with cold $\mathrm{Et}_{2} \mathrm{O}$. The resulting suspensions were centrifuged at $4{ }^{\circ} \mathrm{C}$. The supernatant was discarded and the peptide pellet washed several times with $\mathrm{Et}_{2} \mathrm{O}$ and dried in vacuo. For mass spectrometry analyses peptide samples were dissolved in TFE/formic acid $(5 / 1, v / v)$. 


\subsubsection{Synthesis of $\alpha / \beta$-peptide hybrid oligomers}

$\alpha-/ \beta$-Peptide hybrid oligomers were synthesized via manual SPPS on a Pam resin (loading: $0.75 \mathrm{mmol} / \mathrm{g}$ for syntaxin and $0.45 \mathrm{mmol} / \mathrm{g}$ for synaptobrevin) at a $25 \mu \mathrm{mol}$ scale. Peptides (ACTA-Syx, TGAT-Sb, ACTA-ext-Syx, TGAT-ext-Sb) were synthesized with manual SPPS for the a-peptide sequences Syx/linker and $\mathrm{Sb} /$ linker (see section 2.2) and continued with manual modified protocol for $\beta$ peptides (ACTA, TGAT with or without 14-helix linker) (see section 2.3).

\subsection{Preparation of peptide/lipid complexes}

\subsubsection{Multilamellar vesicles (MLVs)}

Lipids and cholesterol were dissolved in $\mathrm{CHCl}_{3}$ (about $20 \mathrm{mg} \cdot \mathrm{mL}^{-1}$ ), mixed with alcoholic peptide stock solutions (TFE) to form a solution of $\mathrm{CHCl}_{3}$ /alcohol (1/1, $\mathrm{v} / \mathrm{v}$ ) with defined $\mathrm{P} / \mathrm{L}$ ratio. Removing the solvents in a nitrogen stream at temperatures above the main phase transition temperature of the respective lipids produced an almost clear lipid/peptide film at the test tube walls. After removing of residual solvent under reduced pressure for $12 \mathrm{~h}$ at $T>\mathrm{tm}$, the lipid films were rehydrated with an appropriate amount of buffer solution (20 mM HEPES, $100 \mathrm{mM}$ $\mathrm{KCl}, 1 \mathrm{mM}$ EDTA, $1 \mathrm{mM}$ DTT, $\mathrm{pH}$ 7.4) yielding the desired peptide concentration. After $1 \mathrm{~h}$ of incubation at $T>T \mathrm{~m}$, the hydrated lipid films were vortexed (30 s) and incubated $\left(5 \mathrm{~min}\right.$ at $\left.45^{\circ} \mathrm{C}\right)$ in five cycles. The preparation of the unilamellar vesicles and other peptide/lipid complexes was carried out at temperatures above the transition temperature, i.e. in the lipid fluid $L_{\alpha}$ phase $(T>t \mathrm{~m})$. 


\subsubsection{Large unilamellar vesicles (LUVs)}

The milky MLV suspensions were extruded 31 times through a polycarbonate membrane (100 nm nominal pore size) using a Liposofast mini extruder (Avestin, Ottawa, Canada) to produce an almost clear vesicle suspension containing vesicles of $100 \mathrm{~nm}$ size with a low degree of polydispersity as determined by dynamic light scattering (see below). ${ }^{[126]}$

\subsection{Spectroscopic and analytical methods}

\subsubsection{NMR Spectrometry}

${ }^{1} \mathrm{H}$ - and spectra were recorded with a Varian Unity 300 spectrometer or a Varian Inova 600 spectrometer. Chemical shifts are referenced to the residual solvent peak of $\left[\mathrm{D}_{6}\right]$ DMSO $(1 \mathrm{H}: \delta=2.49 \mathrm{ppm})$ or $\mathrm{CDCl}_{3}(1 \mathrm{H}: \delta=7.26 \mathrm{ppm})$. Chemical shifts are given in parts per million (ppm). Abbreviations for multiplicities are as follows: s, singlet; d, doublet; t, triplet; q, quartet; m, multiplet; br, broad. Coupling constants are given in $\mathrm{Hz}$.

\subsubsection{Mass spectrometry (MS)}

Electrospray ionization mass spectra (ESI-MS) were obtained with a Finnigan LCQ instrument. Liquid chromatography mass spectrometry (LC-MS) spectra were obtained with the Thermo (HPLC) and Finnigan (MS) instrument. A Phenomenex, MAX-RP Synergi C-18 $(150 \times 2 \mathrm{~mm}, 4 \mu \mathrm{m})$ column was used. All synthesized $\beta$ PNA/peptide conjugates were characterized by ESI-MS and LC-MS. High resolution mass spectra (HRMS-ESI) were obtained from a Bruker APEX-Q IV FTICR-MS instrument. 


\subsubsection{Dynamic light scattering (DLS)}

Experimental diffusion coefficients (D) were measured at $25 \stackrel{\circ}{\circ}$ by dynamic light scattering at a laser wavelength of $830 \mathrm{~nm}$ and scattering angle of $90^{\circ}$ using a DynaPro Titan DLS. The Stokes-Einstein relationship: $D=k_{B T} / 3 p \eta D_{h}\left(k_{B}\right.$ is the Boltzman constant and $\eta$ the solvent viscosity) was used to estimate the hydrodynamic radius, $D_{h}(n m)$. The radius of the vesicle containing ACTA-Syx was determined as $73 \mathrm{~nm}$ and with TAGT-Sb $75 \mathrm{~nm}$.

\subsubsection{UV-Spectroscopy}

Peptide concentrations were estimated with a Jasco V5550 UV spectrometer (Gross Umstadt, Germany) while the sample cell was floated with nitrogen. Molecular absorption coefficients were calculated for each oligomer sequence via summation of the monomer absorption coefficients at a certain wavelength. Nucleobases and peptides conjugate concentrations were estimated at $260 \mathrm{~nm}$. Concentrations were calculated with LAMBERT BEER's law.

ACTA-Syx and ACTA-ext-Syx:

$$
\begin{aligned}
& \varepsilon=2\left(\varepsilon_{\text {Adenin }}\right)+\varepsilon_{\text {Cytosin }}+\varepsilon_{\text {Thymin }} \\
& \varepsilon=2(15400)+7400+8700 \\
& \varepsilon=46900 \mathrm{~L} \cdot \mathrm{mol}^{-1} \cdot \mathrm{cm}^{-1}
\end{aligned}
$$

TGAT-Sb and TGAT-ext-Sb:

$$
\begin{aligned}
& \varepsilon=2\left(\varepsilon_{\text {Thymin }}\right)+\varepsilon_{\text {Guanin }}+\varepsilon_{\text {Adenin }}+2\left(\varepsilon_{\text {Tryptophan }}\right) \\
& \varepsilon=2(8700)+11500+15400+2(5000) \\
& \varepsilon=54300 \mathrm{~L} \cdot \mathrm{mol}^{-1} \cdot \mathrm{cm}^{-1}
\end{aligned}
$$




\subsubsection{Fluorescence spectroscopy}

Fluorescence spectra were obtained with a Jasco FP 5600 (Gross Umstadt, Germany) under temperature control using a thermostat (Model 1162A, VWR International, Darmstadt, Germany). The excitation and emission bandwidth was set to $5 \mathrm{~nm}$, the data pitch was $1 \mathrm{~nm}$ and the response time was adjusted to $0.1 \mathrm{~s}$. NBD-DOPE was used as fluorescence donor, rhodamine-DOPE as acceptor. Data were recorded at a P/L ratio of $1 / 200$ in DOPC/DOPE/cholesterol (50/25/25) LUVs.

\subsubsection{Lipid mixing assay}

Lipid mixing assay excitation was performed at $460 \mathrm{~nm}$ with a detection of the fluorescence emission at $535 \mathrm{~nm} .{ }^{[45,117]} \mathrm{NBD} /$ rhodamine labeled vesicles (1.5\% NBD-DOPE and $1.5 \%$ rhodamine-DOPE), containing TGAT-Sb peptide constructs (or TGAT-ext-Sb), were mixed with unlabeled vesicles, containing ACTA-Syx constructs (or ACTA-ext-Syx) at a defined ratio (1 to 4); the total lipid concentration in the cuvette was $180 \mu \mathrm{M}$. The reaction buffer was $20 \mathrm{mM}$ HEPES, $100 \mathrm{mM} \mathrm{KCl}$, $1 \mathrm{mM}$ EDTA, $1 \mathrm{mM} \mathrm{DTT}$ at $\mathrm{pH} 7.4$ and the reaction temperature $25{ }^{\circ} \mathrm{C}$. The change in donor intensity is plotted as:

$$
F(\%)=100^{*}\left(F_{t} \cdot F_{0}\right) /\left(F_{\text {total }} \cdot F_{0}\right)
$$

with $\mathrm{F}_{0}$ being the donor intensity at $\mathrm{t}=0$ before lipid mixing and Ftotal the donor intensity after disruption of the vesicles in $1 \%(\mathrm{w} / \mathrm{v})$ Triton $\mathrm{X}-100$. The same procedure was used for the inner leaflet mixing assay except NBD/rhodamine labeled vesicles were treated with sodium dithionite as described below. 


\subsubsection{Reduction of NBD/Rhodamine labeled vesicles}

A 1:1 mixture of $\mathrm{NBD} /$ rhodamine labeled vesicles $(5 \mathrm{mM})$ and $50 \mathrm{mM} \mathrm{Na} 2 \mathrm{~S}_{2} \mathrm{O}_{4}$ (20 mM HEPES, pH 7.4) was incubated at room temperature for $5 \mathrm{~min}$. Free sodium dithionite was removed by gel filtration using Superdex G550 Superfine columns (GE Healthcare). Reduction was immediately carried out before use of the vesicles. ${ }^{[122]}$

\subsubsection{Content mixing assay}

A vesicle population with an encapsulated fluorophore (sulforhodamine $B$ ) is mixed with vesicles without sulforhodamine B. The observed increase of fluorescence caused by decreasing of fluorophore concentration indicates that vesicle contents are mixed and fusion takes place. Content mixing assay excitation was performed at $567 \mathrm{~nm}$ with a detection of the fluorescence emission at $583 \mathrm{~nm}$. The vesicles containing TGAT-Sb (or TGAT-ext-Sb) constructs with encapsulated sulforhodamine $B(20 \mathrm{mM}$ in $20 \mathrm{mM}$ HEPES, $100 \mathrm{mM} \mathrm{KCl}, 1 \mathrm{mM}$ EDTA, $1 \mathrm{mM}$ DTT, pH 7.4) were extruded through a polycarbonate membrane $(100 \mathrm{~nm}$ nominal pore size). The free sulforhodamine $B$ was removed by gel filtration using Superdex G550 Superfine columns (GE Healthcare). Unlabeled vesicles, containing ACTA-Syx constructs (or ACTA-ext-Syx), were prepared in the same way as described in section 3.2. Both types of vesicles were mixed at a defined ratio (1:4); the total lipid concentration in the cuvette was $180 \mu \mathrm{M}$. The reaction buffer was $20 \mathrm{mM}$ HEPES, $100 \mathrm{mM} \mathrm{KCl,} 1 \mathrm{mM}$ EDTA, $1 \mathrm{mM}$ DTT, pH 7.4 and the reaction temperature was $25^{\circ} \mathrm{C}$. The change in sulforhodamine $\mathrm{B}$ intensity is plotted as:

$$
F(\%)=100^{*}\left(F_{t} \cdot F_{0}\right) /\left(F_{\text {total }} \cdot F_{0}\right)
$$


with $F_{0}$ being the sulforhodamine $B$ intensity at $t=0$ before content mixing and Ftotal the sulforhodamine B intensity after disruption of the vesicles in $1 \%(\mathrm{w} / \mathrm{v})$ Triton X-100.

\subsection{Synthesis of $\alpha / \beta$-peptide hybrid oligomers}

\subsubsection{Synthesis of $\mathrm{N}-\mathrm{Boc}-\beta^{3}$-amino acids}

\subsubsection{1. (S)-3-((tert-Butoxycarbonyl)amino)-4-(1-formyl-1H-indol-3-yl) butanoic acid (3)}

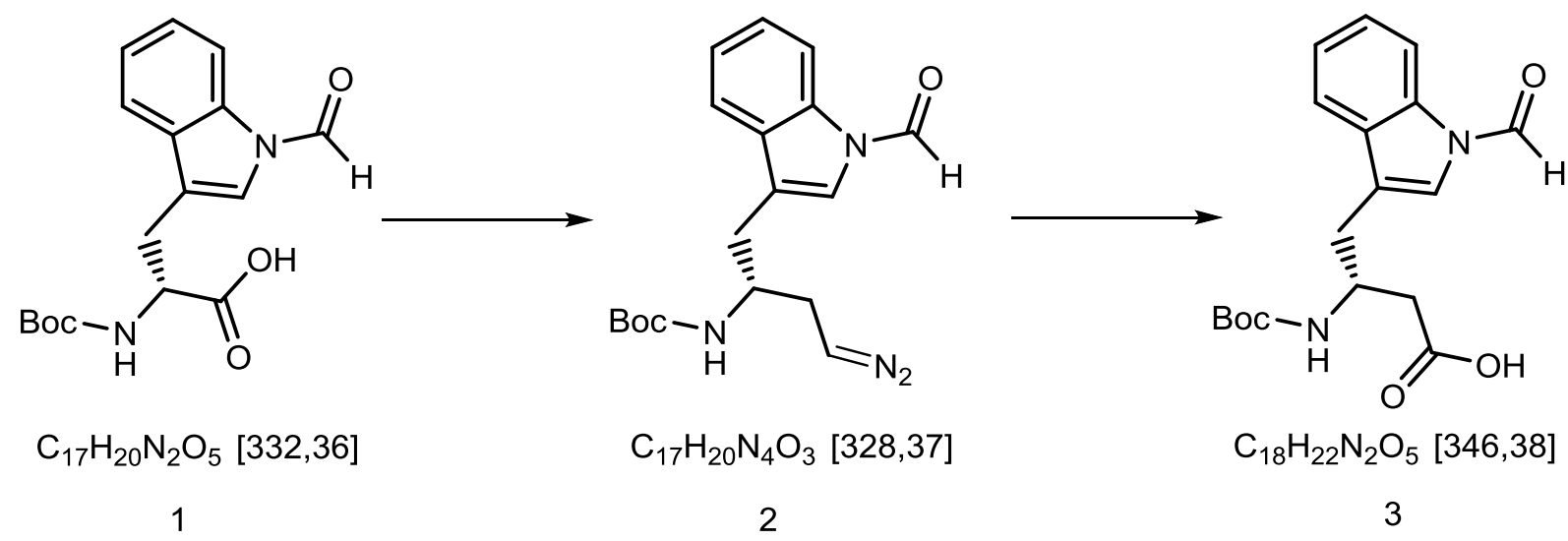

Under dry conditions, Boc-D-Trp(For)-OH $1(5.55 \mathrm{~g}, 10.7 \mathrm{mmol}$ ) was dissolved in dry THF $(50 \mathrm{~mL})$ under exclusion of light. At $-21^{\circ} \mathrm{C}$ triethylamine $\mathrm{Et}_{3} \mathrm{~N}(1.63 \mathrm{~mL}$, $11.7 \mathrm{mmol}$ ) and isobutyl chlorformate $(1.52 \mathrm{~mL}, 11.7 \mathrm{mmol})$ were added to the amino acid and stirred at $-21^{\circ} \mathrm{C}$ for 45 min under argon. The mixture was warmed to $0^{\circ} \mathrm{C}$ and the diazomethane $(30.46 \mathrm{~mL}, 21.3 \mathrm{mmol})$ was added over $30 \mathrm{~min}$ and 
stirred at $\mathrm{rt}$ for $5 \mathrm{~h}$. The reaction was stopped with acetic acid $(1.4 \mathrm{~mL})$ and EtOAc $(75 \mathrm{~mL})$ was added. The organic phase was washed with $6 \% \mathrm{NaHCO}_{3}(100 \mathrm{~mL})$, $\mathrm{NH}_{4} \mathrm{Cl}(100 \mathrm{~mL})$ and $\mathrm{NaCl}(100 \mathrm{~mL})$. The extracted organic phase was dried over $\mathrm{MgSO}_{4}$ and the solvents were removed under reduced pressure. The resulting crude 2 was dissolved in THF: $\mathrm{H}_{2} \mathrm{O}(9: 1)(75 \mathrm{~mL})$ and the silverbenzoate $(250 \mathrm{mg}$, $1.1 \mathrm{mmol}$ ) was added at $0^{\circ} \mathrm{C}$. After $2 \mathrm{~h}$ reaction time in ultrasonic bath the reaction mixture was neutralized with $\mathrm{HCl}(1 \mathrm{M})$ by reducing the $\mathrm{pH}$ to 2-3. The suspension was extracted with EtOAc $(100 \mathrm{~mL})$ and the organic layer was dried over $\mathrm{MgSO}_{4}$. The product crude was suspended in a pentane:DCM mixture (10:1) to crystallize the pure product $3(68 \%)$ as a yellowish white solid.

Analytical data:

ESI-MS: $m / z=347.1\left[\mathrm{M}+\mathrm{H}^{+}\right]^{+}, 369.1\left[\mathrm{M}+\mathrm{Na}^{+}\right]^{+}, 385.1\left[\mathrm{M}+\mathrm{K}^{+}\right]^{+}$.

ESI-HRMS: calculated for $\mathrm{C}_{18} \mathrm{H}_{22} \mathrm{~N}_{2} \mathrm{O}_{5} \mathrm{~K} 385.1160$, found $385.1164\left[\mathrm{M}+\mathrm{K}^{+}\right]^{+}$.

${ }^{1} \mathrm{H}$ NMR (300 MHz, $\mathrm{CDCl}_{3}$ ): $\delta=1.39$ (s, 9H; Boc), 2.51-2.68 (m, 2H; $\left.\alpha-\mathrm{CH}_{2}\right), 3.00$ (m, $2 \mathrm{H}$; $\mathrm{v}-\mathrm{CH} 2), 4.27(\mathrm{~d}, J=48.0 \mathrm{~Hz}, 1 \mathrm{H} ; \beta-\mathrm{CH} 2), 7.21(\mathrm{~s}, 1 \mathrm{H}$; aromatic $\mathrm{H}), 7.3-$ $7.76(\mathrm{~m}, 4 \mathrm{H}$; aromatic $\mathrm{H}), 8.30-8.42(\mathrm{~m}, 1 \mathrm{H} ; \mathrm{NH}), 9.04(\mathrm{~s}, 1 \mathrm{H} ;-\mathrm{CHO}), 9.35(\mathrm{~s}, 1 \mathrm{H}$; $\mathrm{COOH}) \cdot \mathrm{ppm}$ 


\subsubsection{2. (S)-4-(4-((((2-bromobenzyl)oxy)carbonyl)oxy)phenyl)-3-((tert- butoxycarbonyl) amino) butanoic acid (6)}

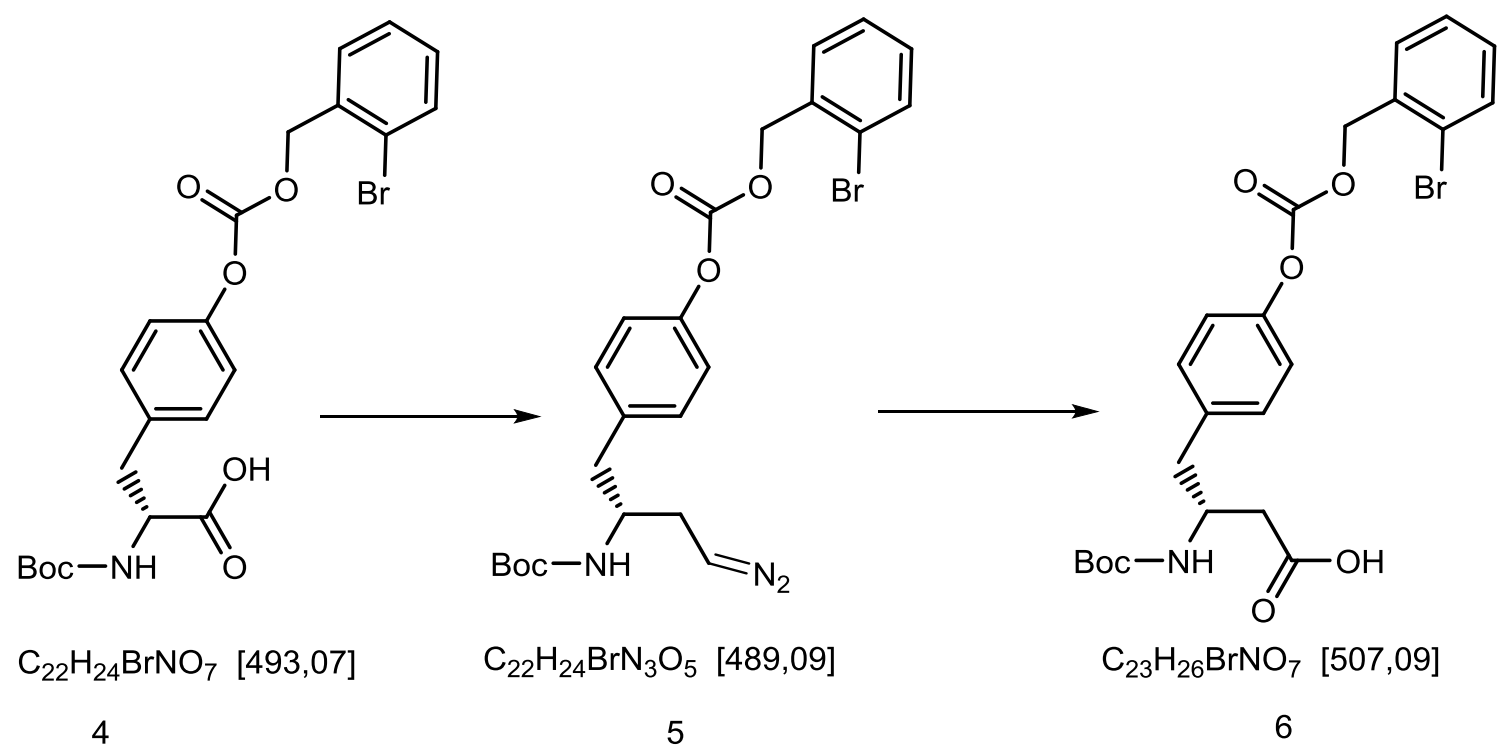

Under dry conditions, Boc-D-Tyr(2-Br-Z)-OH 4 (5.26 g, $10.7 \mathrm{mmol})$ was dissolved in dry THF $(50 \mathrm{~mL})$ under exclusion of light. At $-21^{\circ} \mathrm{C}$ triethylamine $\mathrm{Et}_{3} \mathrm{~N}(1.63 \mathrm{~mL}$, $11.7 \mathrm{mmol})$ and isobutyl chlorformate $(1.52 \mathrm{~mL}, 11.7 \mathrm{mmol}$ ) were added to the amino acid and stirred at $-21^{\circ} \mathrm{C}$ for 45 min under argon. The mixture was warmed to $0{ }^{\circ} \mathrm{C}$ and the diazomethane $(30.46 \mathrm{~mL}, 21.3 \mathrm{mmol})$ was added over $30 \mathrm{~min}$ and stirred at $\mathrm{rt}$ for $5 \mathrm{~h}$. The reaction was stopped with acetic acid $(1.4 \mathrm{~mL})$ and EtOAc $(75 \mathrm{~mL})$ was added. The organic phase was washed with $6 \% \mathrm{NaHCO}_{3}(100 \mathrm{~mL})$, $\mathrm{NH}_{4} \mathrm{Cl}(100 \mathrm{~mL})$ and $\mathrm{NaCl}(100 \mathrm{~mL})$. The extracted organic phase was dried over $\mathrm{MgSO}_{4}$ and the solvents were removed under reduced pressure. The resulting crude 5 was dissolved in THF: $\mathrm{H}_{2} \mathrm{O}(9: 1)(75 \mathrm{~mL})$ and the silverbenzoate $(250 \mathrm{mg}$, $1.1 \mathrm{mmol}$ ) was added at $0^{\circ} \mathrm{C}$. After $2 \mathrm{~h}$ reaction time in ultrasonic bath the reaction mixture was neutralized with $\mathrm{HCl}(1 \mathrm{M})$ by reducing the $\mathrm{pH}$ to 2-3. The suspension was extracted with EtOAc $(100 \mathrm{~mL})$ and the organic layer was dried over $\mathrm{MgSO}_{4}$. The product crude was suspended in a pentane:DCM mixture $(10: 1)$ to crystallize the pure product 6 (59\%) as a yellowish white solid. 
Analytical data:

ESI-MS: $m / z 530.1\left[\mathrm{M}+\mathrm{Na}^{+}\right]^{+}, 546.1\left[\mathrm{M}+\mathrm{K}^{+}\right]^{+}$.

ESI-HRMS: calculated for $\mathrm{C}_{23} \mathrm{H}_{26} \mathrm{BrNO}_{7} \mathrm{Na} 530.0785$, found $530.0777\left[\mathrm{M}+\mathrm{Na}^{+}\right]^{+}$.

${ }^{1} \mathrm{H}$ NMR (300 MHz, $\left.\mathrm{CDCl}_{3}\right): \delta=1.37$ (s, 9H; Boc), 2.46-2.68 (m, 2H; $\left.\alpha-\mathrm{CH}_{2}\right), 2.81-$ $2.93\left(\mathrm{~m}, 2 \mathrm{H} ; \mathrm{\gamma}-\mathrm{CH}_{2}\right), 4.15\left(\mathrm{~s}_{\mathrm{br}}, 1 \mathrm{H} ; \beta-\mathrm{CH}_{2}\right), 5.09(\mathrm{~s}, 1 \mathrm{H}, \mathrm{NH}), 5.34\left(\mathrm{~s}, 2 \mathrm{H},-\mathrm{CH}_{2} \mathrm{Z}\right)$, 7.1-7.5 (m, 8H; aromatic $\mathrm{H}) . \mathrm{ppm}$

\subsubsection{3. (S)-6-amino-3-((tert-butoxycarbonyl)amino)-6-oxohexanoic acid (9)}

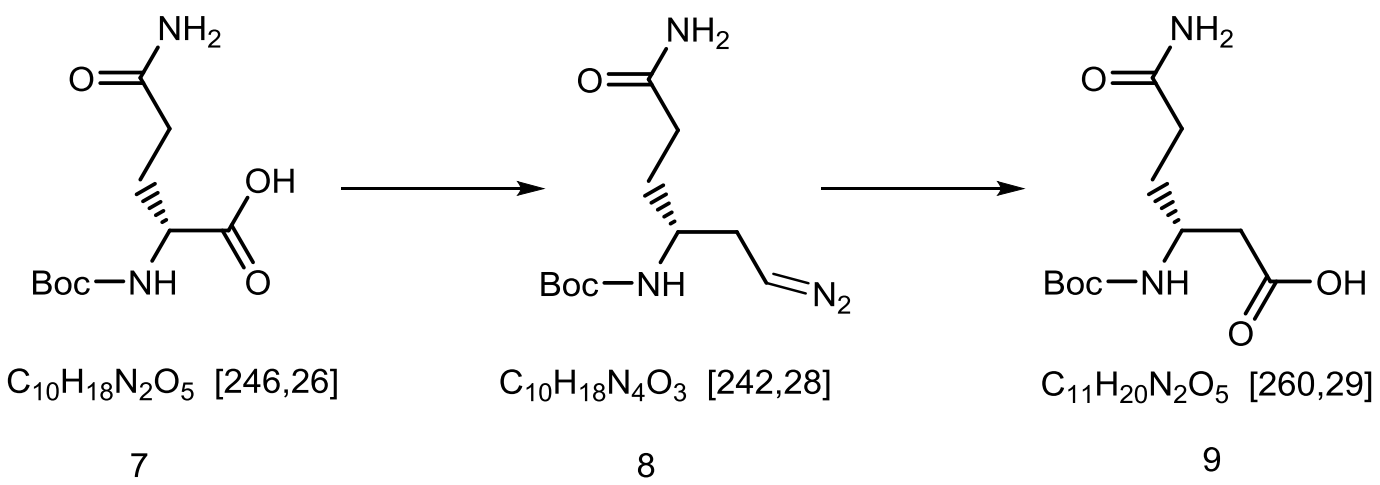

Under dry conditions, Boc-D-Gln-OH 7 (3 g, $12.2 \mathrm{mmol}$ ) was dissolved in dry THF $(50 \mathrm{~mL})$ under exclusion of light. At $-21^{\circ} \mathrm{C}$ triethylamine $\mathrm{Et}_{3} \mathrm{~N}(1.71 \mathrm{~mL}, 13.4 \mathrm{mmol})$ and isobutyl chlorformate $(1.74 \mathrm{~mL}, 13.4 \mathrm{mmol})$ were added to the amino acid and stirred at $-21{ }^{\circ} \mathrm{C}$ for $45 \mathrm{~min}$ under argon. The mixture was warmed to $0{ }^{\circ} \mathrm{C}$ and the diazomethane ( $34.14 \mathrm{~mL}, 24.4 \mathrm{mmol}$ ) was added over $30 \mathrm{~min}$ and stirred at $\mathrm{rt}$ for 
$5 \mathrm{~h}$. The reaction was stopped with acetic acid $(1.5 \mathrm{~mL})$ and EtOAc $(75 \mathrm{~mL})$ was added. The organic phase was washed with $6 \% \mathrm{NaHCO}_{3}(100 \mathrm{~mL}), \mathrm{NH}_{4} \mathrm{Cl}$ $(100 \mathrm{~mL})$ and $\mathrm{NaCl}(100 \mathrm{~mL})$. The extracted organic phase was dried over $\mathrm{MgSO}_{4}$ and the solvents were removed under reduced pressure. The resulting crude 8 was dissolved in THF: $\mathrm{H}_{2} \mathrm{O}(9: 1)(75 \mathrm{~mL})$ and the silverbenzoate $(285.43 \mathrm{mg}, 1.2 \mathrm{mmol}$ ) was added at $0^{\circ} \mathrm{C}$. After $2 \mathrm{~h}$ reaction time in ultrasonic bath the reaction mixture was neutralized with $\mathrm{HCl}(1 \mathrm{M})$ by reducing the $\mathrm{pH}$ to 2-3. The suspension was extracted with EtOAc $(100 \mathrm{~mL})$ and the organic layer was dried over $\mathrm{MgSO}_{4}$. The product crude was suspended in a pentane:DCM mixture (10:1) to crystallize the pure product $9(70 \%)$ as a white solid.

Analytical data:

ESI-MS: $m / z 260.2\left[\mathrm{M}+\mathrm{H}^{+}\right]^{+}, 283.1\left[\mathrm{M}+\mathrm{Na}^{+}\right]^{+}, 299.1\left[\mathrm{M}+\mathrm{K}^{+}\right]^{+}$.

ESI-HRMS: calculated for $\mathrm{C}_{11} \mathrm{H}_{20} \mathrm{~N}_{2} \mathrm{O}_{5} \mathrm{Na} 283.1264$, found $283.1259\left[\mathrm{M}+\mathrm{Na}^{+}\right]^{+}$.

${ }^{1} \mathrm{H}$ NMR (300 MHz, [D $\left.\mathrm{D}_{6}\right] \mathrm{DMSO}$ ): $\delta=1.37$ (s, 9H; Boc), 1.61 (d, $J_{H, H}=19.3 \mathrm{~Hz} ; 2 \mathrm{H}$; $\mathrm{v}-\mathrm{CH} 2$ ), 2.01-2.07 (td, $\left.J_{H, H}=7.2, J_{H, H}=3.8 \mathrm{~Hz} ; 2 \mathrm{H} ; \delta-\mathrm{CH} 2\right), 2.29-2.34\left(\mathrm{t}, J_{H, H}=6.2\right.$ $\left.\mathrm{Hz}, 2 \mathrm{H} ; \alpha-\mathrm{CH}_{2}\right), 3.70\left(\mathrm{~d}, \mathrm{~J}_{H, H}=5.4 \mathrm{~Hz} ; 1 \mathrm{H} ; \beta-\mathrm{CH} 2\right), 6.62\left(\mathrm{~d},{ }^{3} \mathrm{~J}_{H, H}=10.5 \mathrm{~Hz} 2 \mathrm{H}\right.$, $\mathrm{NH} 2), 7.2(\mathrm{~s}, 1 \mathrm{H}, \mathrm{NH}), 12.06(\mathrm{sbr}, 1 \mathrm{H} ;-\mathrm{COOH}) . \mathrm{ppm}$

\subsubsection{Synthesis of the peptides}

\section{Pep1}

\section{HO-G-A-R-E-NH(Boc)}

$$
\mathrm{C}_{20} \mathrm{H}_{35} \mathrm{~N}_{7} \mathrm{O}_{9}[417.4 \mathrm{~g} / \mathrm{mol}]
$$


Pep1 was synthesized using the Boc-Gly-PAM-resin (20 $\mu \mathrm{mol}, 26.7 \mathrm{mg})$ according to the general procedure described in section 7.6.3. After the final coupling, $10 \mathrm{mg}$ of the peptide resin was cleaved from the resin followed by lyophilization to afford the peptide as a white solid.

ESI-HRMS: Calculated for $\mathrm{C}_{20} \mathrm{H}_{35} \mathrm{~N}_{7} \mathrm{O}_{9} \mathrm{Na} 440.2393$, found $440.2396[\mathrm{M}+\mathrm{Na}]^{+}$ ESI-MS: $m / z=418.2[\mathrm{M}+\mathrm{H}]^{+}$

\title{
Pep2
}

\author{
$\mathrm{NH}_{2} \mathrm{CO}-\mathrm{G}-\mathrm{K}(\mathrm{Fmoc})-\mathrm{F}-\mathrm{K}(\mathrm{Fmoc})-\mathrm{F}-\mathrm{K}(\mathrm{Fmoc})-\mathrm{F}-\mathrm{NH}_{2}$ \\ $\mathrm{C}_{92} \mathrm{H}_{99} \mathrm{~N}_{11} \mathrm{O}_{13}[1566.8 \mathrm{~g} / \mathrm{mol}]$
}

Pep2 was synthesized using the Boc- $\beta$-Gly-MBHA-resin $(25 \mu \mathrm{mol}, 50 \mathrm{mg})$ according to the general procedure described in section 7.6.3. After the final coupling the peptide was cleaved from the resin followed by lyophilization to afford the peptide as a white solid.

Analytical HPLC: (RP C-18, $250 \times 4.6 \mathrm{~mm}, 5 \mu \mathrm{m}): \mathrm{t}_{\mathrm{R}}=20.4 \mathrm{~min}$, gradient: 5 to $70 \%$ $B$ in 30 min.

ESI-HRMS: Calculated for $\mathrm{C}_{92} \mathrm{H}_{99} \mathrm{~N}_{11} \mathrm{O}_{13} \quad 1588.7321$, found $1588.7323[\mathrm{M}+\mathrm{Na}]^{+}$ ESI-MS: $m / z=1567.5[\mathrm{M}+\mathrm{H}]^{+}$

\section{Pep3}

HO-G-A-R-E-F-K(Fmoc)-F-K(Fmoc)-F-K(Fmoc)-G-CONH

$$
\mathrm{C}_{107} \mathrm{H}_{124} \mathrm{~N}_{18} \mathrm{O}_{19}[1966.2 \mathrm{~g} / \mathrm{mol}]
$$


The coupling reaction between the peptides Pep1 on the resin and Pep2 was performed to obtain Pep3. The synthesis started with adding (HATU 1 eq, HOAt $1 \mathrm{eq}$ in DMF and $500 \mu \mathrm{l})$ and DIEA $(7 \mu \mathrm{l}, 6 \mathrm{eq})$ to $10 \mathrm{mg}$ of the pep1 resin. Pep2 $(120 \mathrm{mg}$, in DMF, $500 \mu \mathrm{l}$ ) is added to the pep1 resin and shaked together at rt overnight. The peptide was cleaved from the resin followed by lyophilization to afford the peptide as a white solid.

Analytical HPLC: (RP C-18, $250 \times 4.6 \mathrm{~mm}, 5 \mu \mathrm{m}): \mathrm{t}_{\mathrm{R}}=21.2 \mathrm{~min}$, gradient: 5 to $70 \%$ $B$ in 30 min.

ESI-HRMS: Calculated for $\mathrm{C}_{107} \mathrm{H}_{124} \mathrm{~N}_{18} \mathrm{O}_{19}$ 1987.9187, found $1987.9189[\mathrm{M}+\mathrm{Na}]^{+}$

ESI-MS: $m / z=1966.8[\mathrm{M}+\mathrm{H}]^{+}, 984.0[\mathrm{M}+2 \mathrm{H}]^{2+}$

\section{TMD-Sb}

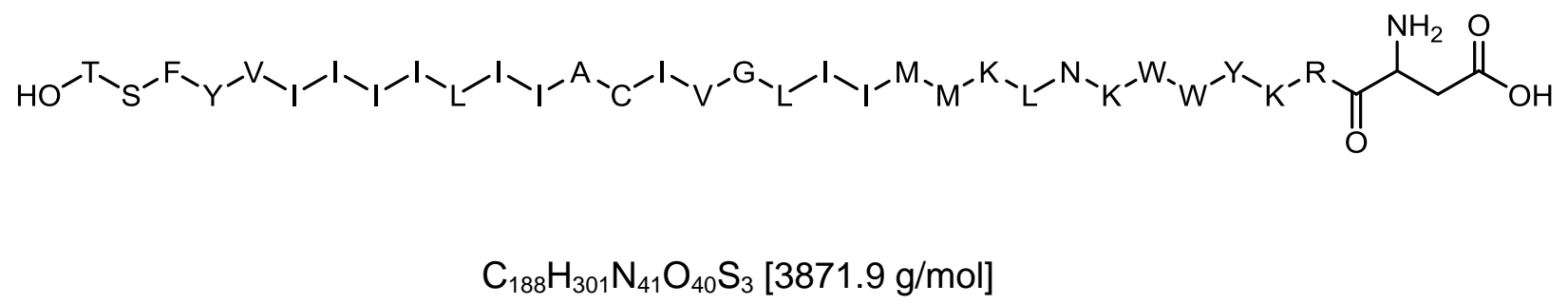

TMD-Sb was synthesized using the Boc-Thr(Bzl)-Pam-resin $(25 \mu \mathrm{mol}, 28 \mathrm{mg}$ ) according to the general procedure described in section 7.6.3. After the final coupling, $10 \mathrm{mg}$ of the peptide resin was cleaved from the resin followed by lyophilization to afford the peptide as a white solid.

ESI-MS: $m / z=1291.6[\mathrm{M}+3 \mathrm{H}]^{3+}, 969[\mathrm{M}+4 \mathrm{H}]^{4+}$ 


\section{TAGT}

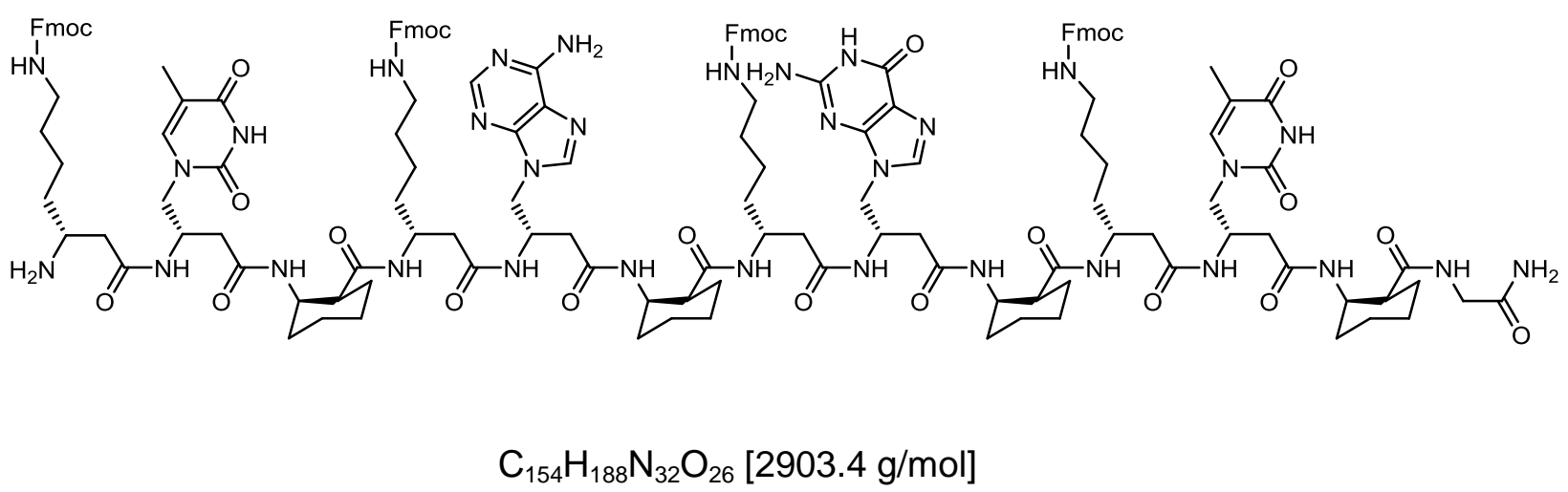

TAGT was synthesized using the Boc- $\beta$-Gly-MBHA-resin (25 $\mu \mathrm{mol}, 50 \mathrm{mg}$ ) according to the general procedure described in section 7.6.4. After the final coupling the peptide was cleaved from the resin followed by lyophilization to afford the peptide as a white solid.

Analytical HPLC: (synergi, Max-RP, $150 \times 4.6 \mathrm{~mm}, 5 \mu \mathrm{m}$ ): $\mathrm{t}_{\mathrm{R}}=25.6 \mathrm{~min}$, gradient: 5 to $70 \% \mathrm{~B}$ in $30 \mathrm{~min}$.

ESI-MS: $m / z=1452[\mathrm{M}+2 \mathrm{H}]^{2+}, 968,7[\mathrm{M}+3 \mathrm{H}]^{3+}$

\section{ACTA-Syx}

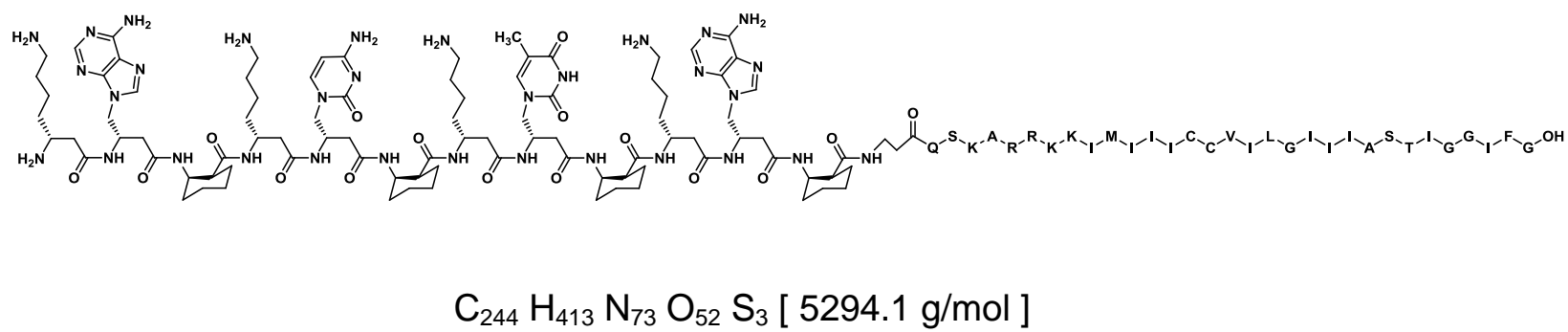


ACTA-Syx was synthesized using the Boc-Gly-PAM-resin $(20 \mu \mathrm{mol}, 26.7 \mathrm{mg}$ ) according to the general procedure described in section 7.6.3 and 7.6.4. After the final coupling the peptide was cleaved from the resin followed by lyophilization to afford the peptide as a white yellowish solid.

LC-MS: $\mathrm{m} / \mathrm{z}=[\mathrm{M}+3 \mathrm{H}]^{3+}$ calc: 1765.7 , found: $1765.8 ;[\mathrm{M}+4 \mathrm{H}]^{4+}$ calc: 1324.5 , found: $1324.2 ;[\mathrm{M}+5 \mathrm{H}]^{5+}$. calc: 1059.8 , found: 1059.8

\section{TGAT-Sb}

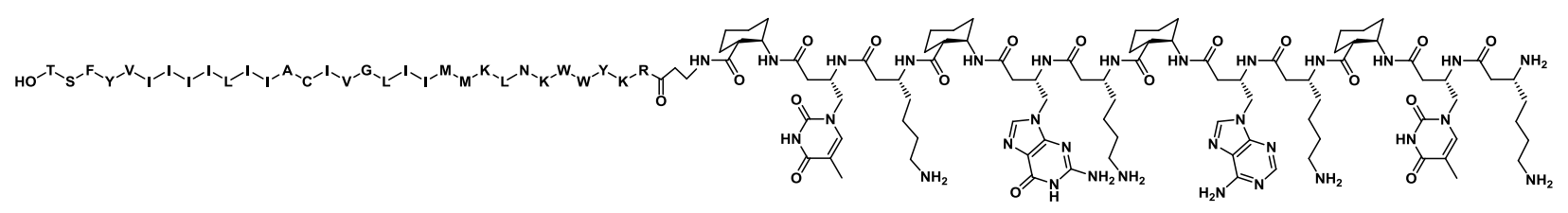

$$
\mathrm{C}_{279} \mathrm{H}_{443} \mathrm{~N}_{71} \mathrm{O}_{55} \mathrm{~S}_{3}[5764.32 \mathrm{~g} / \mathrm{mol}]
$$

TGAT-Sb was synthesized using the Boc-Thr(Bzl)-PAM-resin $(25 \mu \mathrm{mol}, 28 \mathrm{mg})$ according to the general procedure described in section 7.6.3 and 7.6.4. After the final coupling the peptide was cleaved from the resin followed by lyophilization to afford the peptide as a white yellowish solid.

LC-MS: $m / z=[M+4 H]^{4+}$ calc: 1442.1 , found: $1442.2 ;[M+5 H]^{5+}$, calc: 1153.9, found: $1154.4 ;[\mathrm{M}+7 \mathrm{H}]^{7+}$ calc: 824.4 , found: 823.9 


\section{ACTA-ext-Syx}

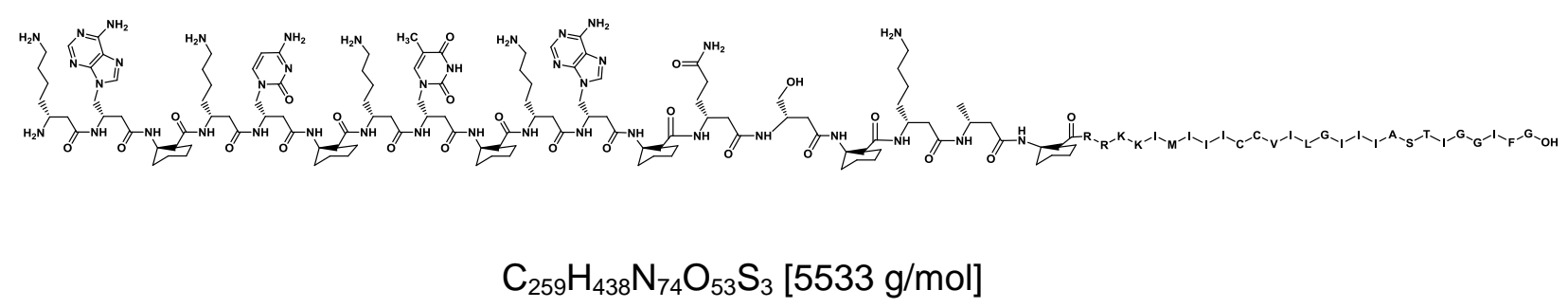

ACTA-ext-Syx was synthesized using the Boc-Gly-PAM-resin (20 $\mu \mathrm{mol}, 26.7 \mathrm{mg})$ according to the general procedure described in section 7.6.3 and 7.6.4. After the final coupling the peptide was cleaved from the resin followed by lyophilization to afford the peptide as a white yellowish solid.

LC-MS: $m / z=[M+5 H]^{5+}$ calc: 1107.6 , found: 1108,7; $[\mathrm{M}+6 \mathrm{H}]^{6+}$. calc: 923,1 , found: 925,2

\section{TGAT-ext-Sb}

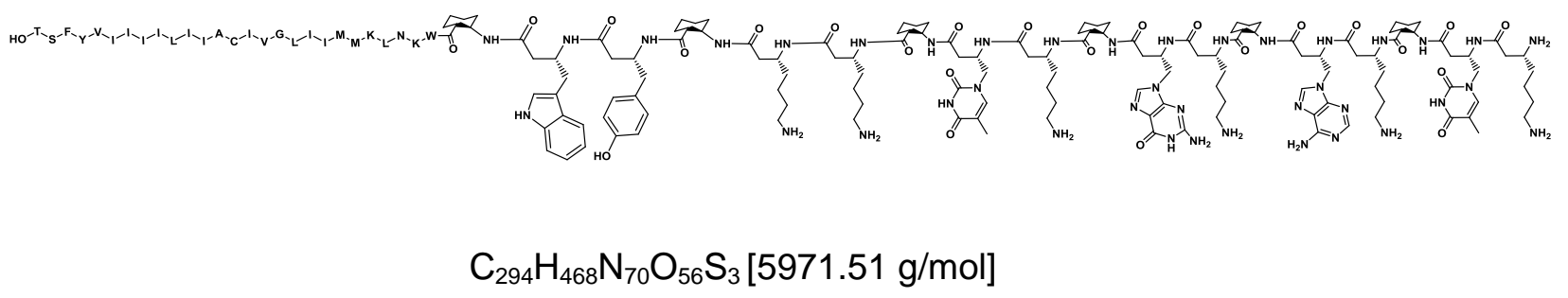

TGAT-ext-Sb was synthesized using the Boc-Thr(Bzl)-PAM-resin $(25 \mu \mathrm{mol}, 28 \mathrm{mg})$ according to the general procedure described in section 7.6.3 and 7.6.4. After the final coupling the peptide was cleaved from the resin followed by lyophilization to afford the peptide as a white yellowish solid. 
LC-MS: $m / z=[\mathrm{M}+4 \mathrm{H}]^{4+}$ calc: 1493.9 , found: $1494.7 ;[\mathrm{M}+5 \mathrm{H}]^{5+}$, calc: 1195.3 , found: 1196.0 


\section{Abbreviations}
AA amino acid
Ac acyl
ACHC 2-aminicyclohexanecarboxylic acid
aeg aminoethylglycine
ATP adenosine-5'-triphosphate
Boc tert-butyloxycarbonyl
calc. calculated
CD circular dichroism
CLSM confocal laser scanning fluorescence microscope
DAG diacylglycerol
DBU 1,8-diazabicyclo[5.4.0]undec-7-en
DCC dicyclohexylcarbodiimide
DCM dichloromethane
DCU dicyclohexylurea
DHPE 1,2-dihexadecanoyl-sn-glycero-3-phosphoethanolamine
DIC N,N'-diisopropylcarbodiimide
DIEA diisopropylethylamine
DLS dynamic light scattering
DMAP 4-dimethylaminopyridine
DMF dimethylformamide
DMT dimethoxytrityl
DNA desoxyribonucleic acid
DOPC dioleoyl-sn-glycero-3-phosphatidylcholine
DOPE dioleoyl-sn-glycero-3-phosphoethanolamine
DPA dipicolinic acid
ds double-strand 
DTT dithiothreitol

EDC 1-ethyl-3-(3-dimethylaminopropyl)carbodiimide

EDT 1,2-ethandithiol

EDTA ethylenediamin-tetra acetic acid

EDMA ethyldimethylamine

EM electron microscopy

ER endoplasmic reticulum

ESI electrospray ionization

$\mathrm{Et}_{3} \mathrm{~N} \quad$ triethylamine

FC flash chromatography

Fmoc fluorenylmethoxycarbonyl

FRET Förster resonance energy transfer

GTP guanosine-5'-triphosphate

GUV giant unilamellar vesicle

HATU 2-(1H-9-azabenzotriazole-1-yl)-1,1,3,3-tetramethylaminium hexafluorophosphate

HBTU 2-(1H-benzotriazole-1-yl)-1,1,3,3-tetramethylaminium hexafluorophosphate

HEPES 4-(2-hydroxyethyl)-1-piperazineethanesulfonic acid

HIV human immunodeficiency virus

HOAt N-hydroxy-9-azabenzotriazole

HOBt hydroxybenzotriazole

HPLC high performance liquid chromatography

HR-MS high resolution mass spectrometry

IR infrared

LED light-emitting diodes

LPC lysophosphatidylcholine 
LUV large unilamellar vesicles

m.p. melting point

$\mathrm{MeOH}$ methanol

MLV multilamellar vesicle

MS mass spectrometry

MTBE methyl-tert-butylether

NBD 7-nitro-2-1,3-benzoxadiazol-4-yl

NCL native chemical ligation

NMP N-methyl-pyrrolidone

NMR nuclear magnetic resonance

NSF N-ethylmaleimide-sensitive factor

o/n over night

PhiPr phenylisopropyl

OG Oregon Green

$\mathrm{P} / \mathrm{L} \quad$ peptide-to-lipid

PC phosphatidylcholine

PE phosphatidylethanolamine

PEG polyethyleneglycole

PG protection group

PI phosphoinositide

$\mathrm{pH} \quad$ potentia hydrogenii

PNA peptide nucleic acid

POPC 1-palmitoyl-2-oleoyl-sn-glycero-3-phosphocholine

POPS 1-hexadecanoyl-2-(9Z-octadecenoyl)-sn-glycero-3-phospho-Lserine

Pra propargyl amino acid

PS polysterene

PSM pore-spanning membrane 
PyAOP (7-azabenzotriazol-1-yloxy)tripyrrolidinophosphonium

hexafluorophosphate

PyBOP (benzotriazol-1-yloxy)tripyrrolidinophosphonium

hexafluorophosphate

Rh lissamine rhodamine B sulfonul

RNA ribonucleic acid

$\mathrm{RP} \quad$ reverse phase

rt room temperature

SNAP soluble NSF-attachment protein

SNARE soluble $\mathrm{N}$-ethylmaleimide-sensitive-factor attachment receptor

SPPS solid phase peptide synthesis

SPS solution phase synthesis

SRB sulforhodamine B

ss single-strand

SSM solid-supported membrane

SUV small unilamellar vesicle

$\mathrm{Sb} \quad$ synaptobrevin 2 (VAMP II)

Syx syntaxin-1A

$\mathrm{tBu} \quad$ tret-butyl

tret tertiary

TES triethylsilane

TFA trifluoroacetic acid

TFMSA Trifluoromethanesulfonic acid

TFE trifluoroethanol

THF tetrahydrofuran

TIS triisopropylsilane

TLC thin layer chromatography

TMD trans membrane domain 
TMS trimethylsilyl

Trt trityl

UV ultraviolet 


\section{References}

[1] M. M. Kozlov, S. L. Leikin, L. V. Chernomordik, V. S. Markin, Y. A. Chizmadzhev, Eur. Biophys. J. 1989, 17, 121-129.

[2] L. V. Chernomordik, M. M. Kozlov, Annu. Rev. Biochem. 2003, 72, 175-207.

[3] B. R. Lentz, V. Malinin, M. E. Haque, K. Evans, Curr. Opin. Struct. Biol. 2000, 10, 607-615.

[4] L. V. Chernomordik, M. M. Kozlov, Nat. Struct. Mol. Biol. 2008, 15, 675-683.

[5] M. M. Kozlov, V. S. Markin, Biofizika 1983, 28, 255-261.

[6] L. V. Chernomordik, G. B. Melikyan, Y. A. Chizmadzhev, Biochim. Biophys. Acta. 1987, 906, 309-352.

[7] J. Lee, B. R. Lentz, Biochemistry 1997, 36, 6251-6259.

[8] L. V. Chernomordik, S. S. Vogel, A. Sokoloff, H. O. Onaran, E. A. Leikina, J. Zimmerberg, FEBS Lett. 1993, 318, 71-76.

[9] C. Reese, A. Mayer, J. Cell Biol. 2005, 171, 981-990.

[10] C. Reese, F. Heise, A. Mayer, Nature. 2005, 436, 410-414.

[11] Y. Xu, F. Zhang, Z. Su, J. A. McNew, Y.-K. Shin, Nat. Struct. Mol. Biol. 2005, 12, 417-422.

[12] B. Podbilewicz, E. Leikina, A. Sapir, A. Valansi, M. Suissa, G. Shemer, L. V. Chernomordik, Dev. Cell. 2006, 11, 471-481.

[13] G. B. Melikyan, R. M. Markosyan, G. M. Roth, F. S. Cohen, Mol. Biol. Cell 2000, 11, 3765-3775

[14] R. T. Amstrong, A. S. Kushnir, J. M. White, J. Cell Biol. 2000, 151, 425-437.

[15] A. Chanturiya, L. V. Chernomordik, J. Zimmerberg, Proc. Natl. Acad. Sci. U.S.A. 1997, 94, 14423-14428.

[16] A. Sapir, O. Avinoam, B. Podbilewicz, L. V. Chernomordik, Dev. Cell, 2008, 14, 11-21.

[17] T. Kirchhausen, Nat. Rev. Mol. Cell Biol. 2000, 1, 187-198.

[18] J. S. Bonifacino, J. Lippincott-Schwartz, Nat. Rev. Mol. Cell Biol. 2003, 4, 409-414. 
[19] R. Jahn, R. H. Scheller, Nat. Rev. Mol. Cell Biol. 2006, 7, 631-643.

[20] J. S. Bonifacino, B. S. Glick, Cell, 2004, 116, 153-166.

[21] T. Söllner, S. W. Whiteheart, M. Brunner, H. Erdjument-Bromage, S. Geromanos, P. Tempst, J. E. Rothman, Nature, 1993, 362, 318-324.

[22] C. Walch-Solimena, R. Jahn, T. C. Südhof, Curr. Opin. Neurobiol. 1993, 3, 329-336.

[23] K. G. Hales, M. T. Fuler, Cell 1997, 90, 121-129.

[24] T. Koshiba, S. A. Detmer, J. T. Kaiser, H. Chen, J. M. McCaffery, D. C. Chan, Nature 2004, 365, 858-862.

[25] V. I. Titorenko, R. A. Rachubinski, TRENDS Cell Biol. 2001, 11, 22-29.

[26] J. C Bock, H. T. Matern, A. A. Peden, R. H. Scheller, Nature. 2001, 409, 839-841.

[27] W. Hong, Biochim. Biophys. Acta 2005, 1744, 120-144.

[28] D. Fasshauer, Biochim. Biophys. Acta 2003, 1641, 87-97.

[29] T. Söllner, M. K. Brunner, S. W. Whiteheart, R. H. Scheller, J. E. Rothman, Cell 1993, 75, 409-418.

[30] R. B. Sutton, D. Fasshauer, R. Jahn, A. T. Brunge, Nature 1998, 395, 347353.

[31] W. Antonin, D. Fasshauer, S. Becker, R. Jahn, Nat. Struct. Mol. Biol. 2002, 9, 107-111.

[32] a) D. Fasshauer, R. B. Sutton, A. T. Brunge, R. Jahn, Proc. Natl. Acad. Sci. U.S.A. 1998, 95, 15781-15786. b) T. H. Kloepper, C. N. Kienle, D. Fasshauer, Mol. Biol. Cell 2007, 18, 3463 - 3471.

[33] W. Wickner, R. Schekman, Nat. Struct. Mol. Biol. 2008, 15, 658-664.

[34] L. Wang, S. Seeley, W. Wickner, A. Merz, Cell 2002, 108, 357-369.

[35] L. Wang, A. Merz, K. Collins, W. Wickner, J. Cell Biol. 2003, 160, 365-374.

[36] R. Fratti, Y. Jun, A. Merz, N. Margolis, W. Wickner, J. Cell Biol. 2004, 167, 1087-1098.

[37] A. T. Brunger, Q. Rev. Biophys. 2005, 38, 1-47. 
[38] T. M. Hohl, F. Parlati, C. Wimmer, J. E. Rothman, T. H. Söllner, H. Engelhardt, Mol. Cell 1998, 2, 539-548.

[39] S. W. Whiteheart, T. Schraw, E. A. Matveeva, Int. Rev. Cytol. 2001, 207, 71-112.

[40] S. C. Harrison, Nat. Struct. Mol. Biol. 2008, 15, 690-698.

[41] A. Richard, V. Marchi-Artzner, M. N. Lalloz, M. J. Brienne, F. Artzner, T. Gulik-Krzywicki, M. A. Guedeau-Boudeville, J. M. Lehn, Proc. Natl. Acad. Sci. USA 2004, 101, 15279 - 15284.

[42] Y. Gong, Y. Luo, D. Bong, J. Am. Chem. Soc. 2006, 128, $14430-14431$.

[43] M. Ma, A. Paredes, D. Bong, J. Am. Chem. Soc. 2008, 130, 14456 -14458.

[44] M. Ma, Y. Gong, D. Bong, J. Am. Chem. Soc. 2009, 131, 16919 -16926.

[45] G. Stengel, R. Zahn, F. Hççk, J. Am. Chem. Soc. 2007, 129, 9584 - 9585.

[46] Y. H. M. Chan, B. van Lengerich, S. G. Boxer, Proc. Natl. Acad. Sci. USA 2009, 106, $979-984$.

[47] a) H. R. Marsden, N. A. Elbers, P. H. H. Bomans, N. A. J. M. Sommerdijk, A. Kros, Angew. Chem. 2009, 121, 2366-2369; Angew. Chem. Int. Ed. 2009, 48, 2330 - 2333. b) H.R. Marsden, A. V. Korobko, T. Zheng, J. Voskuhl, A. Kros. Biomater. Sci. 2013, 1, 1046-1054. c) T. Zheng, J. Voskuhl, F. Versluis, H. R. Zope, I. Tomatsu, H. R. Marsden, A. Kros. Chem. Commun. 2013, 49, 3649-3651. d) F. Versluis, J. Voskuhl, B. von Kolck, H. Zope, M. Bremmer, T. Albregtse, A. Kros. J. Am. Chem. Soc. 2013, 135, 8057-8062.

[48] K. Meyenberg, A. S. Lygina, G. van den Bogaart, R. Jahn, U. Diederichsen, Chem. Comm. 2011, 47, 9405-9407.

[49] G. Pähler, C. Panse, U. Diederichsen, A. Janshoff, Biophysical J. 2012, 103, 2295-2303.

[50] A. S. Lygina, K. Meyenberg, R. Jahn, U. Diederichsen, Angew. Chem. 2011, 123, 8756-8760; Angew. Chem. Int. Ed. 2011, 50, 8597-8601.

[51] A. Kashiwada, M. Tsuboi, K. Matsuda, Chem. Commun. 2009, 695-697.

[52] A. Kashiwada, M. Tsuboi, N. Takamura, E. Brandenburg, K. Matsuda, B. Koksch, Chem. Eur. J. 2011, 17, 6179-6186. 
[53] Y. Gong, M. Ma, Y. Luo, D. Bong, J. Am. Chem. Soc. 2008, 130, 6196-6205.

[54] Y. H. M. Chan, B. van Lengerich, S. G. Boxer, Biointerphases 2008, 3, FA17-FA21.

[55] R. P. Cheng, S. H. Gellman, W. F. DeGrado, Chem. Rev. 2001, 101, 32193232.

[56] D. J. Hill, M. J. Mio, R. B. Prince, T. S. Hughes, J. S. Moore, Chem. Rev. 2001, 101, 3893-4011.

[57] D. Seebach, J. L. Matthews, Chem. Commun. 1997, 2015-2022.

[58] K. Gademann, T. Hintermann, J. V. Schreiber, Curr. Med. Chem. 1999, 6, 905-925.

[59] U. Koert, Angew. Chem. Int. Ed. 1997, 36, 1836-1837.

[60] J. Frackenpohl, P. I. Arvidson, J. V. Schreiber, D. Seebach, ChemBioChem 2001, 2, 445-455.

[61] D. Seebach, A. K. Beck, D. J. Bierbaum, Chem. Biodiv. 2004, 1, 1111-1239.

[62] D. L. Steer, R. A. Law, P. Perlmutter, A. I. Smith, M. I. Aguilar, Curr. Med. Chem. 2002, 9, 811-822.

[63] D. Seebach, T. Kimmerlin, R. Šebesta, M. A. Campo, A. K. Beck, Tetrahedron 2004, 60, 7455-7506.

[64] A. Banerjee, P. Balaram, Curr. Science 1997, 73, 1067-1077.

[65] D. H. Appella, L. A. Christianson, I. L. Karle, D. R. Powell, S. H. Gellman, J. Am. Chem. Soc. 1996, 118, 13071-13072.

[66] J. Frackenpohl, P. I. Arvidson, J. V. Schreiber, D. Seebach, ChemBioChem 2001, 2, 445-455.

[67] D. Seebach, S. Abele, J. V. Schreiber, B. Martinoni, A. K. Nussbaum, H. Schild, H. Schulz, H. Hennecke, R. Woessner, F. Bitsch, Chimia, 1998, 52, 734-739.

[68] S. Abele, D. Seebach, Helv. Chim. Acta 1999, 82, 1559-1571.

[69] T. L. Raguse, E. A. Porter, B. Weisblum, S. H. Gellman, J. Am. Chem. Soc. 2002, 124, 12774-12785. 
[70] D. Seebach, J. L. Matthews, A. Meden, T. Wessels, C. Baerlocher, L. B. McCusker, Helv. Chim. Acta 1997, 80, 173-182.

[71] T. D. Clark, L. K. Buehler, M. R. Ghadiri, J. Am. Chem. Soc. 1998, 120, 651656

[72] D. H. Appella, J. J. Barchi, S. R. Durell, S. H. Gellman, J. Am. Chem. Soc. 1999, 121, $2309-2310$.

[73] T. L. Raguse, J. R. Lai, S. H. Gellman, Helv. Chim. Acta 2002, 85, 4154 4164.

[74] T. L. Raguse, J. R. Lai, S. H. Gellman, J. Am. Chem. Soc. 2003, 125, 55925593.

[75] D. H. Appella, L. A. Christianson, I. L. Karle, D. R. Powell, S. H. Gellman, J. Am. Chem. Soc. 1999, 121, 6206 - 6212.

[76] Y. Hamuro, J. P. Schneider, W. F. DeGrado, J. Am. Chem. Soc. 1999, 121, 12200-12201.

[77] D. Leu, W. F. DeGrado, J. Am. Chem. Soc. 2001, 123, 7553 - 7559.

[78] T. L. Raguse, J. R. Lai, P. R. LePlae, S. H. Gellman, Org. Lett. 2001, 3, 3963- 3966.

[79] U. Diederichsen, Angew. Chem. 1997, 109, 1966-1969; Angew. Chem. Int. Ed. 1997, 36, 1886-1889.

[80] U. Diederichsen, Angew. Chem. 1996, 108, 458-461; Angew. Chem. Int. Ed. 1996, 35, 445-448.

[81] U. Diederichsen, Bioorg. Med. Chem. Lett. 1997, 7, 1743 - 1746.

[82] P. Garner, S. Dey, Y. Huang, X. Zhang, Org. Lett. 1999, 1, 403-406.

[83] P. Garner, S. Dey, Y. Huang, J. Am. Chem. Soc. 2000, 122, 2405-2406.

[84] S. Matsumura, T. Takahashi, A. Ueno, H. Mihara, Chem. Eur. J. 2003, 9, 4829- 4837.

[85] T. Takahashi, A. Ueno, H. Mihara, ChemBioChem 2002, 3, 543-549.

[86] T. Takahashi, K. Hamasaki, I. Kumagai, A. Ueno, H. Mihara, Chem. Commun. 2000, 349-350. 
[87] A. M. Brückner, P. Chakraborty, S. H. Gellman, U. Diederichsen, Angew. Chem. 2003, 115, 4532-4536; Angew. Chem. Int. Ed. 2003, 42, 4395-4399.

[88] P. Chakraborty, U. Diederichsen, Chem. Eur. J. 2005, 11, 3207-3216.

[89] A. T. Brunger, K. Weninger, M. Bowen, S. Chu, Annu. Rev. Biochem. 2009, 78, 903-928.

[90] A. Kashiwada, M. Tsuboi, T. Mizuno, T. Nagasaki, K. Matsuda, Soft Matter. 2009, 5, 4719-4725.

[91] W. J. Li, F. Nicol, F. C. Szoka, Adv. Drug Delivery Rev. 2004, 56, 967-985.

[92] R. B. Merrifield, J. Am. Chem. Soc. 1963, 85, 2149-2154.

[93] R. B. Merrifield, Science 1986, 232, 341-347.

[94] E. Valeur, M. Bradley, Chem. Soc. Rev. 2009, 38, 606-631.

[95] J. C. Sheehan, G. P. Hess, J. Am. Chem. Soc. 1955, 77, 1067-1068.

[96] L. A. Carpino, A. Elfaham, F. Albericio, Tetrahedron Lett. 1994, 35, 2279 2282.

[97] A.Lygina, Design, Synthesis and Fusion Activity of PNA/Peptide Hybrids as SNARE Protein Models, Dissertation Universität Göttingen, 2011.

[98] Jose M. Palomo. RSC Adv., 2014, 4, 32658-32672.

[99] F. Albericio, Curr. Opin. Chem. Biol. 2004, 8, 211-221.

[100] M. Schnölzer, P. Alewood, A. Jones, D Alewood, S. B. H. Kent, Int. J. Pept. Protein Res. 1992, 40, 180-193.

[101] D. C. Cole, Tetrahedron 1994, 50, 9517-9582.

[102] E. Juaristi, H. López-Ruiz, Curr. Med. Chem. 1999, 6, 983-1004.

[103] S. Abele, D. Seebach, Eur. J. Org. Chem. 2000, 1-15.

[104] E. Juaristi, Enantioselective Synthesis of $\beta$-amino Acids, Wiley-VCH, New York, 1997.

[105] J. Podlech, D. Seebach, Liebigs Ann. Chem. 1995, 1217-1228.

[106] S. Abele, G. Guichard, D. Seebach, Helv. Chim. Acta 1998, 81, 2141-2156.

[107] a) A. M. Brückner, H. W. Schmitt, U. Diederichsen Helv. Chim. Acta 2002, 85, 3855-3866. b) T. N. Salzmann, R. W. Ratcliffe, B. G. Christensen, F. A. Bouffard, J. Am. Chem. Soc. 1980, 102, 6161-6163. 
[108] C. Palomo, J. M Aizpurua, I. Ganboa, in Enantioselective Synthesis of $\beta$ Amino Acids; (Ed.: E. Juaristi), Wiley-VHC, New York, 1997, pp. 279-357.

[109] A. M. Brückner, Synthese und Strukturuntersuchung von Nucleobasenfunktionalisierten $\beta$-Peptiden, Dissertation, Universität Göttingen, 2003.

[110] P, Chakraborty, Design, Synthesis, and Structural Investigation of Nucleobase Functionalized $\beta$-Peptides, Dissertation, Universität Göttingen, 2011.

[111] R. C. MacDonald, R. I. MacDonald, B. P. Menco, K. Takeshita, Subbarao, L. R. Hu, Biochim. Biophys. Acta 1991, 1061, 297-303.

[112] J. C. Mclntyre, R. G. Sleight, Biochemistry 1991, 30, 11819-11827.

[113] C. R. Wasmuth, C. Edwards, R. Hutcherson, J. Phys. Chem. 1964, 68, 423425.

[114] C. J. W. Gutch, W. A. Waters, Chem. Commun. 1966, 2, 39-41.

[115] M. Sokolovsky, J. F. Riordan, B. L. Vallee, Biochem. Biophys. Res. Commun. 1967, 27, 20-25.

[116] J. C. Mclntyre, F. S. Schroeder, W. D. Behnke, Biochemistry 1990, 29, 2092-2101.

[117] D. K. Struck, D. Hoekstra, R. E. Pagano, Biochemistry 1981, 20, 4093-4099.

[118] J. Wilschut, N. Duzgunes, R. Fraley, D. Papahadjopoulos, Biochemistry 1980, 19, 6011-6021.

[119] J. Wilschut, D. Papahadjopoulos, Nature 1979, 281, 690-692.

[120] J. N. Weinstein, S. Yoshikami, P. Henkart, R. Blumenthal, W. A. Hagins, Science 1977, 195, 489-492.

[121] B. J. Ravoo, W. D. Weringa, J. Engberts, Biophys. J. 1999, 76, 374-386.

[122] R. E. Jastimi, M. Lafleur, Biospectroscopy 1999, 5, 133-140.

[123] V. S. Malinin, P. Frederik, B. R. Lentz, Biophys. J. 2002, 82, 2090-2100.

[124] J. M Stewart, J. D. Young, Solid Phase peptide Synthesis, Pierce Chemical Company, Rockford, Illinois, 1984.

[125] Introduction to cleavage Techniques, Applied Biosystems, Inc, Foster City, 1990. 
[126] R. C. MacDonald, R. I. MacDonald, B. P. Menco, K. Takeshita, N. K. Subbarao, L. R. Hu, Biochim. Biophys. Acta. 1991, 1061, 297-303.

[127] K. M. Misura, R. H. Scheller, W. I. Weis, J. Biol. Chem. 2001, 276, 1327313282.

[128] K. M. Misura, L. C. Jr. Gonzalez, A. P. May, R. H. Scheller, W. I. Weis, J. Biol. Chem. 2001, 276, 41301-41309.

[129] M. Margittai, D. Fasshauer, S. Pabst, R. Jahn, Langen, J. Biol. Chem. 2001, 276, 13169-13177.

[130] F. Zhang, Y. Chen, D. H. Kweon, C. S. Kim, Y. K. Shin, J. Biol. Chem. 2002, 277, 24294-24298 .

[131] K. Weninger, M. E. Bowen, S. Chu, A. T. Brunger, Proc. Natl Acad. Sci. USA. 2003, 100, 14800-14805.

[132] S. M. Dennison, M. E. Bowen, A. T. Brunger, B. Lentz, Biophys. J. 2006, 90, 1661-1675. 


\section{Acknowledgements}

First of all, I thank my supervisor and teacher Prof. Dr. Ulf Diederichsen for giving me the opportunity to work on this interesting topic, for permanent support during the work, for complete scientific freedom and for financial support during the work on my $\mathrm{PhD}$ thesis.

I would like to express endless gratitude to my wife Susanna: without her priceless help, continuous support and sincere love this work would never be done.

I would like to thank all people in the Diederichsen's group and who have shared with me their experience and knowledge. Special thanks to my lab colleagues Florian Czerny, Dr. Oleg Jochim and Dr. Pawan Kumar for the friendly environment, the great time in the lab and cooperation and advices during my PhD. I am very thankful to Ulrike Rost and Hanna Radzey for their advice and the nice time. I express my special thanks to Dr. Pawan Kumar and Florian Czerny for proofreading of this thesis. I would like to Angela Heinemann and Aoife Neville for their competent help in solving various organizational problems.

I am very grateful to Prof. Dr. Claudia Steinem for co-refering this thesis and Prof. Dr. Rainhard Jahn for the helpful discussions during my PhD work. I would like to express my gratitude to Dragomir Milovanovic (Prof. Dr. R. Jahn research group) for the fruitful cooperation.

I am grateful to Collaborative Research Center 803 for the financial support of my participation in SFB 803 Winter School 2012, 2013 and 2014. I also appreciate the interesting lectures that have been held in SFB 803 Colloquium.

I am indebted all Mass and NMR team for measuring of mass- and NMR-spectra, respectively. I thank Daniel Frank for the help with computer soft- and hardware.

Finally, I express my heartfelt gratitude and indebtedness to my parents, my wife and my brother for their love, understanding, continuous support and encouragement during my live. 


\section{Curriculum Vitae}

\section{Biographical Data}

$\begin{array}{ll}\text { Name } & \text { Sadek } \\ \text { Surname } & \text { Muheeb } \\ \text { Date and place of birth } & 12.11 .1983, \text { Edlib, Syria } \\ \text { Citizenship } & \text { German } \\ \text { Marital Status } & \text { Married } \\ \text { Languages: } & \text { English, German, Arabic }\end{array}$

\section{Education}

$26 / 05 / 2015$

Doctoral examination for obtaining the degree

"Doctor rerum naturalium"

$10 / 2011-06 / 2015$

PhD thesis in the group of Prof. Dr. U. Diederichsen, Institute of Organic and Bimolecular Chemistry, Georg-August-Universität Göttingen, Germany

Title: "Nucleobase-functionalized $\beta$ peptide as a modified Model of a SNARE Protein for Membrane Fusion"

$29 / 06 / 2011$

Graduation from faculty of Chemistry at the TU Dortmund university, Dortmund, Germany "Master of science" in Chemical Biology 
$11 / 2010-06 / 2011$

Master thesis in the group of Prof. Dr. M. Engelhard, Physical Biochemistry Department, Max-Planck Institute of Molecular Physiology, Dortmund, Germany

Title: "Synthesis of a Transmembrane Transducer protein based on HR-II'

$10 / 2007-06 / 2011$

Studies of chemical biology at the TU Dortmund, Dortmund, Germany

01/2006-05/2007

German language course at the Duisburg-Essen University, Essen, Germany

$10 / 2001-09 / 2005$

Studies of Biochemistry at the Aleppo University, Aleppo, Syria

09/1990-06/2001

Primary and secondary school education, Aleppo, Syria

\section{Research and Teaching Experience}

09/2014-11/2014

09/2013-11/2013

06/2013-07/2013
Teaching and heading assistant in the course: "Biological Chemistry"

Teaching assistant in the course: "Biological Chemistry"

Teaching assistant in the course: "Chemistry for Medicine Students" 
01/2013-02/2013

06/2012-07/2012

01/2012-06/2015

01/2011-06/2011
Teaching assistant in the course: "Chemistry for Medicine Students"

Teaching assistant in the course: "Chemistry for Medicine Students"

Research assistant of the Collaborative Research Center 803: "Functionality Controlled by Organization in and between Membranes"

Research assistant in the group of Prof. Dr. M. Englehard

Physical Biochemistry Department, Max-Planck Institute of Molecular Physiology, Dortmund, Germany

\section{Publications}

M. Dittmann, M. Sadek, R. Seidel, M. Engelhard, "Native chemical ligation in dimethylformamide can be performed chemoselectively without racemization" Journal of Peptide Science 18 (5), 2012, 312-316. 